University of Zurich

Department of Economics

Working Paper Series

ISSN 1664-7041 (print)

ISSN 1664-705X (online)

Working Paper No. 256

\title{
Job Mobility and Creative Destruction: Flexicurity in the Land of Schumpeter
}

Andreas Kettemann, Francis Kramarz and Josef Zweimüller

June 2017 


\title{
Job Mobility and Creative Destruction: Flexicurity in the Land of Schumpeter*
}

\author{
Andreas Kettemann ${ }^{\dagger}$ \\ University of Zurich
}

\author{
Francis Kramarz ${ }^{\ddagger}$ \\ CREST, ENSAE
}

\author{
Josef Zweimüller ${ }^{\S}$ \\ University of Zurich
}

June 14, 2017

\begin{abstract}
This paper evaluates the 2003 Austrian severance-pay reform, often advocated as a role model for structural reforms in countries plagued by inflexible labor markets and high unemployment. The reform replaced a system with tenure-based severance payments after a layoff (but not after a quit) by payments into pension accounts that accrue to workers after a layoff as well as after a quit. We identify the reform effects using a regression discontinuity (RD) design and find a substantial increase in job mobility in response to the reform. A search-and-matching model with on-thejob search and tenure-dependent severance payments is structurally estimated using the RD-induced empirical moments. Counterfactual policy experiments suggest that flexicurity reforms spur job creation and can substantially reduce unemployment in countries where severance payments are initially high.
\end{abstract}

\footnotetext{
*We would like to thank David Autor, Pierre Cahuc, David Dorn, Christian Dustmann, David Grubb, Philipp Kircher, Attila Linder, Alan Manning, Sevi Mora, Fabien Postel-Vinay, Julien Prat, Christopher Prinz, as well as seminar participants at CREST-ENSAE, LSE, UCL, OECD, Paris School of Economics, and the universities Bergen, Edinburgh, Salzburg, Tübingen, and Zurich for helpful comments and suggestions. Tobias Renkin, Andreas Steinhauer and Sandro Favre provided excellent research assistance. We are also grateful to Josef Schmid, former staff member at the WKO Linz, for helpful discussions on the institutional background.

${ }^{\dagger}$ Department of Economics, University of Zurich, Schönberggasse 1, CH-8001 Zürich; andreas.kettemann@econ.uzh.ch

${ }^{\ddagger}$ CREST, ENSAE, 15 Boulevard Gabriel Péri, Malakoff, 92245, France; kramarz@ensae.fr

${ }^{\S}$ Department of Economics, University of Zurich, Schönberggasse 1, CH-8001 Zürich; josef.zweimueller@econ.uzh.ch
} 


\section{Introduction}

In a modern economy, globalization, technical change, changes in consumers' tastes, or economic crises continually destroy jobs and firms. Simultaneously, the same forces lead to the creation of jobs and firms, often in emerging industries. This process of creative destruction needs workers to move to these new activities and firms. In such turbulent economic times, it is widely believed that labor market institutions play a critical role for the performance of labor markets in general and the mobility patterns of workers in particular. The divergent experiences of the US (and other Anglo-Saxon countries) on the one side and (continental) Europe on the other have often been attributed to such institutional differences. Ljungqvist and Sargent (1998, 2008), for instance, argue that generous welfare state provisions have caused Europe's high unemployment rates and low productivity, generating Eurosclerosis. In contrast, less regulated labor (and product) markets and more reliance on market forces have led to stronger job creation and superior labor market outcomes in the US, at least since the 1980s.

However, the simple Europe-US dichotomy ignores the enormous variation both between labor market institutions and between labor market performance within Europe. For instance, most Southern European countries grant strong employment protection to workers and impose high firing costs on firms. At least since the mid 1980s, these countries have also been suffering from persistently high unemployment. This is in striking contrast with the Nordic countries, that have relied on "flexicurity", a policy mix combining incentives and insurance (including a significant amount of re-training) to ensure strong job creation by firms and smooth job-to-job transitions for workers. Table 1 compares US and (Western) European unemployment rates. While unemployment was low all-over Europe until the mid 1980s, the picture has changed dramatically since then. Unemployment rates in Southern European countries started to soar and have continued to be substantially above those seen in the US ever since. In the Nordic countries, however, unemployment rates have (slightly) exceeded those observed in the US during the 1990s. Since the early 2000s, unemployment rates in Nordic countries were below those prevailing in the US.

The present paper sheds light on the role of flexicurity institutions by evaluating a specific reform that was implemented in Austria in 2003. This reform has attracted a lot of attention in international policy debates because it constituted a radical step towards labor market flexibility while keeping income security high. The pre-2003 system mandated a severance payment from the firm to the worker in case of a layoff, while entitlement was 
Table 1: Unemployment by regions and periods in percent

\begin{tabular}{lccc}
\hline \hline & $1970-1984$ & $1985-1999$ & $2000-2014$ \\
\hline United States & 6.91 & 5.92 & 6.37 \\
Europe & 5.20 & 9.47 & 8.37 \\
$\quad$ Nordic countries & 3.56 & 6.00 & 5.12 \\
$\quad$ Southern countries & 6.22 & 11.96 & 10.67 \\
Other countries & 4.68 & 8.07 & 7.05 \\
\hline
\end{tabular}

Notes: Unemployment as percentage of civilian labor force. Source is OECD. "Europe" comprises countries Austria, Belgium, Denmark, Finland, France, Germany, Greece, Iceland, Ireland, Italy, Luxembourg, Netherlands, Norway, Portugal, Spain, Sweden, Switzerland and UK. "Nordic" countries are Denmark, Finland, Iceland, Netherlands, Norway, Sweden, and Switzerland, "Southern" countries are France, Greece, Italy, Portugal and Spain, while the remaining countries are in the "Other" group. National unemployment rates are weighted by the civilian labor force to produce averages.

lost for the worker in case of a quit. The 2003 reform abolished severance payments in favor of occupational pension accounts, into which the firm makes monthly contributions. When the employment relationship is terminated, either because of a quit or a layoff, the worker continues to own the accumulated pension wealth and can transfer it to a new employer. The reform fundamentally changed mobility incentives. In the old system, workers in distressed firms had an incentive to wait for a layoff and were reluctant to quit. In the new system, this incentive disappeared.

Three key observations motivate our analysis of the Austrian policy reform. First, while flexicurity institutions have attracted a lot of attention in policy debates, evidence on the effect of these institutions on job mobility and unemployment patterns remains scarce. Most previous studies rely on cross-country comparisons, which are typically difficult to interpret. ${ }^{1}$ Another large strand of the literature has exploited discontinuities in employment protection with respect to firm-size or tenure thresholds (and reforms that changed these thresholds) or changes in the severance pay amounts to identify causal ef-

\footnotetext{
${ }^{1}$ Previous studies include Bertola (1990); Belot and Ours (2004); Di Tella and MacCulloch (2005); Kahn (2007); Messina and Vallanti (2007); Boeri and Garibaldi (2009); Boeri and Jimeno (2016); Bartelsman, Gautier, and De Wind (2016); Bassanini and Cingano (2017). See also Nickell, Nunziata, and Ochel (2005) who find a negative effect of employment protection on job or labor turnover, but ambiguous results in terms of employment. For comprehensive surveys see Boeri (2011) and Boeri, Cahuc, and Zylberberg (2015). Other cross-country studies have studied the effect on productivity or growth, see Bassanini, Nunziata, and Venn (2009); Belot, Boone, and van Ours (2007); DeFreitas and Marshall (1998); Koeniger (2005) and Bentolila and Dolado (1994). Cross-state variation is exploited by Ahsan and Pagés (2009), Autor, Donohue, and Schwab (2006), and Besley and Burgess (2004).
} 
fects of employment protection legislation. Our paper adds to this literature by studying a more fundamental policy reform, that abolished severance payments altogether. ${ }^{2}$ The 2003 Austrian severance-pay reform provides a unique opportunity to measure the consequences for job mobility and unemployment patterns of a policy reform that substantially reduced barriers to job mobility. To the best of our knowledge, our paper is the first one providing a comprehensive empirical evaluation of the causal effects on job mobility of a major flexicurity reform.

Second, the 2003 Austrian reform is relevant for policy debates, because the basic structure of the pre-reform system is qualitatively similar to the one still in place in various Southern European countries. Two main parameters characterized the pre-reform system: (i) the severance pay amount (which increases with tenure in the firm) and (ii) the vesting period, the minimum length of tenure required for severance-pay eligibility. Like the Austrian pre-reform system, these South-European systems are characterized by tenuredependent severance payments and a vesting period (although they vary across countries and systems). In our analysis below, these two parameters will play a crucial role. In our model-based approach, we will use the structural parameters as estimated from the Austrian reform and conduct counterfactual policy experiments to provide an assessment of possible consequences of similar policy reforms in other countries.

Third, the Austrian reform has been often been presented as a role model for reforms in other countries plagued by low labor mobility and high unemployment. For instance, in the Green Paper "Modernizing labor law to meet the challenges of the 21st century" the EU Commission (2006) states: "The Austrian reform provides an interesting example of a radical shift away from a system based on the traditional employment relationship between one worker and one firm to one based on a broader employee benefit provision fund operated at national level. (...) From the employee's perspective, the new system reduces the cost of job mobility since workers no longer lose all of their entitlement to severance payments when taking a new job." Similarly, in its reassessment of the 1994 Jobs Strategy, the OECD (2006) advocates similar reforms in other, particular Southern European, countries and has done so repeatedly since then. ${ }^{3}$

\footnotetext{
${ }^{2}$ This literature includes e.g. Riphahn (2004); Boeri and Jimeno (2005); Ichino and Riphahn (2005); Behaghel, Crépon, and Sdillot (2008); Kugler and Pica (2008); Marinescu (2009); Martins (2009); Hijzen, Mondauto, and Scarpetta (2013); Cingano, Leonardi, Messina, and Pica (2016). The impact of changes in severance pay amounts are studied in Garibaldi and Pacelli (2008), and Kugler (1999, 2005).

${ }^{3}$ For a recent example, see the OECD (2017) report on Portugal, which states in its summary: "The report has also argued that the system of severance pay in Portugal could be reformed further to emulate
} 
Our analysis proceeds in two steps. In a first step, we provide reduced-form evidence on the effects of the 2003 Austrian severance pay reform on job separations and job mobility. Using data from the Austrian Social Security Register (ASSD), we identify the causal effect of the reform in a regression discontinuity (RD) design. Indeed, the new system went in force for all new employment relationships starting on January 1, 2003 or later, whereas jobs having started before this date continued to be subject to the old system. Comparing subsequent mobility patterns of workers who started a job shortly after the reform to workers starting a job shortly before allows us to separate the reform effect from confounding factors. By construction, job entrants around the date of the policy change faced an almost identical economic environment during the years following their entry into their new job. Furthermore, the firms' workforce composition changed smoothly immediately before and after January 2003. ${ }^{4}$ This implies that any observable change in mobility outcomes should be attributed to workers' reaction to the reform.

In the old system, barriers to quit were particularly high for workers whose firm was hit by a negative shock, and who were therefore likely to be laid off. When workers learnt that their job was at risk, they had a strong incentive to "wait for the layoff", rather than to quit, and keeping the option to receive a associated payment when vested (eligible for a payment or close to becoming eligible). After the reform job mobility was unimpeded since workers carried their pension account from one employer to the next. To capture this incentive appropriately, our empirical strategy relies on the analysis of job separations before a mass layoff. An important literature (Jacobson, LaLonde, \& Sullivan, 1993; Fallick, 1996; Stevens, 1997) has documented that a job loss has long-lasting effects on a worker's future career. This literature also emphasizes the importance to account for "early leavers", i.e. workers who leave the firm immediately before a mass layoff (Pfann and Hamermesh (2001) among others). ${ }^{5}$ Our empirical approach builds on this literature and identifies the causal impact of the reform by focusing on workers' behavior in the eve

the one of Austria. (...) The advantage of this system is that it removes the disincentive to worker mobility inherent in systems where severance pay entitlements are strictly linked to the current employer."

${ }^{4}$ As we explain in more detail below, we look at the mobility patterns of workers during the first 36 months after having started their job (the choice of 36 months is motivated by the vesting period.) Treated and control workers face a similar economic environment because they start their job at roughly the same dates and because their "risk period" (the first 36 months after their job start) overlaps almost completely. Moreover, because the reform captured only new - but not ongoing - employment relationships, we will see that the firms' workforce composition did not change discontinuously at the policy threshold.

${ }^{5}$ For recent examples of studies using similar strategies, see e.g. Schmieder, Wachter, and Bender (2010), Huttunen, Moen, and Salvanes (2011), Ichino, Schwerdt, Winter-Ebmer, and Zweimüller (2014), Song and Wachter (2014). 
of a mass layoff.

We find that the 2003 Austrian reform led to a strong increase in job mobility. Consider two workers, both employed in a firm that will experience a mass layoff in the following two years. According to our baseline estimates, the probability that a worker remains employed at this firm at the date of the mass layoff is 12.5 percentage points lower for workers employed under the new system compared to workers employed under the old system (corresponding to a decrease of around 40 percent relative to the pre-reform mean). Furthermore, we document that most of the reaction is driven by workers' higher propensity to switch from job to job, while transitions into unemployment are much less affected. This result is consistent with the reform incentives to increase on-the-job search after learning one's employer economic difficulties with their associated increase layoff probability.

Our finding of a substantial effect of the reform on job mobility is robust to various modifications of our baseline setting. First, it is robust to the exact definition of an adverse shock to the firm. Then, defining a sample of "matched control" workers observationally comparable to the baseline sample of workers at the time of the job start but who do not happen to enter a firm about to experience a mass layoff, we show that this matched sample evolves smoothly around the reform cutoff in contrast to the baseline sample. Moreover, even though there is no direct test of selection around the discontinuity, we demonstrate that workers appear to be "as good as randomly assigned" around January 2003 since we find no significant discontinuity in observable characteristics and no bunching in the number of new job spells.

In a second step, we set up a search-and-matching model of the labor market which we structurally estimate to capture the Austrian mobility responses. ${ }^{6}$ We assume that firms are hit by stochastic productivity shocks and decide when to terminate an employment relationship. Employed workers get outside offers and decide whether to quit the current job or stay. The model incorporates the two crucial parameters of a severance pay system: the vesting period (modeled by a flow probability to become eligible to a payment) and

\footnotetext{
${ }^{6}$ Theoretical work on employment protection was pioneered by Bentolila and Bertola (1990) and Bertola (1990). Lazear (1990) has shown that in a frictionless environment any severance payment scheme can be offset by an efficient labor contract and, thus, should not have real effects. Recent contributions deviated from this baseline environment to understand how severance pay might affect labor market outcomes. Recent contributions include Kugler and Saint-Paul (2000), Cahuc and Postel-Vinay (2002), Garibaldi and Violante (2005), Wasmer (2006),Juan, Marcel, and Juan (2007), Fella (2007), Boeri and Garibaldi (2007), Bentolila, Cahuc, Dolado, and Barbanchon (2012), Boeri, Garibaldi, and Moen (2014), PostelVinay and Turon (2014), and Davoine and Keuschnigg (2015). As discussed in Ljungqvist (2002), these models produced mixed results on the effect of lay-off costs on the employment level.
} 
the amount of the severance pay.

The model predicts that a large severance payment does not only discourage workers from searching for better job matches. It also forces firms to continue inefficient employment relationships with their vested employees, resulting in sub-optimally low productivity and low output. Moreover, firms have little incentives to create new jobs, either because they anticipate low application rates by currently employed workers, or because a large negative shock will induce large separation costs.

Two aspects of the model are worth noting. First, the model disregards any positive features of a severance-pay system, features that may justify why such a system was created in the first place. The main reason is our focus on the effect of severance payments on labor market flexibility, which is at the heart of the policy debate. A full-fledged analysis of the welfare implications is beyond the scope of this paper. However, to the extent that such other forces are at work, we may overestimate some benefits, including productivity responses, of the severance pay reform.

Second, our model helps us understand how severance pay and job-to-job mobility relate to the "bonding critique". Lazear (1990) has argued that severance pay is merely deferred compensation and should be offset by lower wages but should otherwise not affect labor market outcomes on frictionless labor markets. Garibaldi and Violante (2005) present a model in which the neutrality result continues to apply in a labor market with frictions. Our model is very similar, but unlike Garibaldi and Violante (2005), we allow for endogenous job mobility. This breaks the neutrality result because, with endogenous job mobility, the size of the severance payment affects the surplus of the current match through the option value of outside offers. Indeed, when a worker decides to quit, she trades the value of the outside offer against the worker's own share in the surplus of the current match. However, the worker's quit decision does not take into account the destruction of the firm's share in the current surplus. In this set-up, the severance payment is no longer a pure transfer between the firm and the worker within the current match but affects the size of surplus. As a consequence, severance pay affects the labor market equilibrium.

We then structurally estimate this model using coefficients from our RD regressions of pre- and post-reform job mobility patterns as empirical moments. To ensure full correspondence of the empirical moments and the simulated (from the model) moments, we proceed as follows. First, the baseline sample underlying the simulated job mobility patterns is selected from the simulated data in an analogous manner as the baseline sample, used for the reduced-form (RD) estimates, is selected from the (social security) data. In particular, we 
focus on workers in distressed firms and estimate the same RD regression on the simulated data as we do in the reduced form (RD) analysis. Second, to map the job mobility patterns estimated in the reduced-form (RD) analysis into our structural model we must account for the transition from an old to a new system. Indeed, our RD design which identifies the effects of the reform is populated by pre- and post-reform workers, the former anticipating that any future employment relationship will be subject to the post-reform rules. This constraint is explicitly taken into account in our model-simulation procedure. To further discipline the model, we also match macro moments such as the unemployment rate, the aggregate job finding rate, and the job destruction rate with data generated by our model.

The model captures mobility responses to the reform as well as aggregate moments that are in line with those estimated in the reduced-form analysis. Moreover, the model allows us to shed light on changes in job creation (and destruction) and the labor market equilibrium as structural responses to the reform. Comparing steady states, we find that the 2003 Austrian reform led to a moderate decrease in the equilibrium unemployment rate of 0.6 percentage points, mainly driven by higher job creation. The associated mild productivity increase (output per worker increases of 0.33 percent) is driven by workers moving to more productive jobs, shifting the stationary productivity distribution to the right.

The structural approach also allows us to conduct counterfactual policy experiments. Starting from regulations similar to those of a typical Southern European country we simulate mobility and unemployment responses to an Austrian-style reform. In such initially more strongly regulated labor markets, we predict large effects on job mobility and unemployment: unemployment drops by up to 5 percentage points and productivity increases by around 0.66 percent (leading to an increase in total output by more than 6 percent). Even when incorporating temporary/fixed-term jobs in the model, a reform that abolishes severance payment has substantial effects. Both the unemployment rate and the share of temporary/fixed-term jobs plummet by up to 3 percentage points.

The paper is organized as follows. Section 2 gives an overview of the institutional setting before and after the reform. Section 3 describes our data and the empirical strategy. In Section 4, we present empirical evidence on worker mobility in firms facing strong negative shocks. Section 5 describes our model. The structural estimation strategy as well as the results are detailed in Section 6. In Section 7, we discuss our policy simulations and Section 8 concludes. 


\section{Institutional Background}

The 2003 reform of the severance-pay system (Abfertigung Neu) was a major change for the Austrian labor market. After long and tedious negotiations between social partners and the government, the National Parliament enacted the new law (Betriebliches Mitarbeitergesetz) in June 2002. Apart from extending eligibility to a larger number of workers, ${ }^{7}$ the main argument for the new law was increased labor market flexibility while maintaining income security. All jobs that started before January 1, 2003 were subject to the old severance-pay system, whereas all jobs that started on January 1, 2003 or later became subject to the new occupational-pension system.

The old severance-pay system. The pre-reform system required firms to make a lumpsum transfer to each eligible laid-off worker. The size of this transfer depended on the worker's tenure and was increasing in steps: After 3 years of tenure, workers became eligible for severance pay of at least 2 monthly salaries, while there was no mandatory payment below this tenure level. After 5, 10, 15, 20, 25 years of tenure, the severance pay increased to at least 3, 4, 6, 9, 12 times the worker's monthly salary, respectively. Importantly, the worker was eligible only after a layoff, while quits and dismissals for cause were exempt from the severance-pay rule. The former included layoffs, but also job terminations upon mutual agreement (of firm and worker), or terminations at the end of a temporary contract. The only exception was for retirement, when the firms had to pay the severance payment as soon as the worker had at least 10 years of tenure. ${ }^{8}$

The new occupational-pension system. All jobs starting as of January 1, 2003 were subject to the new system of occupational pensions. Starting from the second month of the employment relationship, the employer had to transfer 1.53 percent of the worker's current salary to a pension account, owned by the worker and on which she earns interest. When the job was terminated - be it through a layoff or a quit- the worker continued

\footnotetext{
${ }^{7}$ As large fraction of job separations occur before three years of tenure, the severance-pay eligibility requirement of at least three years of tenure implied that only a minority of job losers actually got a severance payment. This was considered unfair and was an important argument that helped to reach consensus on the new law.

${ }^{8}$ See Manoli and Weber (2016) who study how severance pay rules affected the retirement behavior of Austrian workers. They find that transitions to retirement were significantly lower (higher), immediately before (after) a tenure threshold, suggesting that workers aligned the timing of retirement to the severance pay rules, in line with what should be expected from this pre-reform system for other separations.
} 
to own the pension account. While the claims are never lost, accessing the funds on the pension account is regulated. Withdrawing funds from this account is only possible after three years of tenure, after a layoff, when firm and worker mutually agree to terminate the employment contract, and after the end of a temporary contract. By contrast, when the worker quits her firm (or is dismissed for misconduct), no right to withdraw from the pension account exists.

Transition rules. The transition from the old to the new system was gradual. Jobs that started before 2003 and were still ongoing after January 1, 2003 continued to be covered by the old system. However, the 2003 reform also allowed for the conversion of these oldsystem contracts into new-system contracts, provided that both employee and employer agreed to the switch. There were two switching possibilities. (i) The partial switch "freezes" the severance pay at the level for which the employee is currently eligible and starts the occupational pension account at that date. When the employee quits in the future, she can only transfer the pension wealth to a new employer but loses the "frozen" severance pay. (ii) The full switch puts into her new pension account the amount of severance payment the worker is currently eligible to. Only full switchers lose their incentive to wait whereas this incentive does not (fully) disappear for partial switchers. In practice, only a negligible number of contracts under the old system were converted to the new system (see, e.g., Percher (2003)).

In the data, we can only observe the start date of a new job but not the type of contract (and whether an old contract was converted to a new one). In our empirical analysis, we consider a worker as subject to the old rules if her job started before January 1, 2003 and as subject to the new rules if her job started on January 1, 2003 or later. This means we might erroneously classify a worker who started her job before 2003 as subject to the old system, when her contracts was in fact converted to the new system. (Such misclassification cannot occur for workers who started their job in 2003 or later, as these workers had no option to switch back to the old system.) The resulting downward bias in the estimated reform effect, however, will be small due to the few workers who took up the option to switch.

Reform incentives. In this paper we will focus on the effect of the reform on job separations and job mobility and we will show empirically that the severance-pay reform triggered quantitatively substantial responses on this margin. The 2003 reform transforms the severance-pay eligibility after a quit. Under the old system, severance-pay claims were 
lost. Under the new system, the worker continued to own the funds accumulated on her pension account. As a result, the incentive to "wait for a layoff" (and the associated severance payment) was strong under the old system, but disappeared under the new system. Hence, new-system workers should be more likely engaged in on-the-job search, most particularly when faced with a high layoff risk. In the empirical part below, we focus on distressed firms and show that the abolition of severance pay has indeed led to higher job separation rates among workers with high layoff probabilities. We also show that this increase is largely driven by an increase in job-to-job mobility rather than an increase in job-to-unemployment transitions. This suggests that the reform indeed made workers more likely to quit.

Whereas the reform increased job mobility incentives for workers, it did not create firstorder changes in the incentives for firms to terminate an employment relationship. The reform was indeed designed to be roughly cost-neutral (in expected value) for employers. The old system mandated substantially higher severance-pay claims than the funds accumulated on the pension account under the new system for similar tenure levels (larger than 3 years). ${ }^{9}$ The new level of payments was designed to balance the increased frequency of payments, from layoffs with tenure above 3 years to the universe of workers.

The reform also changed quit incentives of workers close to retirement. (Recall that workers with more than 10 years of tenure were eligible for the severance payment when quitting their job for retirement.) We do not focus on quit behavior of these workers for two reasons. First, job mobility among older workers is low to begin with, hence it is unlikely that the reform triggered quantitatively large effects on this margin. Second, compared to old-system workers, new-system workers with more than 10 years of tenure will be differently selected. The latter are more likely to be in better job matches than the former (who might have rejected outsider offers to keep of the severance pay option). ${ }^{10}$

\footnotetext{
${ }^{9}$ Note that comparing worker claims (acquired in a given employment relationship) under the old and the new system is not completely straightforward. The claims under the old system is a (tenure-dependent) multiple of the average wage earned during the last year before the layoff. The claims under the new system, i.e. the increased funds on the pension account, depend on the entire earnings history within the firm and on the interest rate earned on this account. Much of the policy debate before the reform was about the conjectured interest rate on the pension account.

${ }^{10} \mathrm{~A}$ further change of the 2003 reform was the switch from a severance-pay schedule firm that changed discontinuously with tenure on the current job to an occupational pension scheme where any tenure discontinuity disappears (because firms pay pensions contributions month by month into the worker's pension account). Other papers have shown that the tenure discontinuities of the old system affected unemployment durations Card, Chetty, and Weber (2007) and the timing of retirement Manoli and Weber (2016).
} 


\section{$3 \quad$ Data and Empirical Strategy}

Data sources. Our analysis is based on the Austrian Social Security Database (ASSD), which covers the universe of Austrian private sector workers and provides longitudinal information on the workers' earnings- and employment history from 1972 onward. The data are collected to verify old-age pension claims and hence cover all information relevant to calculate a worker's pension benefits. In addition to individuals' earnings- and employment history, the ASSD reports other labor market states, such as registered unemployment, sickness absence, or maternal leave. The ASSD is a matched firm-worker data set. As the ASSD covers the universe of private sector workers, we observe for all private-sector firms the evolution of firm size and workforce composition. The data also include a limited set of firm characteristics (such as sector, region, and firm age). Unfortunately, there is no information on the firm's balance sheet, sales, etc.

Baseline sample. To test whether workers respond to the severance-pay reform we focus on workers who are likely to be displaced in the future. In this group of workers, the old system generates an incentive to wait for separation if vested whereas no such incentive exists in the new system. To look at workers faced with such a potential choice, we extract from the ASSD universe all job starters who satisfy the following criteria: (i) aged 25-55 at the start of a job, (ii) started a new job during the period January 1, 1997 to December 31, 2008, (iii) stayed at least 12 months in the new firm, and (iv) entered a firm, which experienced a mass layoff 3 to 4 years (36 to 47 months) later. ${ }^{11}$ A "mass-layoff" firm is defined as follows: (a) an employment reduction of more than 33 percent of the firm's work force; (b) the employment reduction has to occur within one month; and (c) the firm had at least 30 employees in the last month before the mass layoff. Workers who satisfy criteria (i) - (iv) constitute our "baseline sample".

To make sure that our results are not driven by the particular criteria that define the baseline sample, we will perform a broad set of robustness checks. Table 1 in the Online Appendix shows the characteristics of workers in our baseline sample in comparison to the universe of job starters. Workers in the baseline sample are slightly less likely to be female, younger, and more experienced. Overall, the baseline sample of mass layoff workers has,

\footnotetext{
${ }^{11}$ Criterion (iii) excludes workers whose jobs that do not last longer than 12 months, because a substantial fraction of them are fixed-term contracts that should not be affected by the reform. Criterion (iv) restricts attention to short-tenured workers, both because most of the job mobility occurs among short-tenured workers; and because it maximizes the sample size.
} 
by and large, similar characteristics to the universe, though starting wages are somewhat higher (which is partly due to the fact that criteria (iv) and (v) select baseline workers from larger firms).

Empirical strategy: RD design. To identify the effect of the severance-pay reform on job mobility, we adopt a regression discontinuity $(\mathrm{RD})$ design: all contracts starting on January 1, 2003 or later, were forced to follow the new policy principles. The start date of a new job is our running variable and the date of implementation of the severance-pay reform, January 1, 2003, is the treatment indicator. In our baseline specifications we will estimate local linear regressions of the form

$$
Y=\beta_{0}+\beta_{1} D+\beta_{2} x+\beta_{3} D \times x+\varepsilon,
$$

where $Y$ denotes the outcome variable, an indicator for job mobility - a job separation or a job-to-job (or job-to-unemployment) transition. $D$ indicates whether the job started on January 1, 2003 or later (new-system contract), $x$ denotes the start date of the job (normalized to 0 at the reform date January 1, 2003) and $\varepsilon$ captures unobservable variables. The main identification assumption is that heterogeneity in the absence of the treatment evolves smoothly around the threshold, so that workers arbitrarily close to (and on both sides of) the cutoff can be considered as good as randomly assigned among those affected by a layoff. In this case $\beta_{1}$, the parameter of interest, measures the impact of the reform. We restrict our analysis to a Regression Discontinuity sample of at most 24 quarters around the cutoff but explore the robustness to smaller bandwidths. We put more weight on observations close to the cutoff by using a triangular kernel following the suggestions by Porter (2003) and Hahn, Todd, and Klaauw (2001). Standard errors are computed using a bootstrap procedure (with 1,000 replications) clustered at the firm level to account for potential correlation in firm-level unobservables.

\section{The Effect of the Severance-Pay Reform on Job Mobility}

We first document a significant upward jump in job mobility immediately after the reform was implemented. We then provide a detailed check of the validity of our RDD and perform a number of robustness checks that confirm that our main results are robust. 
Main results. Figure 1 shows a clear discontinuous increase in the fraction of job separations in response to the reform. On the vertical axis we measure the percentage of job separations that took place before the mass layoff. Recall that the baseline sample includes workers who stayed for at least 12 months and who were hired by a firm that experienced a mass layoff 36 to 47 months after the worker's job start. The vertical axis measures the percentage of job separations, which we define as the fraction of workers having left the firm before reaching 36 months of tenure. ${ }^{12}$ The horizontal axis refers to the quarter during which workers in the sample were hired by a firm that subsequently experienced a mass layoff. The vertical line in the middle of the graph indicates the reform date: jobs that started before this date are still subject to the old severance-pay system; jobs that started after this date are subject to the new occupational-pension system.

Panel (a) of Figure 1 displays the impact of the reform on job separations. The graph indicates a clear discontinuity at the reform date: among workers who started their job immediately before the reform date, less than 25 percent have left the firm before reaching 36 months of tenure. The corresponding number jumps up to above 35 percent for workers who started their job immediately after the reform date. This indicates that the 2003 reform effect was large: job separations increased by 12.5 percentage points or by 40 percent relative to the pre-reform mean. Panel (b) of Figure 1 shows that JTJ transitions increase from less than 9 percent immediately before to above 15 percent immediately after the reform, a increase by more than 60 percent in response to the reform. In contrast, panel (c) indicates that transitions to unemployment (JTU, hereafter) are less affected, they increase from 13 to 17 percent, corresponding to roughly 30 percent relative to the pre-reform mean.

As a first-order approximation, it is reasonable to assume that transitions to new jobs predominantly reflect quits, while transitions to unemployment are more likely driven by layoffs. To the extent this approximation is correct, our results indicate that the increase in job separations caused by the 2003 reform is mainly due to workers' higher willingness to move to new jobs. This is in line with reform incentives. We also note that a transition

\footnotetext{
${ }^{12}$ In the robustness checks below we look at alternative definitions of the job separation measure. Our main results are based on a fixed time window for job separations (percentage leavers within 36 months after job start). Alternatively, we define a separation indicator based on a variable time window for job separations (percentage leavers by 1 month before the mass layoff). The former indicator keeps the separation time window fixed but is subject to a variable time to the mass layoff. The latter indicator keeps the time to the mass layoff fixed but is subject to a variable time since job start. Our RDD estimates are robust to this change of definition in the job separation indicator.
} 
Figure 1: Job separations by date of job start

(a) All job separations

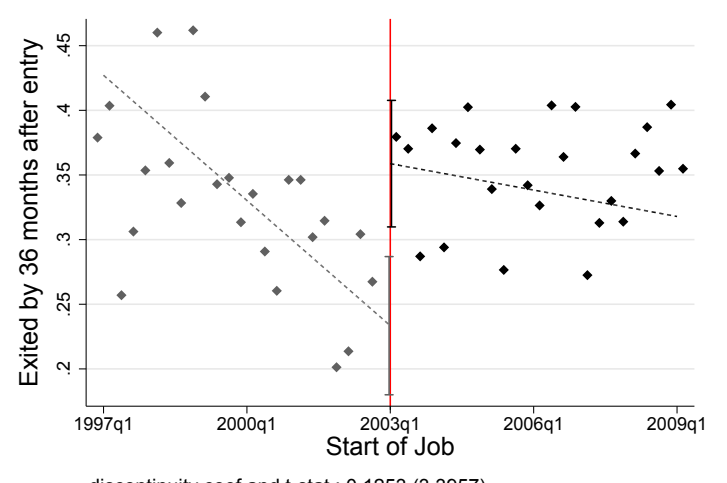

discontinuity coef and t-stat.: $0.1253(3.3957)$

(b) Transitions to a new job (JTJ)

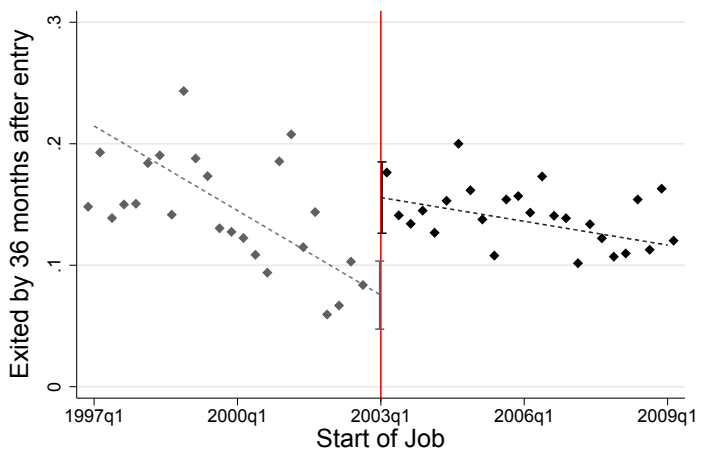

discontinuity coef and t-stat.: 0.0803 (3.9557) (c) Transitions to unemployment (JTU)

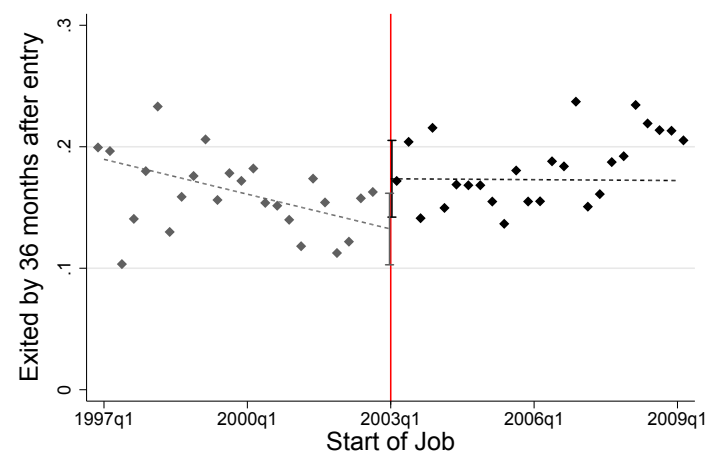

discontinuity coef and t-stat.: 0.0414 (1.8649)

Note: The Figure plots the fraction of workers in our baseline sample $(N=28,099)$ - among those who have entered a firm at the date specified on the horizontal axis, "Start of job" - who stayed in this firm less than 36 months, conditioning on a tenure of at least 12 months. The (red) vertical line displays the date of the severance-pay reform (2003q1). Jobs that started after (before) the reform date were subject to the new (old) system. The fitted lines and confidence intervals are from a local linear regression with triangular weights. Inference is based on a bootstrap procedure (with 1,000 replications), clustered at the firm-level. The Figure displays a stark discontinuity at the reform date: jobs which started immediately after the reform are significantly more likely to be terminated than jobs which started immediately before the reform date, an effect which is mainly driven by Job-to-Job (JTJ, hereafter) moves. This is in line with the incentive to be reluctant to quit and rather wait for a layoff in the old system, which disappeared after the reform. (See text for details.) 
to unemployment may indeed be a quit (as quitters are also eligible to UI benefits after an 28 days waiting period). The worker may have already found a new job but decides to stay on UI benefits for a brief intermediate period. (An error in the opposite direction is less likely because a transition to a new job after an employer-terminated layoff can only happen when a terminated worker finds a new job immediately.)

Table 2 presents the results of a series of RDD regressions. The Table reports the RD-coefficient from linear probability models based on specification (1). Columns 1 to 3 use the entire sample, while columns 4 and 5 use the optimal bandwidth according to Imbens and Kalyanaraman (2012). Columns 3 and 5 include covariates, while column 3 uses a quadratic specification to capture potential nonlinear effects of the running variable (calendar time). Regression results are robust and confirm the graphical evidence of Figure 1. Panel A uses all job separations as the outcome variable. The estimates show that the severance-pay reform increases job separations by 11 to 14 percentage points in our baseline sample (starting from a pre-reform mean of 25 percent), amounting to a 40 percent increase in job separations. Panels B and C run the same RD models using, respectively, transitions to a new job and to unemployment as outcome variables. JTJ transitions increase by 7 to 10 percentage points, or by 54 to 89 percent in terms of the pre-reform mean. The reform effect on JTU transitions is also positive, but substantially smaller in absolute (and relative) value and less precisely estimated.

In Figure 1 of the Online Appendix, we document how the job mobility effect builds up with tenure. We use as our outcome of interest $y(12, x)$, an indicator for a job separation between month 12 and month $x$. Looking at $x=14,16, \ldots, 36$, we get 12 RD coefficients, which show that the effects build up smoothly. The increase in job separations with tenure is paralleled by an increase in JTJ transitions, whereas JTU transitions do not increase much with tenure after month 20. This is further confirmation that the reform effect is predominantly driven by increases in JTJ transitions.

RDD validity. To assess the validity of our RD design we perform a number of checks. First, we address the obvious caveat that manipulation of the job start date might invalidate identification. Notice, however, that it is not obvious why firms (or workers) would be willing to shift the start date of a planned hire forward or backward. Since the reform was cost-neutral on average, there is no clear ex-ante gain from self-selection into the old or the new system. Moreover, revealed behavior suggests that postponing the entry into a job to benefit from the new system was not a dominant option. Otherwise, the possibility 
Table 2: Dependent variable: probability of separation by 36 months after entry

\begin{tabular}{|c|c|c|c|c|c|}
\hline & $(1)$ & $(2)$ & $(3)$ & $(4)$ & $(5)$ \\
\hline \multicolumn{6}{|l|}{ Panel A: All exits } \\
\hline Estimated coefficient & $\begin{array}{c}0.125^{* * *} \\
(0.0371)\end{array}$ & $\begin{array}{c}0.136^{* * *} \\
(0.0468)\end{array}$ & $\begin{array}{l}0.111^{* * *} \\
(0.0294)\end{array}$ & $\begin{array}{c}0.128^{* * *} \\
(0.0454)\end{array}$ & $\begin{array}{c}0.130^{* * *} \\
(0.0387)\end{array}$ \\
\hline Pre-reform mean & 0.316 & 0.316 & 0.316 & 0.280 & 0.280 \\
\hline Effect relative to pre-reform mean & 0.396 & 0.431 & 0.350 & 0.457 & 0.466 \\
\hline \multicolumn{6}{|l|}{ Panel B: Job-to-Job } \\
\hline Estimated coefficient & $\begin{array}{c}0.0803^{* * *} \\
(0.0200)\end{array}$ & $\begin{array}{c}0.0870^{* * *} \\
(0.0247)\end{array}$ & $\begin{array}{c}0.0729 * * * \\
(0.0186)\end{array}$ & $\begin{array}{c}0.0992^{* * *} \\
(0.0270)\end{array}$ & $\begin{array}{c}0.0996^{* * *} \\
(0.0242)\end{array}$ \\
\hline Pre-reform mean & 0.135 & 0.135 & 0.135 & 0.112 & 0.112 \\
\hline Effect relative to pre-reform mean & 0.593 & 0.642 & 0.539 & 0.882 & 0.886 \\
\hline \multicolumn{6}{|l|}{ Panel C: Job-to-Unemployment } \\
\hline Estimated coefficient & $\begin{array}{l}0.0414^{*} \\
(0.0220)\end{array}$ & $\begin{array}{c}0.0603^{* *} \\
(0.0275)\end{array}$ & $\begin{array}{c}0.0372^{* *} \\
(0.0187)\end{array}$ & $\begin{array}{c}0.0418 \\
(0.0260)\end{array}$ & $\begin{array}{l}0.0479^{*} \\
(0.0254)\end{array}$ \\
\hline Pre-reform mean & 0.156 & 0.156 & 0.156 & 0.143 & 0.143 \\
\hline Effect relative to pre-reform mean & 0.264 & 0.386 & 0.238 & 0.291 & 0.334 \\
\hline \multicolumn{6}{|l|}{ Specification } \\
\hline Linear & Yes & Yes & Yes & Yes & Yes \\
\hline Quadratic & No & Yes & No & No & No \\
\hline Controls & No & No & Yes & No & Yes \\
\hline Bandwidth(quarters) & 24 & 24 & 24 & 10 & 10 \\
\hline Observations & 28099 & 28099 & 28099 & 13543 & 13543 \\
\hline
\end{tabular}

Note: The table reports the coefficient $\beta_{1}$ from a linear probability model based on equation (1). Results indicate a discontinuous increase in total job separations after the reform (panel A), which is mainly driven by JTJ transitions (panel B) and to a lesser extent by JTU transitions (panel C). The estimated effects are robust to the inclusion of control variables, the specification of the running variable and the bandwidth choice. 10 quarters is the optimal bandwidth according to Imbens and Kalyanaraman (2012). Standard errors are bootstrapped (1,000 replications) and clustered at the firm-level. Controls are gender, age, age squared, experience, experience squared, Austrian nationality, log firm size 24 months before the mass layoff, and indicators for manufacturing sector, Vienna, and quarter of job entry; ${ }^{*} p<0.10,{ }^{* *} p<0.05$, $* * * p<0.01$.

of switching to the new system (that became possible with the reform for all ongoing employment relationships) would have been taken up much more frequently. Panel (a) of Figure 2 plots the absolute frequency of workers in our baseline sample by their start date. Figure 2 shows that there is no statistically significant discontinuity in the absolute number of job starts at the reform date (2003q1), confirming the presumption that manipulation of hiring and/or job-start dates around the reform date does not appear empirically relevant. However, the figure also shows that the number of monthly hires is quite noisy.

A second potential problem may arise from differential selection of new- and old-system workers into our baseline sample. Recall that a crucial requirement, for including a worker in our baseline sample, is employment in a firm that subsequently experienced a mass 
layoff (an employment reduction of more than 33 percent within one month). However, the reform by itself might affect whether a firm satisfies the mass layoff criterion. Because old-system workers are more likely than new-system workers to stay with the firm until the mass layoff date, a firm that would have qualified as a mass layoff firm in the old system may not qualify as a mass layoff firm in the new system, which might invalidate our identification strategy. However, because of the gradual introduction of the new policy (only new, but not ongoing, jobs are subject to the new system), differential firm selection does not threaten identification in the present context. As we show in Panel (b) of Figure 2, the share of new-system workers (in firms that hired baseline sample workers) changes smoothly at the policy threshold. In other words, firms that hired workers immediately before and after the policy change are equally likely to qualify as mass layoff firms, supporting the validity of our RD design. ${ }^{13}$

A third validity test of our RD design involves checking whether observed covariates are smooth around the threshold. This allows us to shed light on potential selection and to rule out that events or interventions other than the severance-pay reform are driving the discontinuous increase in job mobility at the reform date. Table 2 of the Online Appendix shows that descriptive statistics of the baseline sample, before and after the reform, do not indicate any difference before and after the policy change, and corresponding RD estimates do not show any significant discontinuities either, neither in worker- nor in firm characteristics. The only exception is a somewhat lower percentage of females after the reform. (Below, we provide separate results for males and females to demonstrate that estimates of the reform effect are close in these two samples.)

Fourth, we estimate the RD coefficients from a series of "placebo reforms". We replicate the RD analysis, but instead of assigning the true reform date, we shift the reform cutoff date $x$ quarters away from the true reform date 2003Q1 (the true reform date is normalized to zero), with $x$ varying from 8 quarter before to 7 quarters after the true reform date. The results are reported in Figure 5 of the Online Appendix. The evidence in all three panels consistently shows that $\mathrm{RD}$ estimates are larger for placebo reforms closer to - and

\footnotetext{
${ }^{13}$ To construct the measure on the vertical axis of Figure 2, we construct the (worker-specific) variable "fraction of new-system workers in the firm that hired the worker, 24 months before the mass layoff". Panel (b) of Figure 2 reports the mean of this variable by the quarter of job start. In Figures 2 to 4 in the Online Appendix, we also show that firms hiring baseline sample workers immediately before and immediately after the policy change do not significantly differ in employment levels; absolute and relative sizes of the subsequent mass layoffs; absolute and relative employment reductions in the last two years before the mass layoff.
} 
Figure 2: Firms' new hires and workforce composition, by date of job start

(a) New hires of firms (baseline sample)

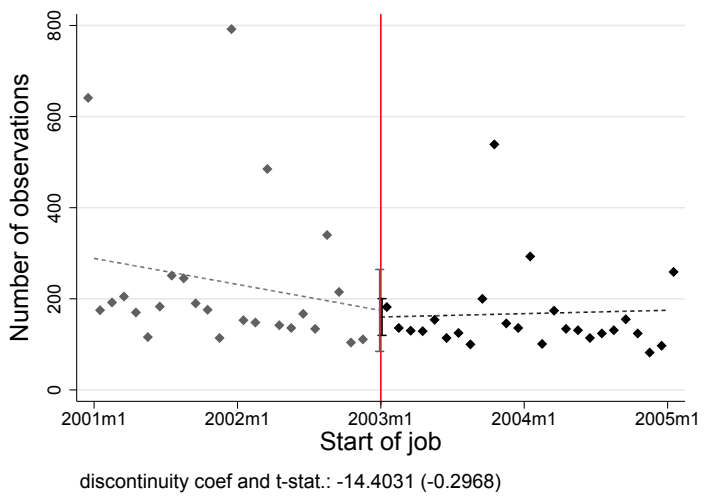

(b) Workforce composition, 24 months before the mass layoff

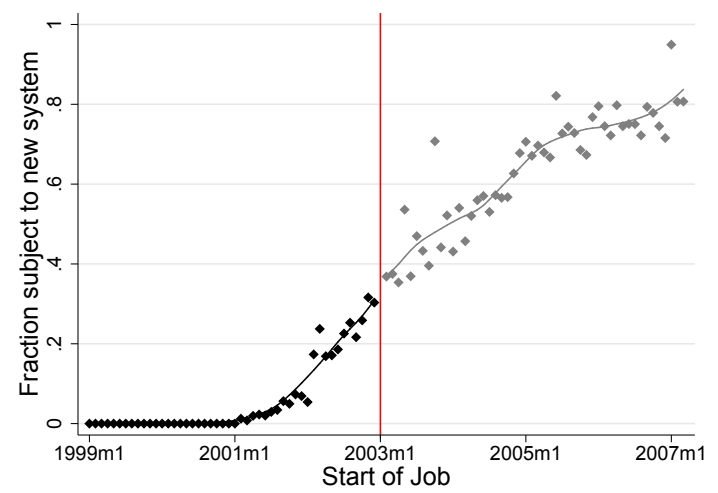

Note: The figures plot the absolute number of newly hired workers by calendar year-months. Panel A restricts attention to our baseline sample $(N=28,099)$, Panel B looks at the universe of job starters $(N=1,300,062)$ observed in the ASSD (who satisfy selection criteria). The fitted lines and confidence intervals are from a local linear regression with triangular weights. Inference is based on a bootstrap (1000 replications), clustered at the firm level. While the number of monthly hires is quite noisy, there is no statistically significant discontinuity in the number of job starts at the reform date (2003q1). This indicates that manipulation of new hires around the reform date does not appear empirically relevant. (See text for details.)

highest at - the true reform date. This supports the idea that the discontinuous change in job separations is indeed caused by the severance-pay reform rather than by some other event or intervention.

Overall, the above checks support our identification strategy, so we can be confident that contrasting mobility outcomes at the policy threshold indeed estimates the causal effect of the policy change on job mobility.

Robustness. In the next paragraphs, we test the robustness of our empirical results. The baseline sample includes workers with high layoff probabilities and hence strong disincentives to quit, if in the old system. However, defining the set of workers with high layoff probabilities rests on specific and potentially arbitrary criteria. In the following, we check whether our results are robust when we alter these criteria.

First, we look at alternative definitions of a mass layoff. In the baseline sample, we looked at workers entering a firm with a subsequent employment reduction of 33 percent 
(between months $t$ and $t+1$ ). Alternatively, we define a mass layoff as an employment reduction of $x$ percent or more, where we let $x$ vary from an employment reduction (between months $t$ and $t+1$ ) of 10 percent to 100 percent (i.e. a plant closure). In Figure 6 of the Online Appendix, we document that the estimated reform effect on all separations increases in $x$. This is in line with incentives. As a higher $x$ means a higher layoff probability for the average worker in the sample. Hence, under the old system, a higher $x$ is associated with a stronger incentive to wait for a layoff with severance pay. In contrast, in the new system, workers with an increased layoff probability will move to new jobs quickly. Moreover, the reform effect is mainly driven by higher JTJ moves and to a smaller extent by JTU transitions. For mass layoff definitions with $x>60$ percent, the reform effect levels off, mainly due to fewer JTU transitions to unemployment, whereas the reform effect on JTJ moves remains large.

Second, a potentially important factor that could invalidate the RD design are responses of firms and workers to changes in macroeconomic conditions or of seasonality effects. To explore this hypothesis, we replicate the analysis of Figure 1 for a sample of "matched control workers". Matched controls are hired by a firm that did not subsequently experience a mass layoff. ${ }^{14}$ In Figure 7 of the Online Appendix, we show that there is no significant upward jump at the reform threshold for matched control. This confirms that the reform affected workers with high layoff probabilities but did not affect our placebo workers whose job is not at risk. By construction, matched control workers have a low probability of being fired and hence to do not have a strong incentive to wait for a layoff with severance pay. Hence we expect them to be essentially unaffected by the severance-pay reform. We conclude that these results are consistent with the incentives created by the policy change.

Third, we report further robustness checks in Table 3, based on alternative samples of workers hired by mass-layoff firms. Panel A repeats the results of our baseline sample for comparison purposes, Panel B splits the baseline sample by sex. In Table 2 above, we have seen that the fraction of female workers was the only variable which showed a marginally significant discontinuous change at the policy threshold-under the new regime, fewer

\footnotetext{
${ }^{14}$ The matching procedure matches to each baseline sample worker a "clone" that enters a firm which will not experience a subsequent mass layoff. The following characteristics are used for an exact match: hired in the same quarter and stayed on the job for at least 12 months; same gender; same region (9 "Bundeslaender"); same industry (21 categories); same age decile. If we obtain multiple controls, we take the one with the closest propensity score based on experience, experience squared, employment status in the four quarters preceding the current job, and decile of the starting wage. 4.5 percent (out of 28,099) workers in the baseline sample could not be matched and were dropped. We end up with 26,841 matched pairs.
} 
women were hired by firms with a subsequent mass layoff. However, the results in Panel B show that reform effects are almost equally large for females as for males. In particular, transitions to new jobs are affected almost equally, when transitions to unemployment increase for women but not for men.

Panel $\mathrm{C}$ assesses robustness to the selection of workers entering firms before a mass layoff. In our baseline specification, we look at workers entering 3 to 4 years before a mass layoff. If we either look at workers entering 3 to 3.5 years before ( 6 months) or 3 to 5 years before (24 months), we find that separations increase significantly under the new regime, mostly because of larger transitions to a new job. In Panel $\mathrm{D}$ we present RD estimates when we increase the employment reduction criterion for a mass layoff to 66 percent and 100 percent. We continue to find a large reform effect on job separations driven by a higher incidence of job-to-job moves. The effect on transitions to unemployment is now small and insignificant.

Panel E varies the sample selection criterion for workers. In the baseline, we select workers that entered the firm 36-47 months before the subsequent mass layoff. In Panel E this time interval is changed to 24-35 and 48-57 months, respectively. We also alter the treatment variable to, respectively, "left the firm before tenure 24 months" or " 48 months". Interestingly, we do not find any significant effect of the reform on job mobility of workers who entered the firm 24-35 months before the mass layoff. Recall that workers became eligible for the severance payment only after at least 36 months of tenure. Since the mass layoff already took place before these workers became eligible for the severance pay, we should actually not find any reform effect for this group. In contrast, workers who entered 48-57 months before the mass layoff were vested (eligible) hence susceptible to react and for them, we see a similar response to that seen in the baseline sample.

Finally, Panel F of Table 5 varies the sample selection criterion for mass layoff firms. In the baseline, we include only firms that had at least 30 employees one month prior to the mass layoff; in Panel F we change minimum firm size to 15 and 60 employees, respectively. The robustness checks confirm the baseline result. The severance pay reform leads to higher job separations - mainly because it induces more job-to-job transitions.

Further results. Due to the increased incentive to quit, accepted wages should be lower on average for those affected by the reform: workers should accept outside wage offers under the new system they would have rejected under the old system. Figure 3 suggest that the wage increases among job changers (JTJ transitions) are indeed smaller under 
Table 3: RD estimates: further robustness checks

\begin{tabular}{|c|c|c|c|c|}
\hline & All exits & 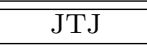 & JTU & Observations \\
\hline $\begin{array}{l}\text { Panel A: Baseline Results } \\
\text { Baseline coefficient }\end{array}$ & $\begin{array}{l}0.125^{* * *} \\
(0.0371)\end{array}$ & $\begin{array}{c}0.0803^{* * *} \\
(0.0200)\end{array}$ & $\begin{array}{l}0.0414^{*} \\
(0.0220)\end{array}$ & 28099 \\
\hline $\begin{array}{l}\text { Panel B: According to gender } \\
\text { Only male }\end{array}$ & $\begin{array}{c}0.123^{* * *} \\
(0.0426)\end{array}$ & $\begin{array}{c}0.0726^{* * *} \\
(0.0251)\end{array}$ & $\begin{array}{c}0.0363 \\
(0.0272)\end{array}$ & 13775 \\
\hline Only female & $\begin{array}{l}0.127^{* * *} \\
(0.0428)\end{array}$ & $\begin{array}{c}0.0788^{* * *} \\
(0.0235)\end{array}$ & $\begin{array}{l}0.0571^{* *} \\
(0.0257)\end{array}$ & 14324 \\
\hline $\begin{array}{l}\text { Panel C: According to width of mass lay } \\
24 \text { months }\end{array}$ & $\begin{array}{l}f \text { window } \\
0.0967^{* * *}\end{array}$ & $0.0569^{* * *}$ & $0.0336^{* *}$ & 53550 \\
\hline 6 months & $\begin{array}{l}0.156^{* * *} \\
(0.0456)\end{array}$ & $\begin{array}{c}0.0991^{* * *} \\
(0.0233)\end{array}$ & $\begin{array}{l}0.0564^{*} \\
(0.0303)\end{array}$ & 14677 \\
\hline $\begin{array}{l}\text { Panel D: According to size of mass layof } \\
\text { At least } 66 \% \text { reduction }\end{array}$ & $\begin{array}{c}0.0921^{* *} \\
(0.0409)\end{array}$ & $\begin{array}{c}0.0873^{* * *} \\
(0.0275)\end{array}$ & $\begin{array}{r}-0.00176 \\
(0.0210)\end{array}$ & 20576 \\
\hline Firm closure & $\begin{array}{c}0.0962^{* * *} \\
(0.0292)\end{array}$ & $\begin{array}{c}0.0720^{* * *} \\
(0.0187)\end{array}$ & $\begin{array}{c}0.0222 \\
(0.0193)\end{array}$ & 13011 \\
\hline \multicolumn{5}{|c|}{ Panel E: According to distance to mass layoff, exit by one month before mass layoff window } \\
\hline Entry 24 - 35 months before mass layoff & $\begin{array}{l}0.00677 \\
(0.0191)\end{array}$ & $\begin{array}{l}0.00219 \\
(0.0137)\end{array}$ & $\begin{array}{r}-0.00347 \\
(0.0116)\end{array}$ & 26244 \\
\hline Entry 48 - 59 months before mass layoff & $\begin{array}{l}0.0880^{* *} \\
(0.0371)\end{array}$ & $\begin{array}{c}0.0519^{* * *} \\
(0.0201)\end{array}$ & $\begin{array}{c}0.0275 \\
(0.0210)\end{array}$ & 26668 \\
\hline \multicolumn{5}{|c|}{ Panel F: According to minimum firm size 1 month before mass layoff } \\
\hline At least 15 employees & $\begin{array}{r}0.108^{* * *} \\
(0.0344)\end{array}$ & $\begin{array}{c}0.0696^{* * *} \\
(0.0183)\end{array}$ & $\begin{array}{l}0.0337^{*} \\
(0.0201)\end{array}$ & 34182 \\
\hline At least 60 employees & $\begin{array}{l}0.136^{* * *} \\
(0.0427)\end{array}$ & $\begin{array}{c}0.0856^{* * *} \\
(0.0235)\end{array}$ & $\begin{array}{l}0.0479^{*} \\
(0.0257)\end{array}$ & 22860 \\
\hline
\end{tabular}

Note: The robustness checks are based on alternative samples of workers hired by mass-layoff firms. Panel A repeats the results based on our baseline sample for comparison, Panel B splits the baseline sample by gender, Panel $\mathrm{C}$ varies the selection of workers entering firms before a mass layoff. In our baseline specification, we look at workers entering 3 to 4 years before a mass layoff, while we now consider either workers entering 3 to 3.5 years before (6 months) or 3 to 5 years before (24 months). Panel D increases the required employment reduction to 66 percent and 100 percent (sticking to the baseline time window of 1 month). Panel $\mathrm{E}$ varies the sample selection criterion for workers. In the baseline, we select workers that entered the firm 36-47 months before the subsequent mass layoff, in Panel E this time interval is changed to 24-35 and 48-57 months, respectively. Finally, Panel F varies the sample selection criterion for mass layoff firms. In the baseline, we include only firms that had at least 30 employees one month prior to the mass layoff; in Panel F we change minimum firm size to 15 and 60 employees, respectively. Inference is based on a bootstrap (1000 replications), clustered at the firm level. The robustness checks confirm the baseline result. The severance pay reform leads to higher job separations - mainly because of higher job-to-job transitions under the new system. 
the new regime. This is in line with is expected, as workers waiting for a future severance payment require higher outside offers to be induced to switch jobs. However, as shown in the Online Appendix Table 3, the point estimates are not very precise. Due to the smaller sample size $(N=4,280)$ the estimated reform effect is not statistically significant.

Figure 3: Wage growth of job changers (JTJ), by date of job start

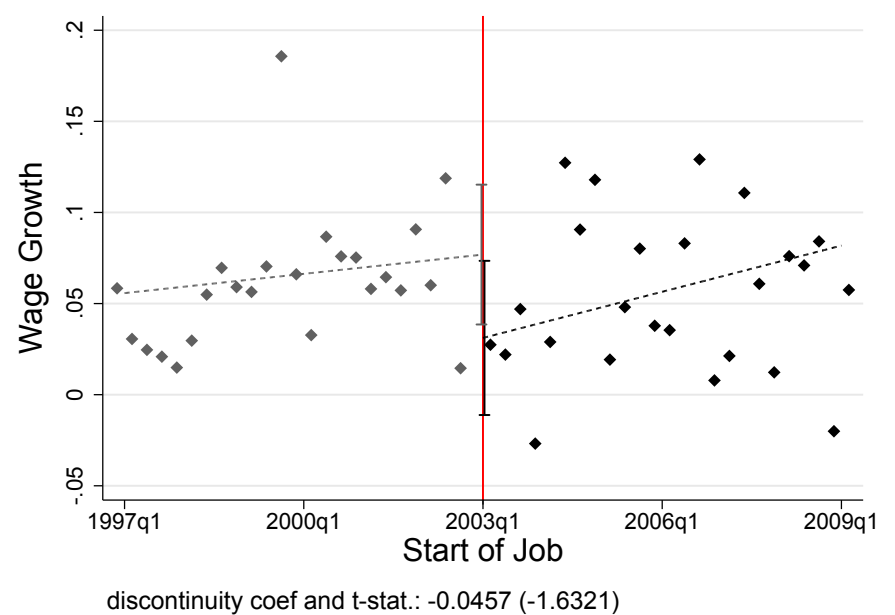

Note: The Figure reports the difference in log earnings in the new job and the previous job (in the masslayoff firm). Only workers classified as job-to-job changers leaving the firm before the mass layoff occurs are considered. Inference is based on a bootstrap (1000 replications), clustered at the firm level. Under the old system, the incentive to change jobs is lower because those not-fired who leave give up their severance pay option. Under the new system, voluntary quitters do not suffer such a loss. Hence, lower wage increases are required to induce new-system workers to accept outside job offers. The Figure shows that there is indeed at negative jump in average wage growth of job changes at the reform date (2003q1), although the effect is not statistically significant.

We also explored which firms might have benefited from the increased willingness to move to new jobs. Unfortunately, our data set does not allow us to explore firm outcomes in more detail, as the ASSD contains only limited firm characteristics. In particular, firms' balance sheet information cannot be linked to the ASSD. However, we find that young firms (firm age $<10$ years) were disproportionately able to attract job movers. In Figure 8 in the Online Appendix, we document a significant increase in the probability of JTJ moves to firms younger than 10 years, while transitions to older firms are not affected. To the extent the former firms are more dynamic and innovative, this is consistent with the idea that the reform sped up the reallocation of labor to more productive/innovative 
activities, very much in the Schumpeterian spirit of Creative Destruction.

\section{A Model of Quits and Layoffs with Severance Pay}

In this section we set up a search and matching model with on-the-job-search and severance pay based on the Mortensen and Pissarides (1994) model. We argue that this is a natural starting point to study the effect of severance pay on the labor market equilibrium. The main text provides a sketch of the model, while the Online Appendix discusses the model in more detail. We then structurally estimate this model and quantitatively explore its equilibrium responses to changes in severance pay rules. In counterfactual policy experiments, we shed light on the potential effects of severance pay reforms in systems that were initially more generous than the Austrian pre-reform system (such as the ones currently in place in various Southern European countries).

Environment. Time is discrete. There is a continuum of risk-neutral workers of mass 1 who are either employed or unemployed. Firms either produce (with stochastic productivity), or search for a worker to fill a vacancy. Due to labor market frictions, it takes time to find a new job and to fill a vacancy. A (constant-returns-to-scale) matching function $m=m(u+\chi(1-u), v)$ determines the likelihood that firms and workers meet, where $v$ denotes the number of vacancies and $u$ the number of unemployed workers. Importantly, employed workers also search for new jobs (though with reduced intensity $\chi<1$ ). Denote labor market tightness by $\theta \equiv v /(u+\chi(1-u))$. Then the probability that a vacant firm meets a worker is $m / v=m\left(\theta^{-1}, 1\right) \equiv q(\theta)$ with $q^{\prime}(\theta)<0$; the probability that an unemployed worker meets a vacancy is $m /(u+\chi(1-u))=m(1, \theta) \equiv f(\theta)$ with $f^{\prime}(\theta)>0$; and the probability that an employed worker meets a vacancy is $\chi f(\theta)$.

Once a firm with a vacancy meets a worker, a draw $p \in[\underline{p}, \bar{p}]$ from an exogenous distribution $G(p)$ reveals the initial productivity $p \in[\underline{p}, \bar{p}]$ of the job match. Productivity is firm-specific, i.i.d. across firms, and evolves according to a Markov process. When productivity falls below a critical threshold, the worker is laid off and the firm shuts down. In case of a layoff, an eligible worker gets a severance payment $\psi$, while a non-eligible workers does not get any payment. We assume that severance-pay eligibility depends on tenure. Every period (including the initial period), an ineligible worker turns eligible with probabiltiy $\alpha<1$. Once the worker becomes eligible, she stays eligible for the remaining 
duration of the employment relationship. ${ }^{15}$ For simplicity, we assume that the worker's eligibility status and the firm's productivity draw are revealed simultaneously. Thereafter a Nash bargain takes place, production starts, and wages and profits accrue. At the end of the period, the worker may receive an outside offer, which happens with probability $\chi f(\theta)$. If she accepts the offer, she does not receive the severance payment $\psi$. The match may also be dissolved for exogenous reasons, which happens with probability $\lambda$, in which case eligible workers also receive a severance payment. In other words, being eligible refers to entitlement to a payment in case of a layoff (after an unfavorable productivity draw) or an exogenous termination of a job, but not in case of a quit.

Quits and layoffs. A crucial element of the model relates to the worker's incentive to quit. Denote by $\mu_{i}^{j}\left(p, p^{o}\right)$ the endogenous decision of an employed worker with eligibility status $i \in\{0,1\}$, in a firm with productivity $p$, to accept an outside offer from a firm with productivity $p^{o}$ where she will have eligibility status $j \in\{0,1\}$. The probability that an employed worker accepts an outside offer is

$$
\bar{\mu}_{i}(p)=\int_{\underline{p}}^{\bar{p}} \alpha \mu_{i}^{1}\left(p, p^{o}\right)+(1-\alpha) \mu_{i}^{0}\left(p, p^{o}\right) d G\left(p^{o}\right) .
$$

Similarly, denote by $\mu_{u}^{j}\left(p^{o}\right)$ the endogenous decision of an unemployed worker to accept an offer by a firm with productivity $p^{o}$. The probability that the offer is acceptable is

$$
\bar{\mu}_{u}=\int_{\underline{p}}^{\bar{p}} \alpha \mu_{u}^{1}\left(p^{o}\right)+(1-\alpha) \mu_{u}^{0}\left(p^{o}\right) d G\left(p^{o}\right) .
$$

The indicator $\gamma_{i}(p) \in\{0,1\}$, on the other hand, takes value 1 if the firm decides to terminate a match with productivity $p$ and eligibility status $i$; and takes the value 0 otherwise.

Denote by $J_{i}(p)$ the value of a firm and by $W_{i}(p)$ the value of employment to a worker, when productivity is $p$ and the worker's eligibility status is $i$. The match surplus is $S_{i}(p)=$ $W_{i}(p)-U+J_{i}(p)$, assuming firms have to pay $\psi$ to eligible workers if bargaining breaks down. As the value of a vacancy is 0 , firms' outside value is $0-\psi=-\psi$ if the worker is eligible and 0 if she is non-eligible. The worker's outside value is $U+\psi$ if eligible, and $U$

\footnotetext{
${ }^{15}$ In the structural estimation below, we set $\alpha=1 / 36$. This implies that, in a stationary equilibrium with monthly periodicity, the average worker gets entitled to a severance payment in case of a layoff after 36 months of tenure on average - corresponding to the rules in the Austrian pre-reform system.
} 
if non-eligible. ${ }^{16}$ Denoting by $\beta$ the worker's bargaining power, Nash bargaining implies $W_{1}(p)-(U+\psi)=\beta S_{1}(p), J_{1}(p)+\psi=(1-\beta) S_{1}(p), W_{0}(p)-U=\beta S_{0}(p)$, and $J_{0}(p)=$ $(1-\beta) S_{0}(p)$. All equilibrium objects can be characterized using the surplus functions. Denote by $\delta$ the discount rate, and by $F\left(p^{\prime} \mid p\right)$ the conditional distribution of a future productivity realization $p^{\prime}$ given the current productivity $p$ (throughout, primes denote next period values). In Section 2.1 of the Online Appendix, we show that the surplus function of a match with productivity $p$ that employs a worker with eligibility status $i$ can be written as

$$
S_{i}(p)=p-b+\delta f O_{i}(p)+\delta\left(1-\lambda-\chi f \bar{\mu}_{i}(p)\right) Q_{i}(p)
$$

Both surplus functions consist of the flow payoff, $p-b$, the workers' option value due to potential job-to-job transitions, $O_{i}(p)$, and the continuation value, $Q_{i}(p)$ (which accounts for exogenous and endogenous destruction). Option and continuation values satisfy

$$
\begin{gathered}
O_{i}(p)=\int_{\underline{p}}^{\bar{p}} \alpha\left(\chi \mu_{i}^{1}\left(p, p^{o}\right)-\mu_{u}^{1}\left(p^{o}\right)\right)\left(\beta S_{1}\left(p^{o}\right)+\psi\right)+(1-\alpha)\left(\chi \mu_{i}^{0}\left(p, p^{o}\right)-\mu_{u}^{0}\left(p^{o}\right)\right) \beta S_{0}\left(p^{o}\right) d G\left(p^{o}\right) \\
Q_{0}(p)=\int_{\underline{p}}^{\bar{p}} \alpha\left(1-\gamma_{1}\left(p^{\prime}\right)\right) S_{1}\left(p^{\prime}\right)+(1-\alpha)\left(1-\gamma_{0}\left(p^{\prime}\right)\right) S_{0}\left(p^{\prime}\right) d F\left(p^{\prime} \mid p\right)
\end{gathered}
$$

and

$$
Q_{1}(p)=\int_{\underline{p}}^{\bar{p}}\left(\left(1-\gamma_{1}\left(p^{\prime}\right)\right) S_{1}\left(p^{\prime}\right) d F\left(p^{\prime} \mid p\right) .\right.
$$

Layoff decisions. When the firm gets a bad enough productivity draw, the worker is laid off and the firm shuts down its operation. The layoff decision depends on the eligibility status of the worker. A firm with a non-eligible worker shuts down if $J_{0}(p)<0$, while a firm with an eligible worker shuts down if $J_{1}(p)<-\psi$. Hence we have ${ }^{17}$

$$
\gamma_{0}=\mathbb{1}\left\{S_{0}(p)<0\right\} \text { and } \gamma_{1}=\mathbb{1}\left\{S_{1}(p)<0\right\} .
$$

\footnotetext{
${ }^{16}$ An alternative assumption, adopted by Saint-Paul (1995), is to assume $U$ and $-\psi$ for the workers' and firms' outside values, respectively, based on the rationale that each party receives the payment she would receive if having initiated the separation. This coordination failure can lead to multiple equilibria and proved to be less stable in the structural estimation to follow. We thus opted for the more parsimonious approach. However, the basic mechanism would still go through, as we discuss further in footnote 19.

${ }^{17}$ It is worth noting that, due to the bargaining assumption, it does not matter whether we think of a "layoff" as firm- or worker-induced, since neither of the two parties are interested in continuing the employment relationship if the joint surplus falls below zero. This is reminiscent of McLaughlin (1991), who argues that the distinction between quits and layoffs is economically inconsequential.
} 
Quit decisions. A worker receiving an outside offer trades off the value in the new job against the value of staying. The value of staying is $\int_{\underline{p}}^{\bar{p}} \gamma_{1}\left(p^{\prime}\right)(U+\psi) d F\left(p^{\prime} \mid p\right)+Q_{1}(p)$, if the worker is eligible; and $\int_{p}^{\bar{p}}\left((1-\alpha) \gamma_{0}\left(p^{\prime}\right) U+\alpha \gamma_{1}\left(p^{\prime}\right)(U+\psi)\right) d F\left(p^{\prime} \mid p\right)+Q_{0}(p)$, if she is not eligible. The crucial quit decision rule, showing the effect we emphasize, characterizes the decision to quit for eligible workers in favor of a new job that does not initially provide severance pay, which can be summarized as

$$
\mu_{1}^{0}\left(p, p^{o}\right)=\mathbb{1}\left\{\beta S_{0}\left(p^{o}\right)>\psi+\beta Q_{1}(p)\right\}
$$

Notice that $\psi$ affects quit decisions in a transparent way, clearly reducing the incentive to accept the outside offer. ${ }^{18}$ The reason is that workers realize that their outside value drops from $U+\psi$ to $U$, when firm's outside value increases from $-\psi$ to 0 , leading to a lower bargained value ceteris paribus. ${ }^{19}$ Figure 4 gives a summary of the model's predictions regarding worker behavior before and after the reform: ${ }^{20}$ Before the reform, a worker had to be compensated for foregoing a severance payment and hence a firm making an outside offer had to have a much higher productivity. After the reform, workers are also willing to move to firms that are weakly more productive.

\footnotetext{
${ }^{18}$ The other decision rules are given by, respectively, $\mu_{1}^{1}\left(p, p^{o}\right)=\mathbb{1}\left\{\beta S_{1}\left(p^{o}\right)+\psi>\psi+\beta Q_{1}(p)\right\}$, $\mu_{0}^{0}\left(p, p^{o}\right)=\mathbb{1}\left\{\beta S_{0}\left(p^{o}\right)>\alpha \psi+\beta Q_{0}(p)\right\}$, and $\mu_{0}^{1}\left(p, p^{o}\right)=\mathbb{1}\left\{\beta S_{1}\left(p^{o}\right)+\psi>\alpha \psi+\beta Q_{0}(p)\right\}$ for eligible workers offered a job where they are initially eligible and for ineligible workers where they initially in-eligible or eligible. While in reality, access to severance pay changes discontinuously with tenure, this accounts for the possibility that eligibility for severance is granted immediately with a (small) probability $\alpha$. Notice that the overall quit probability is a weighted sum of the quit probabilities to jobs with and without immediate eligibility. It turns out that a higher $\psi$ unambiguously decreases the quit probability for eligible workers as $\mu_{1}^{1}$ does not react. For non-eligible workers, we predict a lower willingness to quit to jobs where they are non-eligible and a higher willingness to quit to jobs where they are eligible. The net effect of these contrary forces is unambiguous but likely to be small.

${ }^{19}$ This is the crucial link in the model which is preserved even if we use Saint-Paul (1995)'s assumption discussed in footnote 16 . While in our case the surplus of workers relative to the surplus of firms is given by

$$
W-U=\frac{\beta}{1-\beta} J+\frac{\psi}{1-\beta},
$$
}

the respective expression following Saint-Paul (1995) reads

$$
W-U=\frac{\beta}{1-\beta} J+\frac{\beta}{1-\beta} \psi .
$$

Hence, even if their outside value is not affected, workers still manage to improve their bargaining position with a high $\psi$ as the firms' outside value is lower.

${ }^{20}$ Figure 4 has been generated using the parameterization based on the baseline estimates described later on. 
Figure 4: Offer acceptance rule before and after the reform (eligible workers)

(a) Pre-reform

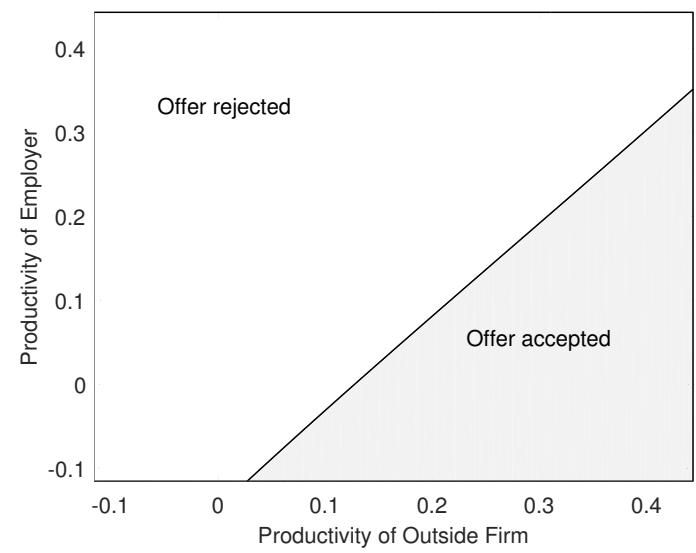

(b) Post-reform

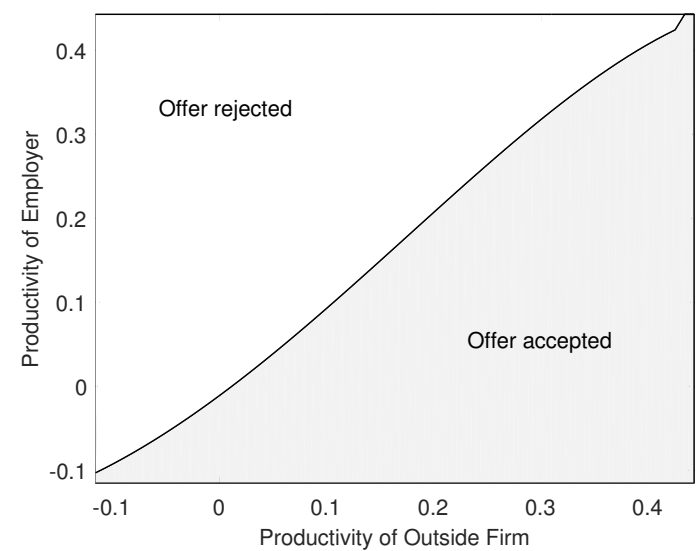

Note: The Figure shows the acceptance rule of outside offers for eligible workers given productivity of the current employer and productivity of the outside firm. The plots are outcomes of the estimated model to be described later in the text.

Equilibrium. We can characterize the general equilibrium of the model by three conditions. The first condition makes sure that firms and workers choose their strategies to maximize expected income, so that the surplus functions $S_{0}(p)$ and $S_{1}(p)$ solve the recursive equation (2).

The second equilibrium condition makes sure that the productivity distribution of active firms is stationary. Denote by $n_{0}(p)$ and $n_{1}(p)$ the (stationary) number non-eligible and eligible workers employed in a firm with productivity $p$, so the (stationary) number of unemployed individuals is $u=1-\int_{p}^{\bar{p}} n_{0}(p)+n_{1}(p) d p$. This second condition states that the inflow into firms with productivity $p$ (from unemployment and from other firms with lower productivities) has to equal the outflow from firms with productivity $p$ (to unemployment or to firms with higher productivities). The recursive equations, which guarantee a stationary productivity distribution are derived in chapter 2.1 of the Online Appendix.

The third equilibrium condition is a zero profit condition for posting a vacancy. The expected value of posting a vacancy satisfies $V=-c+\delta q(\theta) \int_{p}^{\bar{p}}(1-\alpha) a_{0}\left(p^{o}\right) J_{0}\left(p^{o}\right)+$ $\alpha a_{1}\left(p^{o}\right) J_{1}\left(p^{o}\right) d G\left(p^{o}\right)$, where $c$ denotes the flow cost of posting a vacancy and $\delta$ is the discount rate. With probability $q$ the firm meets a potential worker and draws initial productivity $p^{o}$ from the distribution $G\left(p^{o}\right)$, while the worker becomes eligible to severance pay with probability $\alpha$. With probability $a_{i}\left(p^{o}\right)$ the offer of the firm is accepted and the 
firm starts producing in the subsequent period, yielding value $J_{i}\left(p^{o}\right)$. The acceptance probability $a_{i}\left(p^{o}\right)$ is given by

$$
a_{i}\left(p^{o}\right)=\frac{u}{u+\chi(1-u)} \cdot \mu_{u}^{i}\left(p^{o}\right)+\frac{\chi(1-u)}{u+\chi(1-u)} \cdot \frac{\int_{\underline{p}}^{\bar{p}} n_{0}(p) \mu_{0}^{i}\left(p, p^{o}\right)+n_{1}(p) \mu_{1}^{i}\left(p, p^{o}\right) d p}{1-u}
$$

where the first (second) term is the conditional probability of meeting an unemployed (employed) worker times the probability that the offer is accepted. Due to free entry, a vacancy has to yield zero expected profits, i.e. $V=0$. The zero profit condition, which pins down $\theta, q$, and $f$, is

$$
\frac{c}{\delta q(\theta)}=\int_{\underline{p}}^{\bar{p}}(1-\alpha) a_{0}\left(p^{o}\right)(1-\beta) S_{0}\left(p^{o}\right)+\alpha a_{1}\left(p^{o}\right)\left((1-\beta) S_{1}\left(p^{o}\right)-\psi\right) d G\left(p^{o}\right) .
$$

Definition 5.1. An equilibrium is given by functions $\left\{n_{0}(p), n_{1}(p)\right\}$, values $\left\{S_{0}(p), S_{1}(p)\right\}$ and labor market tightness $\theta$ such that

1. $\left\{S_{0}(p), S_{1}(p)\right\}$ solve the recursive equation (2);

2. $\left\{n_{0}(p), n_{1}(p)\right\}$ are stationary;

3. labor market tightness $\theta$ solves the zero-profit condition (3).

We have seen above that changes in $\psi$ directly affect quit decision rules $\mu_{j}^{i}$, but have no direct effect on layoff decision rules $\gamma_{i}$. A decrease in severance pay, through a change in the decision rule, $\mu_{j}^{i}$, makes mobility more frequent. Consider now the effect of a small change in $\psi$, assuming for simplicity that $\psi$ goes back to its initial value in the subsequent period. This yields

$$
\begin{aligned}
\Delta S_{1}(p)= & \delta \chi f \int_{\underline{p}}^{\bar{p}}\left\{(1-\alpha) \Delta \mu_{1}^{0}\left(p, p^{o}\right)\left[\beta S_{0}\left(p^{o}\right)-Q_{1}(p)\right)\right] \\
& \left.\left.\quad+\alpha \Delta \mu_{1}^{1}\left(p, p^{o}\right)\left[\beta S_{1}\left(p^{o}\right)+\psi-Q_{1}(p)\right)\right]\right\} d G\left(p^{o}\right) \\
\approx & \left.\left.\delta \chi f(1-\alpha) g\left(p^{*}\right)\left[\beta S_{0}\left(p^{o}\right)-Q_{1}(p)\right)\right]+\delta \chi f \alpha g\left(p^{* *}\right)\left[\beta S_{1}\left(p^{o}\right)+\psi-Q_{1}(p)\right)\right] \\
= & \delta \chi f\left[(1-\alpha) g\left(p^{*}\right)+\alpha g\left(p^{* *}\right)\right]\left[\psi-(1-\beta) Q_{1}(p)\right] .
\end{aligned}
$$

In the first step, a small change in $\psi, \mu_{1}^{i}\left(p, p^{o}\right)$ will generally have a zero effect, except for outside offers $p^{o}=p^{*}$ or $p^{o}=p^{* *}$, which satisfy $\Delta \mu_{1}^{0}\left(p, p^{*}\right)=1$ and $\Delta \mu_{1}^{1}\left(p, p^{* *}\right)=1$. In 
other words, $p^{*}$ and $p^{* *}$ are offers "on the edge" that trigger additional quits in response to a marginal reduction of $\psi$. Workers receiving these offers will be (almost) indifferent between accepting or rejecting them. Hence this indifference entails that $\beta S_{0}\left(p^{*}\right) \approx \psi+\beta Q_{1}(p)$ and $\beta S_{0}\left(p^{* *}\right) \approx \beta Q_{1}(p)$. Substituting above using these conditions, we obtain the final expression.

The main conclusion is the effect of changes onto the current surplus: it is equal to zero uniquely in the knife-edge case when $Q_{1}(p)=\psi /(1-\beta)$, and different from zero in general, which breaks the neutrality à la Lazear (1990). The sign of the effect, however, is ambiguous. Whereas a worker only accepts offers that make her better off, she ignores the share of the surplus accruing to the firm, which is destroyed by the quit. If the current match surplus is relatively high, the negative effect dominates. On the other hand, for a relatively low current surplus, the option value of worker is sufficiently large so as to dominate the firm's share in the surplus of the current match.

Transition from a system with $\psi>0$ to $\psi=0$. In our structural estimation below, we use pre- and post-reform tenure profiles of job separations estimated in the last section. Prima facie, one might think of a procedure that would use a given set of (estimated and exogenous) parameters to generate pre- and post-reform steady state equilibria as described in Definition 5.1. However, this would not be a correct interpretation of the empirically observed tenure profiles. These profiles derive from an RD setting, comparing quit behaviors in jobs that started immediately before and after January 2003. When these workers make their quit decisions (12-36 months after job start), the labor market consisted of a mixture of workers partly subject to the old and partly subject to the new system. In other words, the empirical tenure profiles derive from a labor market equilibrium in transition to the post-reform steady state.

In fact, the transition equilibrium can be characterized in a rather straightforward way. The only (macro) state variable of the model is labor market tightness $\theta$. As the economy moves from the old to the new steady state, labor market tightness moves from its old to its new equilibrium value. If we fix $\theta$ and hence $f(\theta)$, all quit and layoff decisions take their partial equilibrium values, as can be seen from equation (2). An important asymmetry between old- and new-system workers needs to be taken into account. New-system workers know that any future match will also be subject to the new system and hence their Bellman equations will not change. In contrast, old-system workers need to take into account that any future match will imply a switch to the new system. Denoting by $\tilde{S}^{n e w}\left(p^{o}\right)$ the surplus 
of a match with a new-system worker, the surplus of an eligible old-system worker in transition is given by

$$
\begin{aligned}
\tilde{S}_{1}^{\text {old }}(p)=p-b+\delta f \int_{\underline{p}}^{\bar{p}}\left(\chi \tilde{\mu}_{1}^{\text {old }}\left(p, p^{o}\right)-\tilde{\mu}_{u}\left(p^{o}\right)\right) \beta \tilde{S}^{\text {new }}\left(p^{o}\right) d G\left(p^{o}\right) \\
\quad+\delta\left(1-\lambda-\chi f \overline{\tilde{\mu}}_{1}^{\text {old }}(p)\right) \int_{\underline{p}}^{\bar{p}}\left(1-\tilde{\gamma}_{1}^{\text {old }}\left(p^{\prime}\right)\right) \tilde{S}_{1}^{\text {old }}\left(p^{\prime}\right) d F\left(p^{\prime} \mid p\right)
\end{aligned}
$$

In Section 2.1 of the Online Appendix, we show in more detail how the recursive equations are affected..$^{21}$

Discussion. A few elements on the model are worth stressing. The first point relates to the so-called bonding critique of Lazear (1990), according to which severance payments will not affect the equilibrium in frictionless labor markets. Indeed, such payments can always be "neutralized" by a well-designed wage contract. To generate an equilibrium impact, severance payments are modeled as a "tax", that reduces the surplus of the employment relationship. In such a framework, severance payments ("firing taxes") generate fewer layoffs while employment effects are less clear, as emphasized by Bertola (1990), Bentolila and Bertola (1990) and discussed in Ljungqvist (2002).

In our context, Garibaldi and Violante (2005) provides an interesting benchmark. In their model, severance payments are also neutral in a labor market with frictions. As in our model above, worker starts out as ineligible to severance pay but turns eligible with a constant probability. Severance payments are offset by a contract which pays a low wage as long as the worker is still ineligible, but a high wage once the worker has become eligible. The worker effectively pre-pays a "bond" with principal $\psi$ through a reduced wage when ineligible; receives a "coupon", an increased wage, once eligible; and gets the principal $\psi$ once the job is dissolved. In this framework, varying the severance payment $\psi$ does not affect the match surplus and the equilibrium. Our framework is identical to the one of Garibaldi and Violante (2005), with the only but important exception that we allow workers to change jobs. As discussed above, adding the possibility of non-exogenous job-to-job transitions affects the creation and the destruction of match surplus through the option value associated with job-to-job mobility. The current match surplus is affected by

\footnotetext{
${ }^{21}$ Note that the simplification here is to fix $\theta$ at an intermediate value (between the old and the new steady state), while the precise transition equations should take into account the time path of $\theta$ towards the post-reform steady state.
} 
the severance payment and no wage policy can undo this impact. Hence, the combination of severance payment and voluntary mobility (to more productive firms) eliminates the potential for the bonding critique.

The second comment relates to wage determination. The model assumes that wages are flexible and set through Nash bargaining. Notice that the bargaining assumption is not as restrictive as it might appear. We do not need to assume that bargaining takes place every period, as the equilibrium is only affected by the bargaining parameter $\beta$ through the new matches. On the one hand, the surplus functions depend on $\beta$ as it determines the share of the new match surplus, which is captured by workers moving to a new job. On the other hand, firms' vacancy creation depends on their share of the surplus. It does not matter, however, whether this share of the match is preserved in ongoing matches every period, since the definition of the equilibrium will not be affected. Instead, we can interpret $\beta$ as the share of the match surplus that a worker expects to receive on average over all future periods when entering a new match. The only required additional assumption is that renegotiation takes place if either margin of the bargaining range is hit, see Malcomson (1997).

Finally, note that in the model severance payments are a distortion which ties workers to their current employers but has otherwise no effects. This means that the model does not provide any rationale for the existence of severance pay systems. The main reason for our modeling strategy is our interest in the role of severance pay for labor market flexibility. A full-fledge analysis of the welfare implications of such systems is beyond the scope of this paper. To the extent that severance pay systems have positive productivity effects (say, through facilitating the investments in firm-specific human capital), our model understates the positive productivity effects of a severance pay system.

\section{Structural Estimation}

In this section, we use the RD estimates from the reduced-form analysis as moments for structural estimation. The main motivation behind this exercise is that we want to explore the aggregate implications of the policy change. We need a model to infer the reform's long run effect on unemployment and productivity.

We take a subset of parameters as exogenously given, either from the institutional setting or from the literature. The remaining parameters are estimated by a Simulated Methods of Moments. Targeted moments are monthly job mobility patterns two years 
before a mass layoff and a set of macro moments. In total, we target 92 mobility rates (23 monthly exit rates for JTU and JTJ, pre- and post-reform) and 5 macro moments (unemployment rate, probability of a mass layoff, job finding rate, labor market tightness, hiring cost share).

We take particular care to ensure correspondence of the empirical moments and the simulated (from the model) moments. In particular, we select the sample from the simulated data in an analogous manner as we select the baseline sample, used for the reduced-form (RD) estimates, from the (social security) data. From the simulated data, we pick those workers that enter a firm which subsequently has to close down because of a bad productivity draw. We then estimate the same RD regression on the simulated data as we do in the reduced form (RD) analysis. Applying the same sample selection criteria to the simulated and empirical data ensures consistency between the empirical and simulated moments.

As mentioned above, the simulations also take into account that the empirical moments are identified from a labor market in transition. More precisely, we account for pre-reform worker anticipating that any future employment relationship will be subject to post-reform rules. We impose the simplifying assumption that mobility choices are based on a fixed $\theta$, assuming that it takes an intermediate value between the old and the new steady state. The simplification is that workers do not take into account any future change in in $\theta$ during the transition towards the post-reform steady state. This assumption is innocent in the present context, because the pre- and post-reform steady state values of $\theta$ are very close to each other. Thus disregarding the actual changes of $\theta$ will not make a quantitatively relevant difference.

To further discipline the model, we also match macro moments such as the unemployment rate, the aggregate job finding rate, and the job destruction rate with data generated by our model.

Empirical moments. We require the model to match the observed cumulative exit shares into unemployment (JTU) and to a new job (JTJ) during the last 24 months before a mass layoff. In the data, we classify a transition as JTJ if the intervening period of unemployment does not exceed 28 days (Figure 5) and we apply the same convention also to the simulated data. In order to identify the exit rates in the data, we include workers still employed at the firm two years before the layoff. We run the following regression 
model both on the simulated and the actual data

$$
d_{i}(t)=\beta_{0}(t)+\beta_{1}(t) \mathbb{1}\left[x_{i} \geq 0\right]+\beta_{2}(t) x_{i}+\beta_{3}(t) x_{i} \mathbb{1}\left[x_{i} \geq 0\right]+\varepsilon_{i}(t),
$$

where $d_{i}(t)$ takes the value 1 if worker $i$ has exited the firm $t$ periods before the mass layoff by a JTU or JTJ transition and $x_{i}$ denotes the normalized start date of the job. ${ }^{22}$ We include 24 quarters to the left and the right of the cutoff and give more weight to observations close to the cutoff by choosing a triangular kernel. The exit rates before and after the reform are then identified as $\beta_{0}(t)$ and $\beta_{0}(t)+\beta_{1}(t), t \in\{24, \ldots, 2\}$. We show the resulting empirical moments in Figure 5. Since there is no calendar time dimension in the model generated data, we allocate $x_{i}$ randomly to individual observations using probability weights according to the empirically observed distribution of start dates.

Figure 5: Moments estimated from RDD

(a) Cumulative exit rates (JTJ)

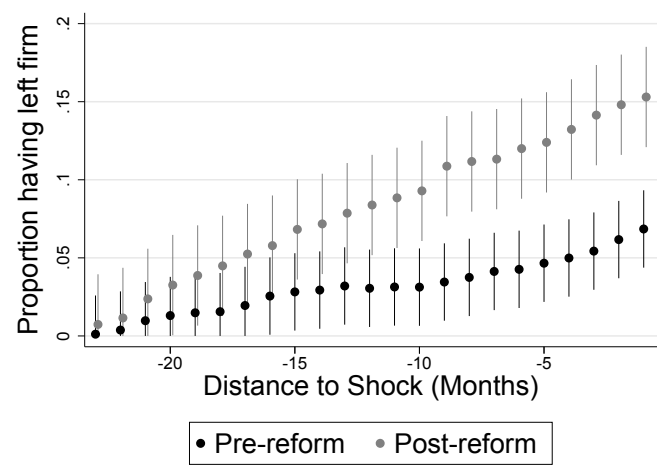

(b) Cumulative exit rates (JTU)

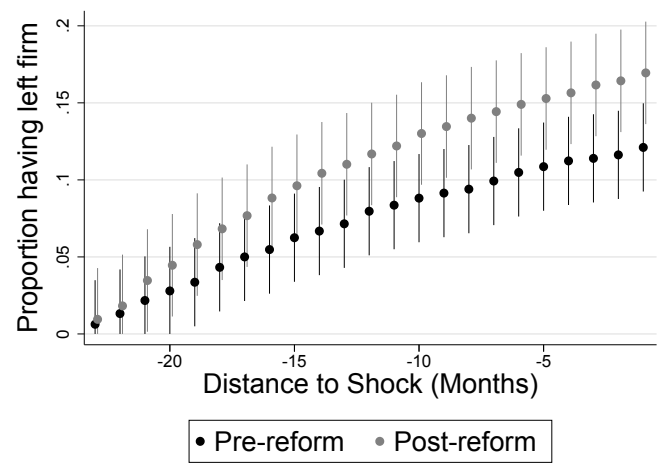

Note: The Figures plot pre- and post-reform cumulative exit rates (either conditioning on a JTJ or a JTU transition) calculated from an RDD (see main text for the exact specification). The point estimates are part of the moments to be fitted. Confidence intervals are based on a bootstrap procedure (1,000 replications) clustered at the firm-level.

\footnotetext{
${ }^{22}$ Notice that the RD estimates presented in section 4 differ (slightly) from the RD estimates used in this section. The RD estimates used as moments in the structural estimation of the present section are obtained using as a dependent variable job mobility between month $\mathrm{x}$ and month 1 before the mass layoff, where $x=24,23, \ldots, 2$. In contrast, in section 4 , we used as a dependent variable job mobility between month 12 and month 36 after the start of the job. (Recall that the underlying sample comprises workers who entered a firm that experienced a mass layoff 36 to 47 months later). We use the "time-to-mass layoff" concept in this section as it has a clear counterpart in the model, while the "time-since-job start" concept seems cleaner for evaluation purposes. As can be seen by comparing the implied effects to Figure 1 in the Online Appendix, the results are quantitatively very similar.
} 
Table 4: Calibrated parameters

\begin{tabular}{llll}
\hline \hline Parameter & Definition & Value & Source/Target \\
\hline$\delta$ & Discount rate & 0.997 & $4 \%$ annual interest rate \\
$\beta$ & Workers' bargaining power & 0.600 & Hosios (1990) condition \\
$\phi$ & Elasticity of $q$ w.r.t. $\theta$ & 0.600 & Petrongolo and Pissarides (2000) \\
$\alpha$ & Probability of becoming eligible & 0.028 & 3 years average waiting time \\
$\psi_{w}$ & Severance payment per previous wage & 2.000 & 2 monthly wages \\
$\rho$ & Autocorrelation of prices & 0.972 & Half-life of shock 8 quarters \\
$b$ & Opportunity cost of employment & 0.710 & Hall and Milgrom (2008) \\
\hline
\end{tabular}

Note: The Table contains the parameter values which are set exogenously either based on the institutional setting or based on the literature.

Model specification and parameter estimates. The parameters that we take as given are summarized in Table 4. Periodicity is set to one month. The level of the severance payment and the probability of becoming eligible, $\psi$ and $\alpha$, are dictated by the institutional setting. We index the severance payment to $w_{1}(\tilde{p})$, where $\tilde{p}$ is the lowest level of productivity for which $\gamma_{1}(p)=0$. We then have $\psi=\psi_{w} w_{1}(\tilde{p})$, where we set $\psi_{w}=2$ to match two monthly wages for the time before the reform, while setting $\psi_{w}=0$ after the reform. Moreover, we set $\alpha=1 / 36$ to match an average waiting time until eligibility of three years. We set the discount factor $\delta=0.997$, which yields an annual interest rate of approximately 4\%. We follow Hall and Milgrom (2008) in choosing $b=0.71$. The meeting function takes the Cobb-Douglas form $m(u+\chi(1-u), v)=m_{0}(u+\chi(1-u))^{\phi} v^{1-\phi}$. Following Petrongolo and Pissarides (2000), we fix the elasticity $\phi$ at 0.6 , while $m_{0}$ will be estimated (see below). The Hosios condition provides a natural benchmark for workers' bargaining power, hence we set $\beta=0.6$. We assume that productivity evolves according to $\log p_{t}=\rho \log p_{t-1}+\varepsilon_{t}$, where $\varepsilon_{t} \sim \mathcal{N}\left(0, \sigma_{\varepsilon}^{2}\right)$. We approximate this process by a 101-state Markov chain using the algorithm due to Tauchen (1986). Finally, we fix the autocorrelation of idiosyncratic firm-level shocks to $\rho=0.972$ (so that the half-life of a shock is two years), while standard deviation of $\varepsilon_{t}$ is estimated (see below). ${ }^{23}$

The remaining parameters are estimated by a Simulated Methods of Moments. Column 1 of Table 5 presents the parameter estimates from the baseline model, while column 2

\footnotetext{
${ }^{23}$ We proceed in this way for computational reasons. In particular, we can keep the same set of stochastic shocks in every iteration. By varying the standard deviation of $\varepsilon_{t}$, we just have to scale the shocks. If we varied $\rho$, by contrast, we would have to re-generate the trajectories in every iteration. Different choices for $\rho$ yield similar results, though we need sufficient persistence for the workers to be able to predict future mass layoffs.
} 
Table 5: Estimates

\begin{tabular}{llcc}
\hline \hline & & \multicolumn{2}{c}{ Specification } \\
\cline { 3 - 4 } Parameter & Definition & Baseline & $\begin{array}{c}\text { Temporary } \\
\text { employment }\end{array}$ \\
\hline$\lambda$ & Exogenous separation rate & $0.0098(0.0001)$ & $0.0098(0.0001)$ \\
$\sigma_{\varepsilon}$ & Standard deviation of innovations & $0.0105(0.0006)$ & $0.0120(0.0005)$ \\
$\chi$ & Relative search effort of the employed & $0.0466(0.0115)$ & $0.0495(0.0112)$ \\
$m_{0}$ & Meeting efficiency & $0.2527(0.0076)$ & $0.2140(0.0068)$ \\
$c$ & Hiring costs & $0.3528(0.0072)$ & $0.3628(0.0073)$ \\
\hline
\end{tabular}

Note: Column 1 of the table shows the estimated parameter values obtained by estimating the baseline model presented above. Column 2 show the corresponding estimates of an extended model, in which firms post vacancies for permanent and temporary jobs. We discuss this model in detail in the online Appendix. Standard errors in parentheses.

shows the corresponding results from an extended model which allows for temporary jobs. (Details on model specification and the estimation procedure are provided in chapter 3 of the Online Appendix.) We estimate a monthly exogenous separation rate of $0.98 \%$, which implies an average job duration in the absence of job-to-job transitions of approximately 8.5 years. Moreover, we estimate a standard deviation of innovations of the idiosyncratic firm-level heterogeneity of $1.05 \%$, which together with $\rho$ corresponds to an unconditional standard deviation of productivity of around 19\%. We finally estimate a relative search intensity of employed workers of $0.05 .^{24}$

Simulated reform effects. In Figure 6 we plot the simulated mobility rates against the rates observed in the data. The estimated model captures overall job separations rates (panel a) and JTJ transitions rates (panel b) very well. It also fits the qualitative finding that mobility responses are mostly driven by JTJ transitions. In the data we also observe a small reform effect on JTU transitions, which the model cannot replicate. ${ }^{25}$ Finally, Table

\footnotetext{
${ }^{24}$ Intuitively, the variation in the data that helps us pin down the estimated parameters can be summarized as follows. The exogenous separation rate $\lambda$ is primarily identified by the exit rates into unemployment and equilibrium unemployment (conditional on the average job-finding rate $f(\theta)$ ). The standard deviation of innovations, $\sigma_{\varepsilon}$ is pinned down by the layoff probability (the probability that $\epsilon(t)$ hits a lower bound). Relative search effort of the employed $\chi$ is identified by the exits into new jobs (conditional on the job finding rate $f(\theta)$. The meeting efficiency $m_{0}$ is pinned down by labor market tightness and the job-finding rate. Finally, hiring costs $c$ are identified by expected hiring costs per quarter (conditional on the vacancy filling rate $q(\theta)$ ). We conducted extensive Monte-Carlo tests showing that the estimation mostly succeeds in recovering the true structural parameters.

${ }^{25}$ One possible explanation for the observed reform effect on JTU transitions could be that post-reform workers are more likely to quit a job in order to become self-employed. Since self-employed workers are not
} 
6 shows that the model fits the macro-moments quite well except for the expected hiring cost that we overestimate. Note, however, that this moment is based on US survey data and might not give a good description of the Austrian labor market.

Figure 6: Cumulative share of workers leaving into unemployment and to another job, simulated values vs. data

(a) Cumulative exit rates (all exits)

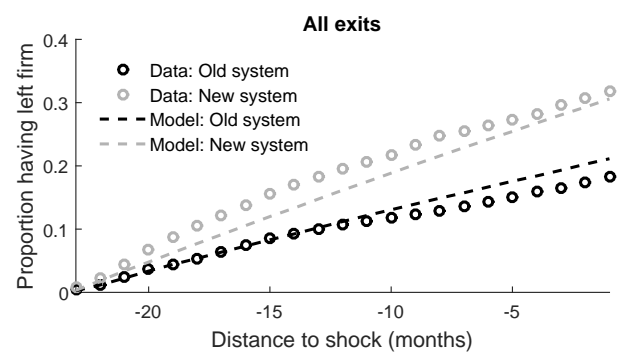

(b) Cumulative exit rates (JTJ)

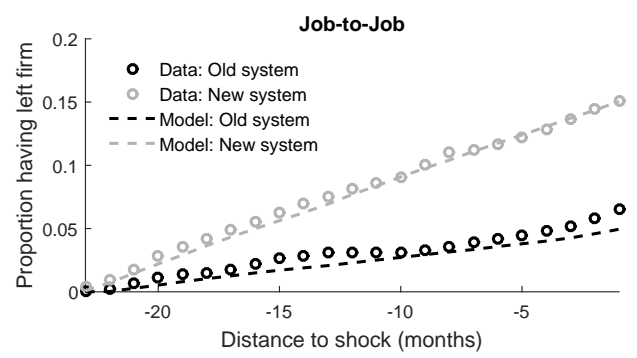

(c) Cumulative exit rates (JTU)

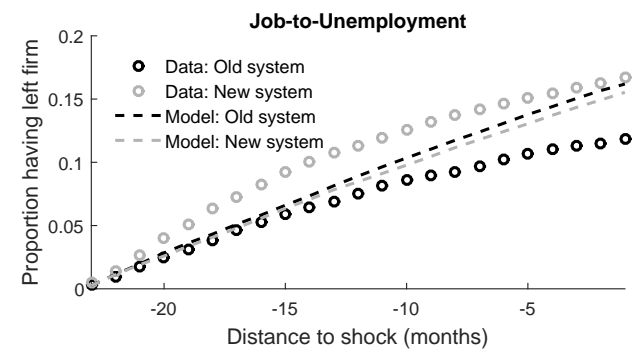

Note: The Figures compare cumulative exit rates implied by an RDD (see main text for details) on our baseline sample to an RDD based on artificial data generated by the model using calibrated (Table 4) and estimated (Table 5) model parameters. Figure (a) shows all exits, while figures (b) and (c) distinguish between JTJ and JTU transitions. Note that we only fit figures (b) and (c) as figure (a) corresponds to the sum of figures (b) and (c).

Finally, we can use the model parameters to calculate pre- and post-reform equilibrium unemployment rates. The model predicts a modest decrease of unemployment from $6.54 \%$ to $5.94 \%$, which is driven by higher job creation. The predicted increase in output amounts to $0.97 \%$, thus productivity per worker increases by $0.33 \%$, suggesting that the reform sped up reallocation of workers towards more productive firms. This can be seen in Figure 10

observed in our data set, these workers would show up as JTU transitions. Indeed, Hacamo and Kleiner (2016) document a positive relationship between bankruptcy and subsequent entrepreneurship by former employees. Observed JTU transitions could also be voluntary quits with a delayed start of the new job and an intermittent unemployment spell. 
Table 6: Model fit: macro variables

\begin{tabular}{lccc}
\hline \hline & & \multicolumn{2}{c}{ Simulated: } \\
\cline { 3 - 4 } Moment & Data & Baseline & $\begin{array}{c}\text { Temporary } \\
\text { employment }\end{array}$ \\
\hline Probability of Mass Layoff & 0.0137 & 0.0137 & 0.0137 \\
Unemployment Rate & 0.0680 & 0.0624 & 0.0709 \\
Labor Market Tightness & 0.3500 & 0.3489 & 0.3501 \\
Job-Finding Rate & 0.1500 & 0.1654 & 0.1865 \\
Hiring Cost Share & 0.1400 & 0.3505 & 0.3187 \\
Share Temporary Employment & 0.0400 & - & 0.0756 \\
\hline
\end{tabular}

Note: The Table compares observed macro moments to moments generated by the model using calibrated (Table 4) and estimated (Table 5) model parameters.

of the Online Appendix, where we compare the stationary productivity distribution in the old and the new steady states.

\section{$7 \quad$ A Role Model for Southern Europe?}

The Austrian reform of 2003 has frequently been proposed as a role model for labor market reforms in Southern European countries to overcome sluggish labor reallocation and spur job creation. While we obviously cannot give a full answer to this question, we can use our structural model to conduct the following thought experiment. Assume a labor market that is adequately described by the structure of our model and characterized by the same parameters as those implemented above for the Austrian case. But instead of the Austrian severance pay rules, assume that we start from a more generous severance pay systemwith higher severance payments and shorter vesting periods. Will the same severance pay reform generate strong equilibrium responses on the labor market?

We want to argue that this is a meaningful thought experiment since Austria's prereform system had features that made it resemble those systems currently in place in many Southern European countries. In Figure 12 in the Online Appendix, we document that, while the level of severance pay appears to be comparable, the vesting period (time to eligibility) is generally much lower in these Southern European countries than in Austria. We therefore explore the consequences of a more generous severance payment scheme by either increasing $\psi$, assuming a higher payment in case of dismissal of an eligible worker, or lowering $\alpha$ and thus mimicking a lower time to eligibility. All other parameters are held at the same level as in the above simulations. We proceed in two steps. We first consider 
more stringent severance pay rules in the baseline model studied above. In a second step, we explore the reform effect in an extended model, where firms cannot only post and fill vacancies with permanent contracts (as in the baseline model) but also with temporary contracts.

Baseline model. The results are shown in the left four columns of Table 7 . In column 1, we summarize the baseline case for Austria, where mandatory severance pay is two monthly wages and time to eligibility is 36 months. Abolishing severance pay (setting $\psi=0$ ) entails a moderate 0.6 percentage points (pp., hereafter) drop in unemployment which is mainly driven by increased job creation (while higher job destruction would have increased unemployment by $0.1 \mathrm{pp}$.). In column 2 , we increase the severance pay amount from 2 to 3 monthly wages. The model predicts a slightly higher pre-reform unemployment rate (and hence a slightly stronger reform effect). Notice, however, that a severance pay level of $\psi=3$ may not adequately mimic the rules of a Southern European country because costs to the firm may include litigation costs (with the potential payment of damages from the firm to the worker), which may substantially exceed 3 monthly wages. In column 3 , we look at a shorter vesting period of 3 months (instead of 36 months) in the pre-reform system. This generates markedly higher unemployment rates in the pre-reform system. The model predicts that, in the post-reform period, unemployment falls by $3.0 \mathrm{pp}$. when the vesting period is shortened to 3 months (rather than 3 years). Column 4 explores more generous severance pay rules. When both parameters are changed-vesting period reduced to 3 month and severance pay increased to 3 monthly wages - the model predicts a 4.9 pp. reduction of unemployment in the post-reform period. Both in columns 3 and 4, the dominant force behind the lower unemployment rate is stronger job creation. While in the post-reform regime also somewhat more jobs get destroyed, responses on this margin are small and do not strongly affect equilibrium unemployment.

Extended model with temporary contracts. The simulated effects of the reform displayed above might be affected by the prevalence in most Southern European coutries of temporary or fixed-term contracts. ${ }^{26}$ Strict severance pay rules may therefore induce firms to hire more temporary/fixed-term workers and not necessarily lead to higher unemployment. We address this concern by extending our baseline model assuming that firms can

\footnotetext{
${ }^{26}$ Both terms are used in many countries for jobs with much less attachment to the employer, including through the use of temporary employment agencies.
} 
Table 7: Simulation results

\begin{tabular}{|c|c|c|c|c|c|c|c|c|}
\hline \multirow{3}{*}{$\begin{array}{l}\text { Time to eligibility (months) } \\
\text { Severance pay (monthly wages) }\end{array}$} & \multicolumn{4}{|c|}{ Baseline } & \multicolumn{4}{|c|}{ Temp. employment } \\
\hline & 36 & 36 & 3 & 3 & 36 & 36 & 3 & 3 \\
\hline & 2 & 3 & 2 & 3 & 2 & 3 & 2 & 3 \\
\hline \multicolumn{9}{|l|}{ Panel A: Unemployment } \\
\hline - pre-reform in \% & 6.54 & 6.71 & 8.95 & 10.80 & 7.32 & 7.47 & 9.17 & 10.27 \\
\hline - post-reform in $\%$ & 5.94 & 5.94 & 5.94 & 5.94 & 6.87 & 6.87 & 6.87 & 6.87 \\
\hline - change in pp. & 0.59 & 0.76 & 3.01 & 4.86 & 0.45 & 0.60 & 2.30 & 3.40 \\
\hline - of which job creation & 0.67 & 0.82 & 3.36 & 5.35 & 0.42 & 0.47 & 1.74 & 2.33 \\
\hline - of which job destruction & -0.08 & -0.06 & -0.36 & -0.50 & 0.03 & 0.13 & 0.56 & 1.07 \\
\hline \multicolumn{9}{|l|}{ Panel B: Output } \\
\hline - change in pp. & 0.97 & 1.17 & 3.84 & 6.13 & 0.77 & 0.93 & 2.78 & 3.85 \\
\hline \multicolumn{9}{|l|}{ Panel C: Output/Worker } \\
\hline - change in pp. & 0.33 & 0.35 & 0.52 & 0.66 & 0.28 & 0.28 & 0.24 & 0.06 \\
\hline \multicolumn{9}{|c|}{ Panel D: Share temporary employment } \\
\hline - pre-reform in $\%$ & & & & & 7.75 & 7.95 & 10.04 & 10.55 \\
\hline - post-reform in $\%$ & & & & & 7.37 & 7.37 & 7.37 & 7.37 \\
\hline - change in pp. & & & & & 0.38 & 0.58 & 2.67 & 3.18 \\
\hline
\end{tabular}

Note: This Table shows results from a policy simulation exercise conducted based on the baseline model using calibrated (Table 4) and estimated (Table 5) model parameters. Column 1 compares the pre- and post-reform steady state in the Austrian case, while columns 2 to 4 vary expected time to eligibility $(1 / \alpha)$ or the size of the mandatory severance payment $(\psi)$ in the pre-reform state.

create vacancies either for regular or temporary/fixed-term jobs. While workers in regular jobs become eligible for severance pay with probability $\alpha$ as before, temporary/fixed-term jobs never turn eligible and their jobs are dissolved at rate $\alpha_{t}$, where $\alpha_{t}$ is an exogenous probability. ${ }^{27}$ Temporary/fixed-term contracts yield lower value, as they are inherently less stable, and workers are less willing to accept outside offers for temporary/fixed-term jobs. In equilibrium, firms are indifferent between posting vacancies in either sub-market. We describe the full model in chapter 2.2 of the Online Appendix.

In the simulation with the baseline parameters, we set $\alpha_{t}=1 / 36$, consistent with the idea that workers become eligible for severance pay automatically after three years and firms create temporary/fixed-term jobs so as to avoid firing costs. In addition to the moments targeted in the baseline estimation, we also target the fraction of jobs subject to a temporary/fixed-term contract. According to the Micro Census, this number is equal

\footnotetext{
${ }^{27}$ We also estimated an alternative version, where a firm gets the possibility of transforming the job into a permanent (eligible) one once the $\alpha_{t}$ shock hits. This leaves results largely unaffected.
} 
to $4 \%$. In columns 5 to 8 of Table 7 , we show the results of conducting the same policy simulation exercise as in the baseline model. The simulations of the extended model leads to qualitatively similar conclusions as in the baseline model. The severance pay reform reduces unemployment and increases output and output per worker. However, the quantitative responses are weaker. In column 8 , where we look at strict severance pay rules (3 months vesting period and 3 monthly wages of severance pay), we find that unemployment is reduced by 3.4 percent. The reason is that firms react along both margins, reducing temporary/fixed-term employment but compensating this by creating new jobs, with the overall effect to reduce unemployment. The reform thus achieves two goals - the reduction of unemployment and the increase in the share of permanent jobs - at the same time.

\section{Conclusion}

This paper has studied the 2003 Austrian flexicurity reform (Abfertigung Neu). This reform has been advocated as a role model for structural reforms in countries plagued by inflexible labor markets and high unemployment. This reform abolished the previous severance pay system which mandated a tenure-based transfer (a severance payment) from the firm to the worker after a layoff. Mandated severance payments were replaced by a system of occupational pensions accounts. The employing firm has to make monthly payments into its workers' accounts. The account, owned by each individual worker, follows her from firmto-firm and is unaffected by the nature of the termination of the employment relationship, be it a layoff or a quit. By abolishing the disincentive to quit - the incentive to wait for a layoff and the associated severance payment - the reform increased labor market flexibility while keeping income security essentially unchanged.

The reform was implemented for all contracts that started from January 1, 2003 on, but left previously signed contracts unchanged. This allows us to identify the reform effect in a regression discontinuity design, comparing job starting immediately before implementation of the reform to jobs starting immediately after the reform was implemented. Using rich administrative data from the Austrian social security register (ASSD), we find that the reform has induced a substantial increase in job mobility for workers in distressed firms. We find that the probability that a worker leaves a distressed firm (with a mass layoff within the next two years) is 12.5 percentage points (or around 40 percent) lower then the corresponding probability for workers employed under the old system. The difference is almost entirely driven by transitions to new jobs as opposed to transitions into unemploy- 
ment. Thus, the new system encourages moves from "bad" to "good" firms with potentially important consequences for the allocation of workers and total factor productivity.

A search-and-matching model with tenure-dependent severance payments can replicate the mobility responses estimated in our RD framework. The model captures the prereform rules assuming that workers start out as non-eligible and turn eligible with some probability. The model incorporates quit decision by assuming that employed workers get outside and decide endogenously whether to accept them or not. Firms face productivity shocks and endogenously layoff the worker when the productivity draw falls short of a reservation productivity. In such a framework, high severance payments will induce the worker to reject many more outside offers and rather wait for the layoff. Under the new system, the disincentive to quit is gone and workers are more likely to move on.

We use the parameterized model to explore the equilibrium consequences of implementing an Austrian-style reform on labor markets in Southern European countries plagued by high firing costs. Starting from severance pay rules that are stricter than Austrian prereform rules (higher severance payments and shorter vesting periods) we evaluate the abolition of these rules in counterfactual policy simulations. Our results show that Austrianstyle reforms can have sizeable effects on unemployment and productivity. This conclusion holds even when accounting for temporary/fixed-term contracts, widespread in Southern European economies.

Austrian-style reforms could and should become potential role models for Southern Europe. Indeed, Emmanuel Macron, just elected French President in May 2017, informed of the Austrian system, proposed in his program to abolish the distinction between quits and layoffs when collecting unemployment benefits. In addition, his program wants to set upper (and lower) limits on severance payments (without moving to pension accounts, though). Our empirical analysis shows, we believe, that a move in the Austrian direction is a very promising avenue for countries facing high unemployment rates, low mobility, and the associated lack of creative destruction. 


\section{References}

Ahsan, A., \& Pagés, C. (2009). Are all labor regulations equal? Evidence from Indian manufacturing. Journal of Comparative Economics, 37(1), 62-75.

Autor, D. H., Donohue, J. J., \& Schwab, S. J. (2006). The Costs of Wrongful-Discharge Laws. The Review of Economics and Statistics, 88(2), 211-231.

Bartelsman, E. J., Gautier, P. A., \& De Wind, J. (2016). Employment protection, technology choice, and worker allocation. International Economic Review, 57(3), 787-826.

Bassanini, A., \& Cingano, F. (2017). Before It Gets Better: The Short-Term Employment Costs of Structural Reforms. mimeo.

Bassanini, A., Nunziata, L., \& Venn, D. (2009). Job Protection Legislation and Productivity Growth in OECD Countries. Economic Policy, 24, 349-402.

Behaghel, L., Crépon, B., \& Sdillot, B. (2008). The perverse effects of partial employment protection reform: The case of French older workers. Journal of Public Economics, 92(3-4), 696-721.

Belot, M., Boone, J., \& van Ours, J. (2007). Welfare-Improving Employment Protection. Economica, 74 (295), 381-396.

Belot, M., \& Ours, J. C. van. (2004). Does the Recent Success of Some OECD Countries in Lowering their Unemployment Rates Lie in the Clever Design of their Labor Market Reforms? Oxford Economic Papers, 56(4), 621-642.

Bentolila, S., \& Bertola, G. (1990). Firing Costs and Labour Demand: How Bad Is Eurosclerosis? Review of Economic Studies, 57(3), 381-402.

Bentolila, S., Cahuc, P., Dolado, J. J., \& Barbanchon, T. L. (2012). Two-Tier Labour Markets in the Great Recession: France Versus Spain. Economic Journal, 122(562), $155-187$.

Bentolila, S., \& Dolado, J. J. (1994). Labour Flexibility and Wages: Lessons from Spain. Economic Policy, 18, 55-99.

Bertola, G. (1990). Job Security, Employment and Wages. European Economic Review, $34(4), 851-879$.

Besley, T., \& Burgess, R. (2004). Can Labor Regulation Hinder Economic Performance? Evidence from India. The Quarterly Journal of Economics, 119(1), 91-134.

Boeri, T. (2011). Institutional Reforms and Dualism in European Labor Markets. In O. Ashenfelter \& D. Card (Eds.), (Vol. 4, p. 1173-1236). Elsevier.

Boeri, T., Cahuc, P., \& Zylberberg, A. (2015). The Costs of Flexibility-Enhancing Structural Reforms (Economics Department Working Papers No. 1264). OECD.

Boeri, T., \& Garibaldi, P. (2007). Two Tier Reforms of Employment Protection: a Honeymoon Effect? Economic Journal, 117(521), 357-385.

Boeri, T., \& Garibaldi, P. (2009). Beyond Eurosclerosis. Economic Policy, 24, 409-461.

Boeri, T., Garibaldi, P., \& Moen, E. R. (2014). Severance Pay (CEPR Discussion Papers No. 10182). 
Boeri, T., \& Jimeno, J. F. (2005). The Effects of Employment Protection: Learning from Variable Enforcement. European Economic Review, 49(8), 2057-2077.

Boeri, T., \& Jimeno, J. F. (2016). Learning from the Great Divergence in Unemployment in Europe During the Crisis. Labour Economics, 41 (C), 32-46.

Cahuc, P., \& Postel-Vinay, F. (2002). Temporary jobs, employment protection and labor market performance. Labour Economics, 9(1), 63-91.

Card, D., Chetty, R., \& Weber, A. (2007). Cash-On-Hand and Competing Models of Intertemporal Behavior: New Evidence from the Labor Market. The Quarterly Journal of Economics, 122(4), 1511-1560.

Cingano, F., Leonardi, M., Messina, J., \& Pica, G. (2016). Employment Protection Legislation, Capital Investment and Access to Credit: Evidence from Italy. Economic Journal, 126(595), 1798-1822.

Davoine, T., \& Keuschnigg, C. (2015). Flexicurity, Taxes and Job Reallocation. mimeo.

DeFreitas, G., \& Marshall, A. (1998). Labour Surplus, Worker Rights and Productivity Growth: A Comparative Analysis of Asia and Latin America. LABOUR, 12(3), 515-539.

Di Tella, R., \& MacCulloch, R. (2005). The Consequences of Labor Market Flexibility: Panel Evidence Based on Survey Data. European Economic Review, 49(5), 12251259.

EU Commission. (2006). Modernising Labour Law to Meet the Challenges of the 21st Century [Green Paper]. Brussels.

Fallick, B. C. (1996). A Review of the Recent Empirical Literature on Displaced Workers. Industrial and Labor Relations Review, 50(1), 5-16.

Fella, G. (2007). When Do Firing Taxes Matter? Economics Letters, 97(1), 24-31.

Garibaldi, P., \& Pacelli, L. (2008). Do Larger Severance Payments Increase Individual Job Duration? Labour Economics, 15(2), 215-245.

Garibaldi, P., \& Violante, G. L. (2005). The Employment Effects of Severance Payments with Wage Rigidities. Economic Journal, 115(506), 799-832.

Hacamo, I., \& Kleiner, K. (2016). Finding Success in Tragedy: Forced Entrepreneurs after Corporate Bankruptcy. Mimeo.

Hahn, J., Todd, P., \& Klaauw, W. Van der. (2001). Identification and Estimation of Treatment Effects with a Regression-Discontinuity Design. Econometrica, 69(1), 201-09.

Hall, R. E., \& Milgrom, P. (2008). The Limited Influence of Unemployment on the Wage Bargain. American Economic Review, 98(4), 1653-74.

Hijzen, A., Mondauto, L., \& Scarpetta, S. (2013). The Perverse Effects of Job-security Provisions on Job Security in Italy: Results from a Regression Discontinuity Design (OECD Social, Employment and Migration Working Papers No. 151). OECD.

Hosios, A. J. (1990). On the Efficiency of Matching and Related Models of Search and Unemployment. Review of Economic Studies, 57(2), 279-98. 
Huttunen, K., Moen, J., \& Salvanes, K. G. (2011). How Destructive Is Creative Destruction? Effects Of Job Loss On Job Mobility, Withdrawal And Income. Journal of the European Economic Association, 9(5), 840-870.

Ichino, A., \& Riphahn, R. T. (2005). The Effect of Employment Protection on Worker Effort: Absenteeism During and After Probation. Journal of the European Economic Association, 3(1), 120-143.

Ichino, A., Schwerdt, G., Winter-Ebmer, R., \& Zweimüller, J. (2014). Too old to work, too young to retire? Mimeo.

Imbens, G., \& Kalyanaraman, K. (2012). Optimal Bandwidth Choice for the Regression Discontinuity Estimator. Review of Economic Studies, 79(3), 933-959.

Jacobson, L. S., LaLonde, R. J., \& Sullivan, D. G. (1993). Earnings Losses of Displaced Workers. American Economic Review, 83(4), 685-709.

Juan, D., Marcel, J., \& Juan, J. S. (2007). A Positive Analysis of Targeted Employment Protection Legislation. The B.E. Journal of Macroeconomics, 7(1), 1-30.

Kahn, L. M. (2007). The Impact of Employment Protection Mandates on Demographic Temporary Employment Patterns: International Microeconomic Evidence. Economic Journal, 117(521), 333-356.

Koeniger, W. (2005). Dismissal costs and innovation. Economics Letters, 88(1), 79-84.

Kugler, A. (1999). The Impact of Firing Costs on Turnover and Unemployment: Evidence from the Colombian Labour Market Reform. International Tax and Public Finance, $6(3), 389-410$.

Kugler, A. (2005). Wage-shifting Effects of Severance Payments Savings Accounts in Colombia. Journal of Public Economics, 89(2-3), 487-500.

Kugler, A., \& Pica, G. (2008). Effects of Employment Protection on Worker and Job Flows: Evidence from the 1990 Italian Reform. Labour Economics, 15(1), 78-95.

Kugler, A., \& Saint-Paul, G. (2000). Hiring and Firing Costs, Adverse Selection and Long-term Unemployment (IZA Discussion Papers No. 134). Institute for the Study of Labor (IZA).

Lazear, E. P. (1990). Job Security Provisions and Employment. The Quarterly Journal of Economics, $105(3)$, 699-726.

Ljungqvist, L. (2002). How Do Lay-off Costs Affect Employment? Economic Journal, $112(482), 829-853$.

Ljungqvist, L., \& Sargent, T. J. (1998). The European Unemployment Dilemma. Journal of Political Economy, 106(3), 514-550.

Ljungqvist, L., \& Sargent, T. J. (2008). Two Questions about European Unemployment. Econometrica, 76(1), 1-29.

Malcomson, J. M. (1997). Contracts, Hold-Up, and Labor Markets. Journal of Economic Literature, 35(4), 1916-1957.

Manoli, D., \& Weber, A. (2016). Nonparametric Evidence on the Effects of Financial Incentives on Retirement Decisions. American Economic Journal: Economic Policy, $8(4), 160-182$. 
Marinescu, I. (2009). Job Security Legislation and Job Duration: Evidence from the United Kingdom. Journal of Labor Economics, 27(3), 465-486.

Martins, P. S. (2009). Dismissals for Cause: The Difference That Just Eight Paragraphs Can Make. Journal of Labor Economics, 27(2), 257-279.

McLaughlin, K. J. (1991). A Theory of Quits and Layoffs with Efficient Turnover. Journal of Political Economy, $99(1), 1-29$.

Messina, J., \& Vallanti, G. (2007). Job Flow Dynamics and Firing Restrictions: Evidence from Europe. Economic Journal, 117(521), 279-301.

Mortensen, D. T., \& Pissarides, C. A. (1994). Job Creation and Job Destruction in the Theory of Unemployment. Review of Economic Studies, 61(3), 397-415.

Nickell, S., Nunziata, L., \& Ochel, W. (2005). Unemployment in the OECD Since the 1960s. What Do We Know? Economic Journal, 115(500), 1-27.

OECD. (2006). Employment Outlook. Paris.

OECD. (2017). Labour Market Reforms in Portugal 2011-2015: A Preliminary Assessment. Paris.

Percher, P. (2003). Das große Taktieren hat begonnen. Die Presse(April 19, 2003).

Petrongolo, B., \& Pissarides, C. A. (2000). Looking into the Black Box: A Survey of the Matching Function. Journal of Economic Literature, 39(2), 390-431.

Pfann, G. A., \& Hamermesh, D. S. (2001). Two-Sided Learning, Labor Turnover and Displacement (NBER Working Papers No. 8273). National Bureau of Economic Research, Inc.

Porter, J. (2003). Estimation in the Regression Discontinuity Model. Mimeo.

Postel-Vinay, F., \& Turon, H. (2014). The Impact of Firing Restrictions on Labour Market Equilibrium in the Presence of On-the-Job Search. Economic Journal, 124, 31-61.

Riphahn, R. T. (2004). Employment protection and effort among German employees. Economics Letters, 85(3), 353-357.

Saint-Paul, G. (1995). The High Unemployment Trap. Quarterly Journal of Economics, $110(2), 527-50$.

Schmieder, J. F., Wachter, T. von, \& Bender, S. (2010). The Long-Term Impact of Job Displacement in Germany During the 1982 Recession on Earnings, Income, and Employment (IAB Discussion Paper No. 201001).

Song, J., \& Wachter, T. von. (2014). Long-Term Nonemployment and Job Displacement [Jackson Hole Symposium].

Stevens, A. H. (1997). Persistent Effects of Job Displacement: The Importance of Multiple Job Losses. Journal of Labor Economics, 15(1), 165-88.

Tauchen, G. (1986). Finite State Markov-Chain Approximations to Univariate and Vector Autoregressions. Economics Letters, 20(2), 177-181.

Wasmer, E. (2006). General versus Specific Skills in Labor Markets with Search Frictions and Firing Costs. American Economic Review, 96(3), 811-831. 


\title{
Job Mobility and Creative Destruction: Flexicurity in the Land of Schumpeter: Online Appendix
}

\author{
Andreas Kettemann* $^{*} \quad$ Francis Kramarz $^{\dagger} \quad$ Josef Zweimüller ${ }^{\ddagger}$ \\ University of Zurich CREST-ENSAE University of Zurich
}

June 13, 2017

\section{Contents}

1 Supplementary Reduced Form Results 2

2 Details and Extension of the Model 14

2.1 The Baseline Model . . . . . . . . . . . . . . . . . . . . . . . . 14

2.2 Model Extension: Temporary Jobs . . . . . . . . . . . . . . . . . 18

3 Further Details on Structural Estimation $\quad 25$

4 Further Details on the "Southern-European" Counterfactual $\quad 27$

$\begin{array}{ll}\text { References } & 30\end{array}$

\footnotetext{
${ }^{*}$ Department of Economics, University of Zurich, Schönberggasse 1, CH-8001 Zürich; andreas.kettemann@econ.uzh.ch

${ }^{\dagger}$ CREST-ENSAE, 15 Boulevard Gabriel Peri, Malakoff, 92245, France; kramarz@ensae.fr

${ }^{\ddagger}$ Department of Economics, University of Zurich, Schönberggasse 1, CH-8001 Zürich; josef.zweimueller@econ.uzh.ch
} 


\section{Supplementary Reduced Form Results}

The empirical strategy to identify the effect on job mobility of the the Austrian 2003 reform in an RD design. In this section of the online Appendix we provide supplementary evidence that provides descriptive statistics the sample and sheds further light on the validity of the $\mathrm{RD}$ design. We also performs a broad set of checks to test the robustness of the results obtained in the baseline sample. Recall that the baseline sample based on specific criteria (both for workers and for mass layoff firm). We preform a broad set of robustness checks which show that the empirical results do not hinge upon variations of these criteria.

Table 1 shows descriptive statistics both for the universe of newly hired workers observed in the ASSD and for workers in the baseline sample. All descriptives shown in the table are based on workers who satisfy the following criteria: (i) aged 25-55 at the start of a job; (ii) started a new job between January 1, 1997 and December 31, 2008; (iii) stayed at least 12 months in the new firm. Column 3 restricts attention to the subsample of workers who (iv) entered a firm that experienced a mass layoff within 3 to 4 years after the workers job start date. Workers who satisfy criteria (i)-(iv) constitute our baseline sample. Column 2 is based on workers satisfying criteria (i)-(iii), but reweights observations according to the firm size distribution observed in the baseline sample at the time of the job start, which differs by construction as we restrict to firms with at least 30 employees before the mass layoff. We group observation in 50 size quantiles, hence the median firm size does not necessarily correspond to the baseline sample exactly. The table shows that the baseline sample of mass layoff workers shows by and large similar characteristics, though starting wages are somewhat higher in the baseline sample. Reweighting shows that part of this discrepancy is explained by differences in firm size.

Figure 1 shows how the job mobility effect builds up with tenure. The main result presented in the main text was based on job separations within the first 36 months of tenure in the current firm. Instead of using 36 months, the figure provides evidence for job separations with the first $14,16, \ldots, 36$ months. This allows us to verify how the effect builds up with tenure. We see that the job separation effect builds up smoothly with tenure. JTJ transitions follow closely the pattern of overall separations while JTU flatten out after 24 months. This is additional support for the claim that job separation patterns are mainly driven by JTJ moves.

The provide further evidence on the validity of the $\mathrm{RD}$ design, we check whether covariates are smooth around the reform threshold. This is done in Table 2. The table provides descriptives of firm and worker characteristics before and after the reform, and - to check smoothness at the reform threshold - also the corresponding RD estimates. We do not find any significant differences in these characteristics. The only exception is that the baseline sample has a lower share of females in the post-reform period and also shows a significant discontinuity at the reform threshold. In the main text, we therefore run separate analyses for males and females. Both for females and for males we confirm that job separation patterns are significantly affected by the reform and that these effects are primarily driven by 
JTJ transition. Females are slightly more likely to transition to unemployment before the mass layoff (though the JTU coefficients are not significantly different from each other).

Figures 2 to 4 checks whether employment stocks and employment flows of mass layoff firms show any discontinuities at the reform threshold that might invalidate our RDD. Figure 2 displays, by job start dates, the mean $(\log )$ size of those firms that were entered by baseline sample workers. The figure does not show any discontinuity at the policy threshold. It also does not matter whether we measure firm size at different dates before a mass layoff. Figure 3 uses the size of the mass layoff as the interesting firm outcome. The figures do not indicate any discontinuities at the policy threshold, neither for absolute nor for relative (to employment stocks) layoff sizes. Finally, Figure 4 looks at differences in the firms' employment dynamics before the mass layoff, i.e. between months 24 and month 1 before the mass layoff (not including the employment reduction of the mass layoff itself). Again, we do not find a discontinuities at the reform threshold. We conclude our RDD is not invalidated by differences in the employment dynamics of the firms that were entered by workers who started their job immediately before the reform, compared to firms that were entered by workers who started their job immediately after the reform.

Figures 5 to 7 provide robustness checks. In Figure 5 we apply placebo reform, assigning "wrong" reform dates. We clearly see that placebo reform that are the farther away from the true reform, produce smaller estimates. This supports the idea that our estimates are driven by the severance pay reform implemented with the beginning of the year 2003. In Figure 6 we apply different criteria to what we consider a "mass layoff". Recall that we defined a mass layoff firm as a firm with an employment reduction of more than 33 percent between month $\mathrm{t}$ and month $\mathrm{t}+1$. Defining a mass layoff as an employment reduction of $20, \ldots, 100$ percent lead to qualitatively very similar results. Moreover, we find that larger mass layoffs increase the separation probability (up to employment reductions of 60 percent). This is in line with the idea that a higher likelihood to be fired creates stronger incentives. Furthermore, we confirm that JTJ transitions are the dominant driver of overall job separations.

Figure 7 looks at workers in non-mass layoff firms. In line with reform incentives, we do not find any significant change in job separation behaviour of workers at the policy threshold, neither for overall separations nor for JTJ and JTU transitions separately.

In Table 3 and Figure 8 we shed light on reform effects beyond job mobility. Table 3 looks at wage growth. Workers in the new system should be willing to accept wage offers which are associated with lower wage growth because they do not sacrifice any expected future severance payment when switching the job. The point estimates are indeed negative and of a similar size in all specification though they are not very precisely estimated. Most likely, it is the smaller sample size (we can only look at the subset of workers who switched jobs), which reduces the statistical power and leads to imprecise estimates.

Figure 8 looks at the characteristics of the firms that were entered by the baseline sample workers after leaving the mass layoff firm. The figures plot the coefficients from $\mathrm{RD}$ regressions, where we use as outcome whether the workers exited the mass layoff firm 
within 36 months and entered a new firm that was founded $\mathrm{x}$ years ago. The results show that reform effect is driven by JTJ transitions to younger firms.

Figure 1: How does the effect build up over time?

(a) All job separations

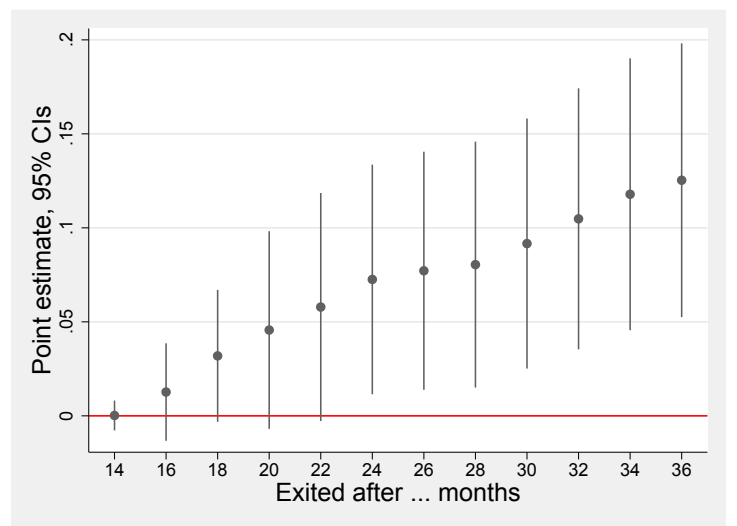

(b) Transitions to a new job (JTJ)

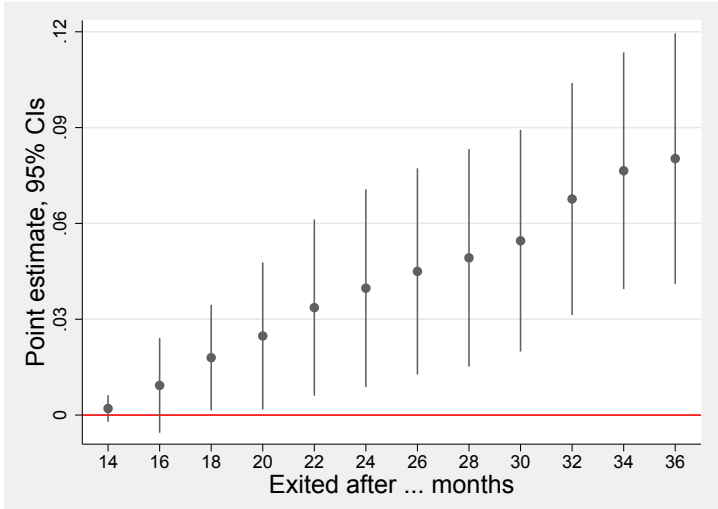

(c) Transitions to unemployment (JTU)

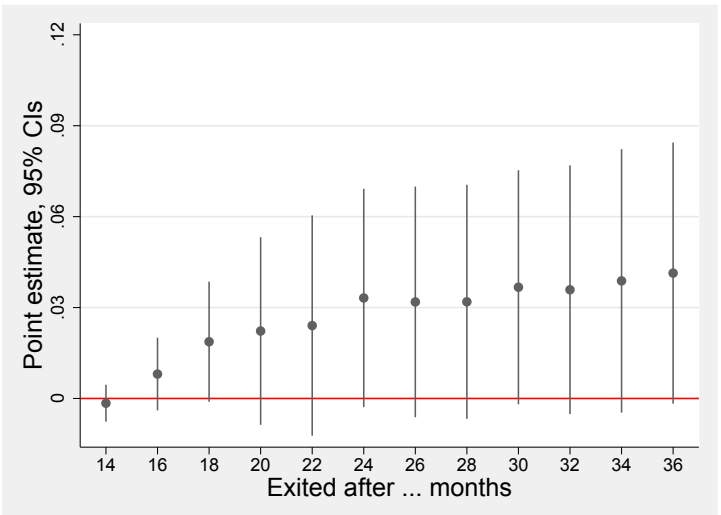

Note: The Figures plot the RD coefficients $\beta_{1}$ estimated from equation (1) of the main text using our baseline sample when we vary the time window of a job separations; i.e. between month 12 and month $x>12$ after the start of a job. (This means we look at workers who stayed at least 12 months and at most $x>12$ months in a firm that subsequently experienced a mass layoff, whereas in Table 2 in the main text we restrict attention to $x=36$.) Panel A uses as the dependent variable an indicator for a job separation between month 12 and month $x$ after job start; Panels B and C use an indicator for a JTJ and a JTU transition, respectively, as the dependent variable. Estimates are from a linear probability model, using the specification of column 1 in Table 2 of the main text. Inference is based on a bootstrap (1000 replications), clustered at the firm level. Panel A shows that the fraction of separated workers increases continuously with tenure, $x$, panel B shows that this increase is mainly due to JTJ transitions, while panel C shows that also JTU transitions increase, but estimates are smaller and barely statistically significant. (See text for details.) 
Figure 2: Log Firm Size

(a) Two years before shock

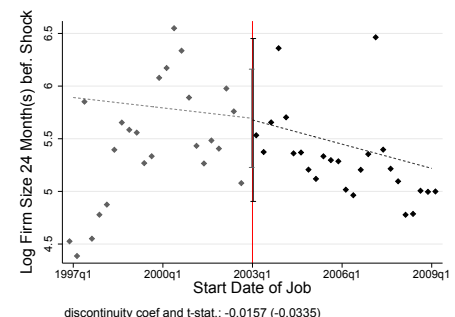

(b) One year before shock

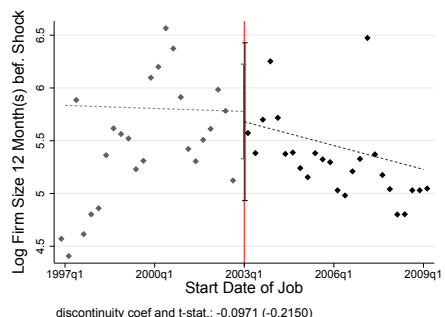

(c) One month before shock

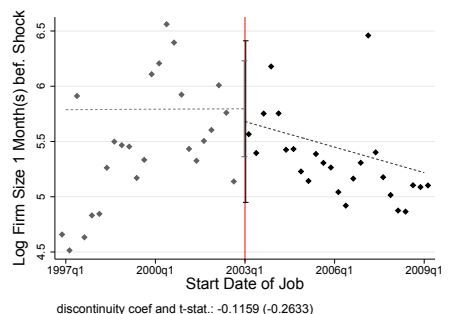

Note: The figures show results of RD regressions (based on equation (1) of the main text). The dependent variable is the $\log$ of the firm size 24,12 , and 1 month before the mass layoff measured at the worker level. We give more weight to observations close the cutoff by using a triangular kernel. Inference is based on a bootstrap (1000 replications) clustered at the firm level. The results demonstrate that there are no signs of differential firm size dynamics at the time of the reform.

Figure 3: Average layoff size by start date

(a) Relative

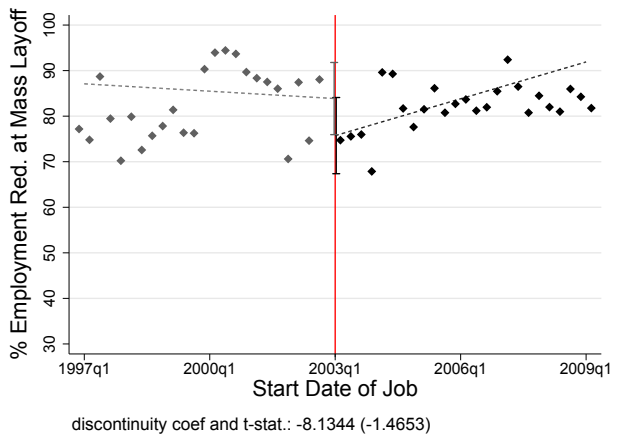

(b) Absolute

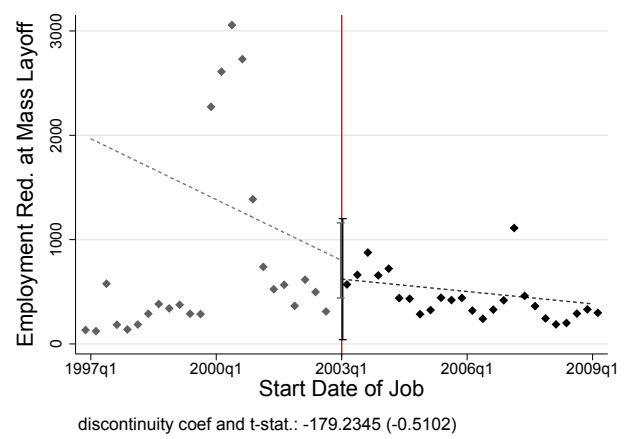

Note: The figures show results of RD regressions (based on equation (1) of the main text). The dependent variable is the monthly employment reduction at the time of the mass layoff relative to the firm size one month before (panel (a)) and in absolute terms (panel (b)) measured at the worker level. We give more weight to observations close the cutoff by using a triangular kernel. Inference is based on a bootstrap (1000 replications) clustered at the firm level. The results demonstrate that there are no signs of differences in shock size at the time of the reform. 
Figure 4: Change in employment 24 months before mass layoff until 1 month before mass layoff

(a) Relative change

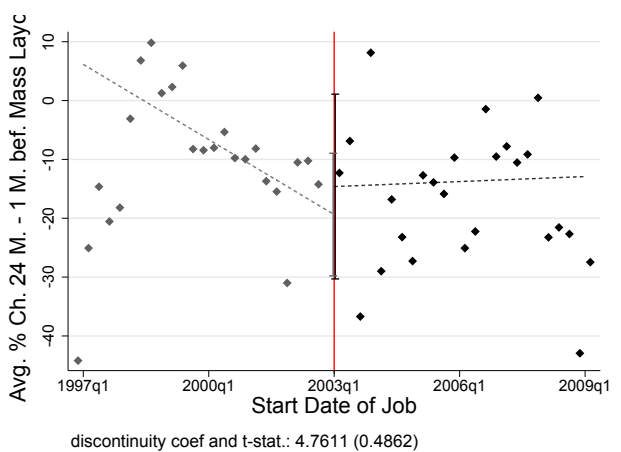

(b) Absolute change

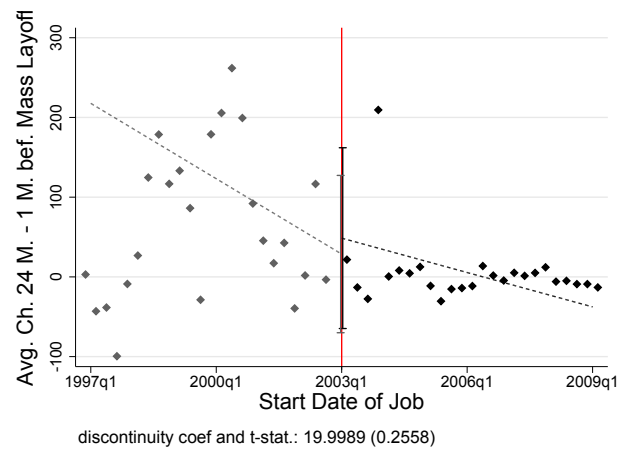

Note: The figures show results of RD regressions (based on equation (1) of the main text). The dependent variable is the employment reduction between two years and one month before the mass layoff, relative to employment two years before (panel (a)) and in absolute terms (panel (b)) measured at the worker level. We give more weight to observations close the cutoff by using a triangular kernel. Inference is based on a bootstrap (1000 replications) clustered at the firm level. The results demonstrate that there are no signs of differences in shock size at the time of the reform. 
Figure 5: Placebo reforms

(a) All job separations

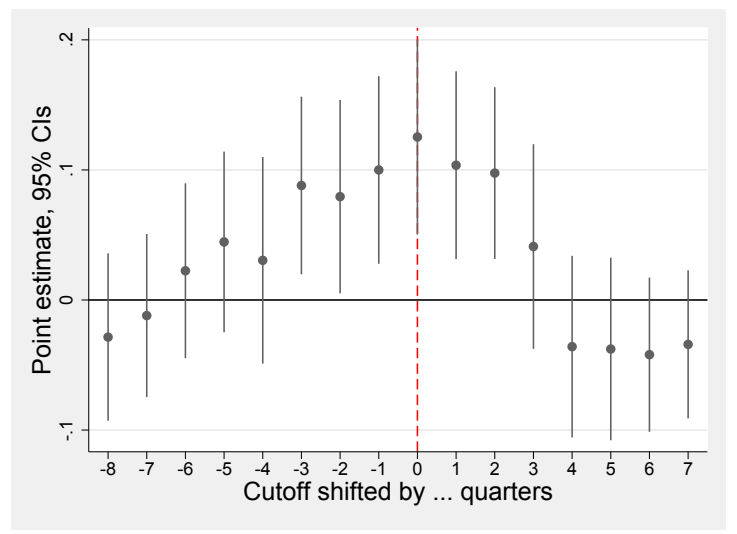

(b) Transitions to a new job (JTJ)

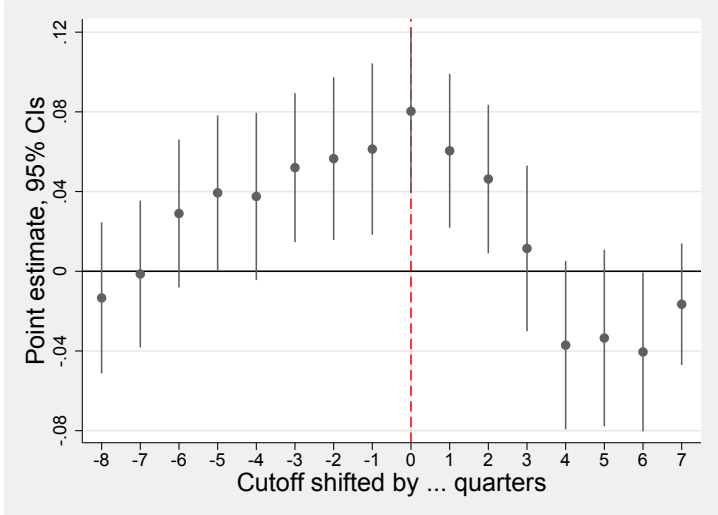

(c) Transitions to unemployment (JTU)

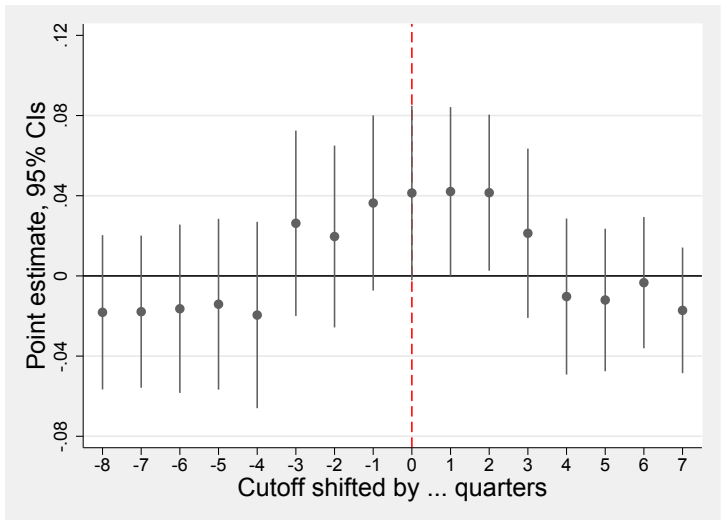

Note: The Figures show the RD coefficients from a series of "placebo reforms". The placebo reform shifts the reform cutoff date $x$ quarters away from the true reform date 2003q1 (the true reform date is normalized to zero), and we let $x$ vary from -8 to +7 quarters. Panel a) uses an indicator for a job separation (12-36 months after the start of the new job) as the dependent variable; panels b) and c) look at, respectively, JTJ and JTU transitions as the outcome variable. Inference is based on a bootstrap (1000 replications), clustered at the firm level. The evidence in all three panels consistently shows that RD estimates are larger for placebo reforms closer to - and are highest at - the true reform date. This supports the idea that the discontinuous change in job separations is indeed caused by the severance-pay reform rather than by some other event or intervention. (See text for details.) 
Figure 6: Results by alternative definitions of a mass layoff

(a) All job separations

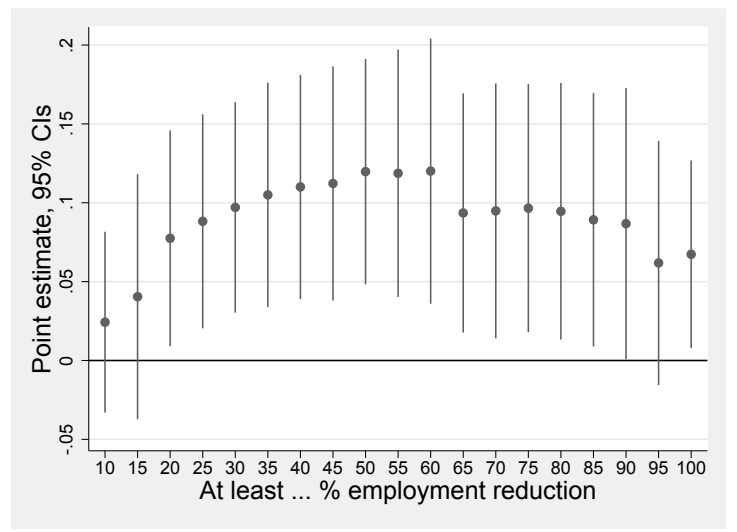

(b) Transitions to a new job (JTJ)

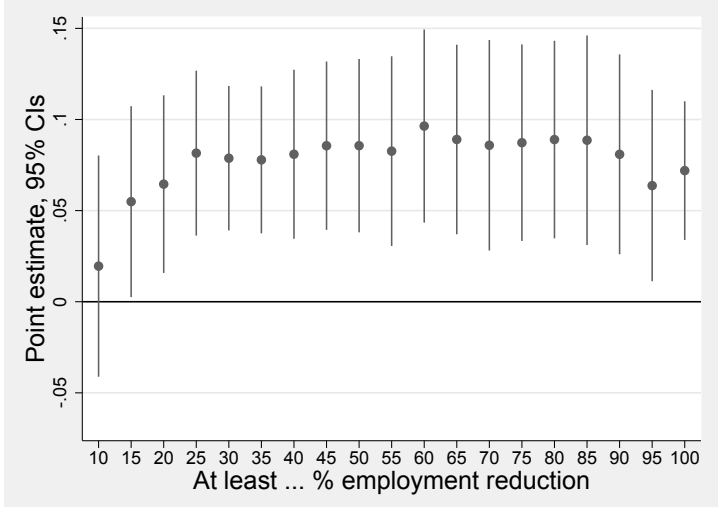

(c) Transitions to unemployment (JTU)

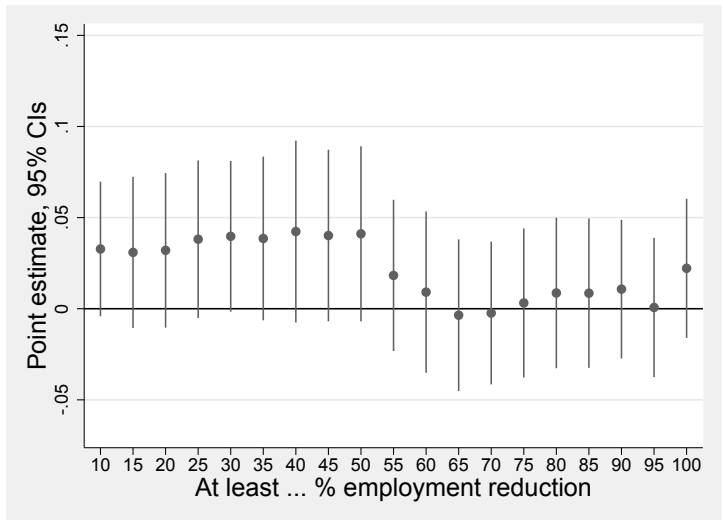

Note: The figures provides estimates for the RD coefficients when a mass layoff is defined as an employment reduction of $x$ percent or more between months $t$ and $t+1$. (In the baseline sample, the required employment reduction is $x=33$ percent). Inference is based on a bootstrap (1000 replications), clustered at the firm level. Results show that the reform effect on all separations increases in $x$ (over the range $x=10$ to $x=60$ percent). This is in line with incentives: A higher $x$ means a higher layoff probability of the average worker in the sample. Hence, under the old system, a higher $x$ is associated with a stronger incentive to wait for a layoff (with severance pay). In contrast, in the new system workers with an increased layoff probability move to new jobs quickly. Panel (b) shows that, indeed, the reform effect is mainly driven by higher jobto-job moves and to a smaller extent by increased transitions to unemployment (panel (c)). Beyond $x=60$ percent, the reform effect levels off, mainly due to fewer transitions to unemployment, while the reform effect on job-to-job moves remains large. (See text for details.) 
Figure 7: Reform effect on workers not in a mass-layoff firm ("matched controls")

(a) All job separations

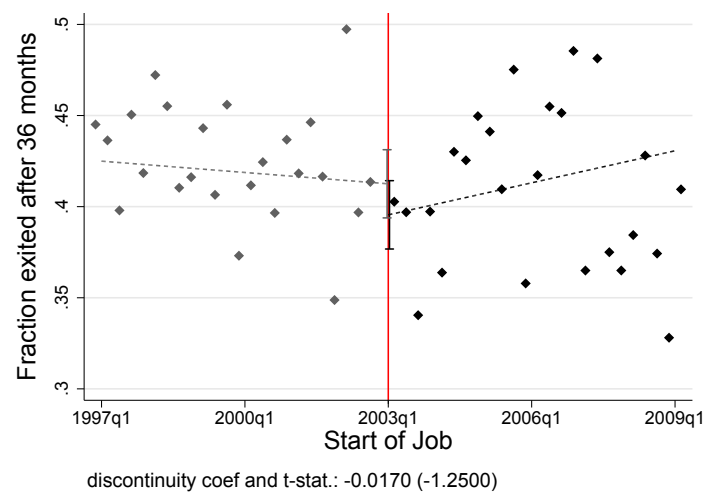

(b) Transitions to a new job (JTJ)

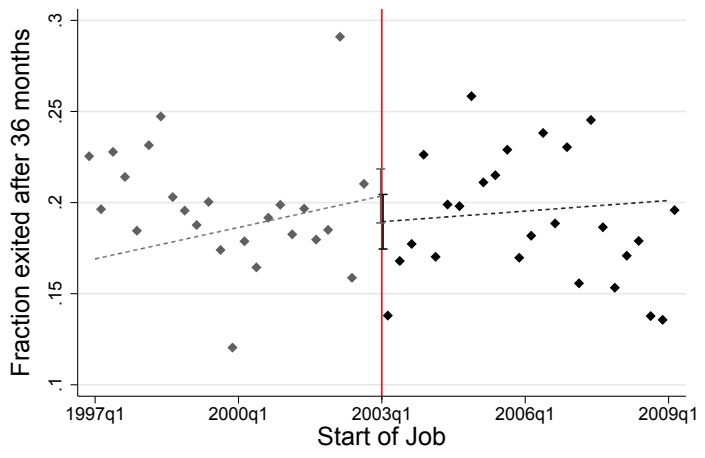

discontinuity coef and t-stat: $-0.0142(-1.3654)$ (c) Transitions to unemployment (JTU)

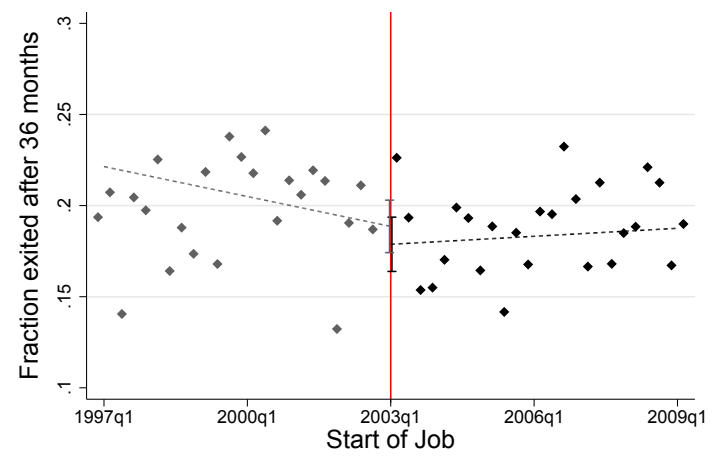

discontinuity coef and t-stat: $-0.0098(-0.9423)$

Note: The figures replicates Figure 1 of the main text for a sample of "matched control workers" hired by a firm that did not subsequently experience a mass layoff. For each worker in the baseline sample, we look for exact matches in terms of the following characteristics: hired in the same quarter and stayed on the job for at least 12 months; same gender; same region (9 "Bundeslaender"); same industry (21 categories); same age decile. If we obtain multiple controls, we take the one with the closest propensity score based on experience, experience squared, employment status in the four quarters preceding the current job, and decile of the starting wage. 4.5 percent (out of 28,099 workers) in the baseline sample could not be matched and were dropped. We end up with 26,841 matched pairs. Inference is based on a bootstrap (1000 replications), clustered at the firm level. The graphs confirm the hypothesis that matched control workers (who, by construction, have a low probability of being fired and hence to do not have a strong incentive to wait for a layoff with severance pay) were not affected by the severance pay reform. 
Figure 8: Treatment effect according to age categories of subsequent employer (excluding transitions to new firms)

(a) All exits

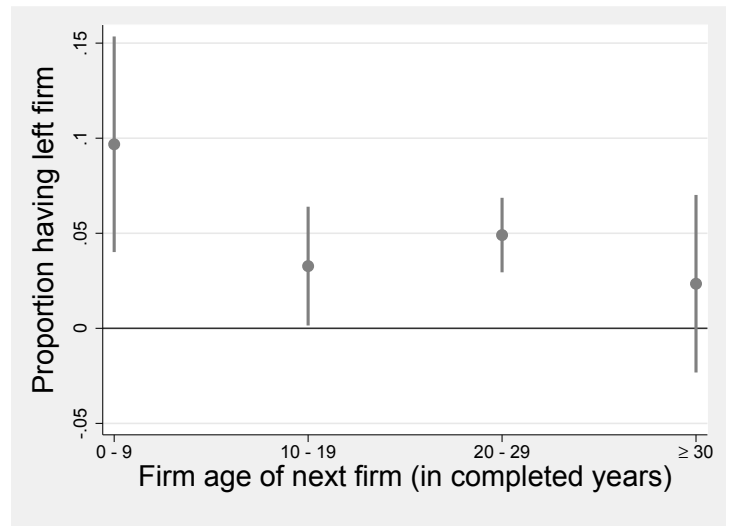

(b) JTJ

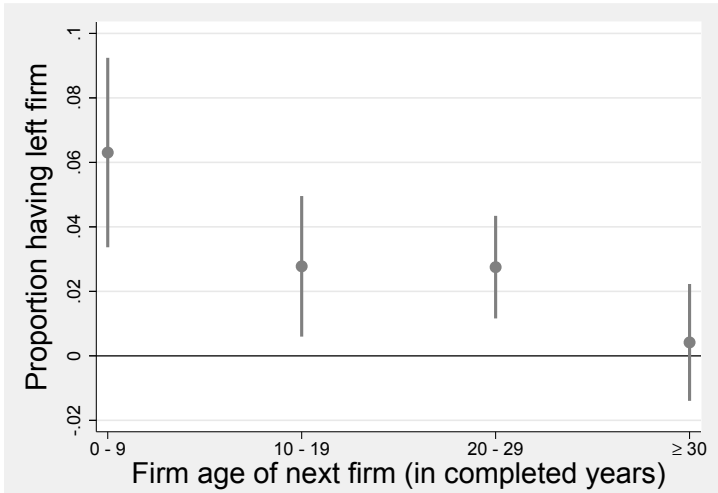

(c) JTU

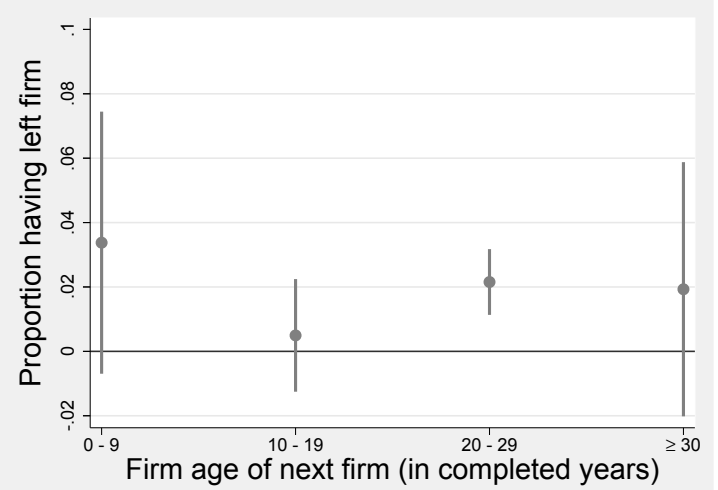

Note: The figures plot the coefficients from RD regressions, where we adapt the baseline specification shown in Table 2 of the main text by interacting the main outcome with firm age categories, i.e. taking $\mathbb{1}[$ Exited after 36 months] $\times \mathbb{1}$ [Firm age of subsequent firm $=x]$ as the outcome. Inference is based on a bootstrap (1000 replications), clustered at the firm level. We only include transitions to already existing firms to focus on hiring firms as opposed to firms opened by the separated workers themselves (the effects are comparable without this restriction). Clearly, the effect is mainly driven by JTJ transitions going to young firms. 
Figure 9: Job separations by date of job start (optimal bandwidth)

(a) All job separations

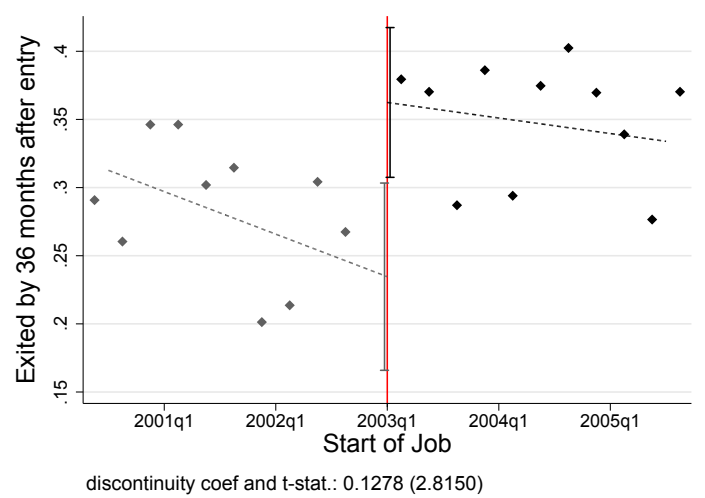

(b) Transitions to a new job (JTJ)

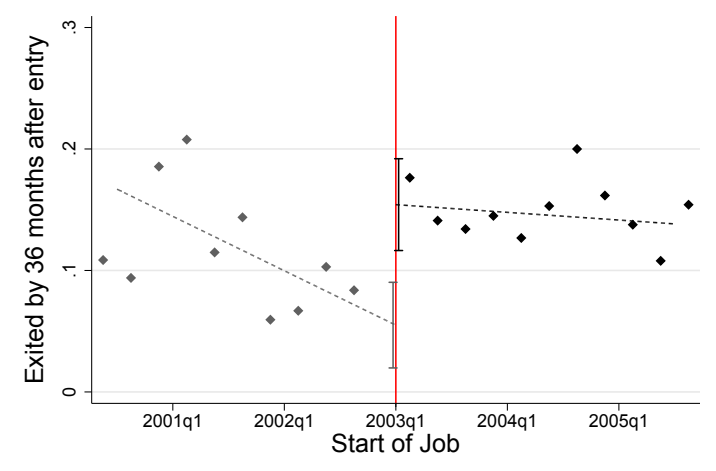

discontinuity coef and t-stat.: 0.0992 (3.6741) (c) Transitions to unemployment (JTU)

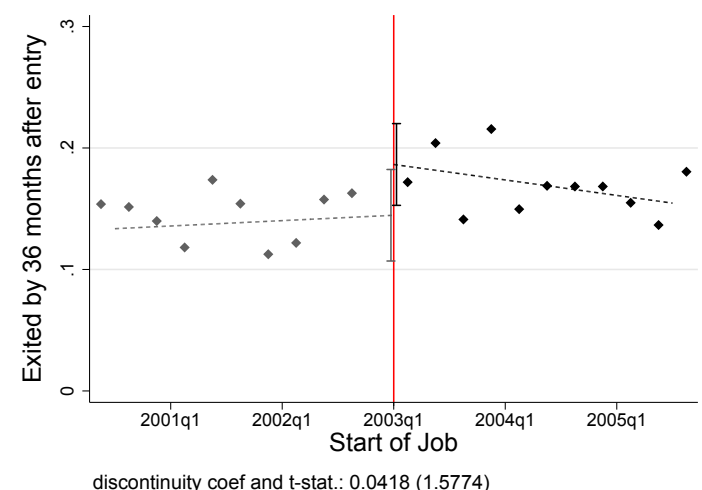

discontinuity coef and t-stat.: $0.0418(1.5774)$

Note: The Figure replicates the baseline analysis (Figure 1 in the main text) using the optimal bandwidth due to Imbens and Kalyanaraman (2012). The main conclusions stay unchanged. 
Table 1: Summary statistics, all job starters and baseline sample

\begin{tabular}{lccc}
\hline \hline & All Job Starts & Reweighted & Baseline \\
\hline Female & 0.55 & 0.53 & 0.51 \\
Age (years) & 37.79 & 37.59 & 36.73 \\
Experience (years) & 13.13 & 13.14 & 11.79 \\
Austrian & 0.79 & 0.79 & 0.78 \\
Previous Jobs & 4.99 & 4.97 & 5.37 \\
Manufacturing & 0.22 & 0.25 & 0.24 \\
Vienna & 0.32 & 0.33 & 0.36 \\
Starting wage in $€$ & 1,779 & 1,876 & 1,992 \\
Number of Firms & 173,528 & 173,528 & 4,198 \\
Median firm size at entry & 98 & 210 & 212 \\
Median firm size before shock & $\cdot$ & $\cdot$ & 222 \\
Median size reduction &. & $\cdot$ & 175 \\
Observations & $1,300,062$ & $1,300,062$ & 28,099 \\
\hline \hline
\end{tabular}

Note: Column 1 of the table reports descriptive statistics for the universe of newly hired workers observed in the ASSD who satisfy the following criteria: (i) aged 25-55 at the start of a job; (ii) started a new job between January 1, 1997 and December 31, 2008; (iii) stayed at least 12 months in the new firm. Column 3 restricts attention to the subsample of workers who (iv) entered a firm that experienced a mass layoff within 3 to 4 years after the worker's job start date. Workers who satisfy criteria (i)-(iv) constitute our "baseline sample". Column 2 is based on workers satisfying criteria (i)-(iii), but reweights observations according to the firm size distribution observed in the baseline sample at the time of the job start, which differs by construction as we restrict to firms with at least 30 employees before the mass layoff. We group observation in 50 size quantiles, hence the median firm size does not necessarily correspond to the baseline sample exactly. The table shows that the baseline sample of mass layoff workers shows by and large similar characteristics, though starting wages are somewhat higher in the baseline sample. Reweighting shows that part of this discrepancy is explained by differences in firm size. 
Table 2: Are covariates smooth around the cutoff?

\begin{tabular}{|c|c|c|c|c|c|}
\hline & Mean before & Mean after & Difference & RDD estimate & $p$-value \\
\hline \multicolumn{6}{|l|}{ Panel A: Worker characteristics } \\
\hline Age (years) & 36.65 & 36.83 & 0.175 & -0.231 & 0.757 \\
\hline Female & 0.544 & 0.467 & -0.0776 & -0.110 & $0.0883^{*}$ \\
\hline Experience (years) & 11.98 & 11.56 & -0.421 & -0.452 & 0.715 \\
\hline Austrian & 0.800 & 0.761 & -0.0389 & -0.0402 & 0.118 \\
\hline Log previous wage & 4.024 & 4.159 & 0.135 & -0.0212 & 0.815 \\
\hline \multicolumn{6}{|l|}{ Panel B: Firm characteristics } \\
\hline Manufacturing & 0.162 & 0.216 & 0.0545 & 0.145 & 0.157 \\
\hline Located in Vienna & 0.314 & 0.426 & 0.112 & 0.129 & 0.260 \\
\hline Log firm size $2 \mathrm{y}$. bef. shock & 5.668 & 5.445 & -0.224 & -0.0157 & 0.973 \\
\hline Log firm size 1 y. bef. shock & 5.694 & 5.450 & -0.243 & -0.0971 & 0.831 \\
\hline Log firm size $1 \mathrm{~m}$. bef. shock & 5.689 & 5.453 & -0.236 & -0.116 & 0.794 \\
\hline
\end{tabular}

Note: The table compares descriptive statistics of the baseline sample, before and after the reform (columns 1-3), as well as the corresponding RD estimates (columns 4-5). Panel A focuses on worker characteristics, Panel B focuses on the characteristics of the firms that hired these workers. Comparing sample means does not indicate any differences before and after the policy change. Moreover, the corresponding RD estimate do not show significant discontinuities at the reform date (2003q1), neither in worker- nor in firm characteristics (the only exception being a somewhat lower percentage of females after the reform). Inference is based on a bootstrap (1000 replications), clustered at the firm level. Overall, the evidence supports the validity of the RD design. (See text for details.)

Table 3: Wage growth of job changers (JTJ), RD estimates

\begin{tabular}{lccccc}
\hline \hline & $(1)$ & $(2)$ & $(3)$ & $(4)$ & $(5)$ \\
\hline Post-reform & $-0.0457^{*}$ & -0.0433 & -0.0274 & -0.0564 & -0.0383 \\
& $(0.099)$ & $(0.251)$ & $(0.261)$ & $(0.172)$ & $(0.349)$ \\
Linear & Yes & Yes & Yes & Yes & Yes \\
Quadratic & No & Yes & No & No & No \\
Controls & No & No & Yes & No & Yes \\
\hline $\begin{array}{l}\text { Bandwidth (quarters) } \\
\text { Observations }\end{array}$ & 24 & 24 & 24 & 8 & 8 \\
\hline \hline
\end{tabular}

Note: The table reports the RD estimate of the effect of the severance pay reform on the difference in log earnings between the new job and the previous job (in the mass-layoff firm). Only workers classified as job-to-job changers leaving the firm before the mass layoff occurs are included in the regression. The hypothesis is that, under the new system, lower wages increases are required to induce workers to accept an outside offer. The estimated reform effect is indeed negative (though not statistically significant) in all regressions. Bootstrapped standard errors (1,000 replications), clustered at the firm-level, are reported in parentheses. Controls are gender, age, age squared, experience, experience squared, Austrian nationality, $\log$ firm size 24 months before mass layoff, manufacturing sector, Vienna, and quarter of job entry. *(p< $0.10), * *(p<0.05), * * *(p<0.01)$ 


\section{Details and Extension of the Model}

\subsection{The Baseline Model}

Derivation of the surplus equations. The value of a firm employing an eligible worker, $J_{1}(p)$, is given by (throughout, primes denote next-period values)

$J_{1}(p)=p-w_{1}(p)+\delta \lambda(-\psi)+\delta\left(1-\chi f \bar{\mu}_{1}(p)-\lambda\right) \int_{\underline{p}}^{\bar{p}} \gamma_{1}\left(p^{\prime}\right)(-\psi)+\left(1-\gamma_{1}\left(p^{\prime}\right)\right) J_{1}\left(p^{\prime}\right) d F\left(p^{\prime} \mid p\right)$,

where $w_{1}(p)$ is the bargained wage of an eligible worker given productivity $p$. Firms currently earn $p-w_{1}(p)$. With probability $\left(1-\chi f \mu_{1}(p)-\lambda\right)$, the match persists and a new productivity realization $p^{\prime}$ is drawn. Upon observing this draw, firms can either shut down and pay $\psi$ or continue to produce, earning $J_{1}\left(p^{\prime}\right)$.

The value of a firm employing a non-eligible worker, $J_{0}(p)$, satisfies

$$
\begin{array}{r}
J_{0}(p)=p-w_{0}(p)+\delta\left(1-\chi f \bar{\mu}_{0}(p)-\lambda\right) \int_{\underline{p}}^{\bar{p}} \alpha\left(\gamma_{1}\left(p^{\prime}\right)(-\psi)+\left(1-\gamma_{1}\left(p^{\prime}\right)\right) J_{1}\left(p^{\prime}\right)\right) \\
+(1-\alpha)\left(1-\gamma_{0}\left(p^{\prime}\right)\right) J_{0}\left(p^{\prime}\right) d F\left(p^{\prime} \mid p\right) .
\end{array}
$$

Given that the match persists, workers become eligible with probability $\alpha$. In this case, the firm has to pay $\psi$ if shutting down and has continuation value $J_{1}\left(p^{\prime}\right)$ else. If the worker does not become eligible, the firm does not have to make a transfer in case of a layoff, while it continues with $J_{0}\left(p^{\prime}\right)$ if not.

The value of an eligible worker, $W_{1}(p)$, is given by

$$
\begin{aligned}
& W_{1}(p)=w_{1}(p)+\delta \lambda(U+\psi) \\
& +\delta \chi f \int_{\underline{p}}^{\bar{p}} \alpha \mu_{1}^{1}\left(p, p^{o}\right) W_{1}\left(p^{o}\right)+(1-\alpha) \mu_{1}^{0}\left(p, p^{o}\right) W_{0}\left(p^{o}\right) d G\left(p^{o}\right) \\
& \quad+\delta\left(1-\chi f \bar{\mu}_{1}(p)-\lambda\right) \int_{\underline{p}}^{\bar{p}} \gamma_{1}\left(p^{\prime}\right)(U+\psi)+\left(1-\gamma_{1}\left(p^{\prime}\right)\right) W_{1}\left(p^{\prime}\right) d F\left(p^{\prime} \mid p\right),
\end{aligned}
$$

where $U$ is the value when unemployed. A worker currently earns $w_{1}(p)$, with probability $\lambda$ an exogenous separation occurs, and with probability $\chi f$ an outside offer with productivity $p^{o}$ is obtained. If the workers does not receive an outside offer or turns it down, the worker becomes unemployed and receives $\psi$ if the firm is shut down, while receiving continuation value $W_{1}\left(p^{\prime}\right)$ otherwise.

The value of a non-eligible worker, $W_{0}(p)$, is given by 


$$
\begin{aligned}
W_{0}(p)=w_{0}(p)+\delta \lambda U & \\
& +\delta \chi f \int_{\underline{p}}^{\bar{p}} \alpha \mu_{0}^{1}\left(p, p^{o}\right) W_{1}\left(p^{o}\right)+(1-\alpha) \mu_{0}^{0}\left(p, p^{o}\right) W_{0}\left(p^{o}\right) d G\left(p^{o}\right) \\
+ & \delta\left(1-\chi f \bar{\mu}_{0}(p)-\lambda\right) \int_{\underline{p}}^{\bar{p}} \alpha\left[\gamma_{1}\left(p^{\prime}\right)(U+\psi)+\left(1-\gamma_{1}\left(p^{\prime}\right)\right) W_{1}\left(p^{\prime}\right)\right] \\
& +(1-\alpha)\left[\gamma_{0}\left(p^{\prime}\right) U+\left(1-\gamma_{0}\left(p^{\prime}\right)\right) W_{0}\left(p^{\prime}\right)\right] d F\left(p^{\prime} \mid p\right) .
\end{aligned}
$$

Note that neither an eligible nor a non-eligible worker will accept an offer that results in an immediate layoff $\gamma_{i}\left(p^{o}\right)=1$ due to the bargaining assumption. Hence, we do not have to account for this possibility.

The value when unemployed reads:

$$
U=b+\delta f \int_{\underline{p}}^{\bar{p}} \alpha \mu_{u}^{1}\left(p^{o}\right) W_{1}\left(p^{o}\right)+(1-\alpha) \mu_{u}^{0}\left(p^{o}\right) W_{0}\left(p^{o}\right) d G\left(p^{o}\right)+\delta\left(1-f \bar{\mu}_{u}\right) U
$$

We assume that firms have to pay $\psi$ to an eligible worker if bargaining breaks down. As the value of a vacancy is 0 , firms' outside value is $0-\psi=-\psi$. Workers' outside value is $U+\psi$. The common surplus, $S_{1}(p)$ is then given by

$$
S_{1}(p)=\left(W_{1}(p)-(U+\psi)\right)+\left(J_{1}(p)-(-\psi)\right)=W_{1}(p)-U+J_{1}(p) .
$$

Nash bargaining implies

$$
W_{1}(p)-(U+\psi)=\beta S_{1}(p) \text { and } J_{1}(p)+\psi=(1-\beta) S_{1}(p),
$$

where $\beta$ denotes workers' bargaining power. Similarly, the surplus if the worker is not eligible, $S_{0}(p)$, is given by

$$
S_{0}(p)=W_{0}(p)-U+J_{0}(p)
$$

and

$$
W_{0}(p)-U=\beta S_{0}(p) \text { and } J_{0}(p)=(1-\beta) S_{0}(p) .
$$

There is no need to solve explicitly for the values of workers and firms, since all equilibrium objects can be characterized as functions of the surplus functions. Combining the 
firm's and worker's value functions and using the bargaining assumption, we find

$$
\begin{aligned}
S_{1}(p)=p-b+\delta f \int_{\underline{p}}^{\bar{p}} \alpha\left(\chi \mu_{1}^{1}\left(p, p^{o}\right)-\mu_{u}^{1}\left(p^{o}\right)\right)\left(\beta S_{1}\left(p^{o}\right)+\psi\right) \\
+(1-\alpha)\left(\chi \mu_{1}^{0}\left(p, p^{o}\right)-\mu_{u}^{0}\left(p^{o}\right)\right) \beta S_{0}\left(p^{o}\right) d G\left(p^{o}\right) \\
\quad+\delta\left(1-\lambda-\chi f \bar{\mu}_{1}(p)\right) \int_{\underline{p}}^{\bar{p}}\left(1-\gamma_{1}\left(p^{\prime}\right)\right) S_{1}\left(p^{\prime}\right) d F\left(p^{\prime} \mid p\right)
\end{aligned}
$$

and

$$
\begin{aligned}
& S_{0}(p)=p-b+\delta f \int_{\underline{p}}^{\bar{p}} \alpha\left(\chi \mu_{0}^{1}\left(p, p^{o}\right)-\mu_{u}^{1}\left(p^{o}\right)\right)\left(\beta S_{1}\left(p^{o}\right)+\psi\right) \\
& +(1-\alpha)\left(\chi \mu_{0}^{0}\left(p, p^{o}\right)-\mu_{u}^{0}\left(p^{o}\right)\right) \beta S_{0}\left(p^{o}\right) d G\left(p^{o}\right) \\
& +\delta\left(1-\lambda-\chi f \bar{\mu}_{0}(p)\right) \int_{\underline{p}}^{\bar{p}} \alpha\left(1-\gamma_{1}\left(p^{\prime}\right)\right) S_{1}\left(p^{\prime}\right)+(1-\alpha)\left(1-\gamma_{0}\left(p^{\prime}\right)\right) S_{0}\left(p^{\prime}\right) d F\left(p^{\prime} \mid p\right) .
\end{aligned}
$$

Stationary productivity distribution. Denote by $n_{0}(p)$ and $n_{1}(p)$ the stationary number of non-eligible and eligible workers employed at a firm with current productivity $p$. Since there is a unit measure of workers, the unemployment rate satisfies $u=$ $1-\int_{\underline{p}}^{\bar{p}} n_{0}(p)+n_{1}(p) d p$.

$n_{0}(p)$ and $n_{1}(p)$ satisfy the following properties: for all $p^{\prime} \in[\underline{p}, \bar{p}]$,

$$
\begin{aligned}
& n_{0}\left(p^{\prime}\right)=\left(1-\gamma_{0}\left(p^{\prime}\right)\right)(1-\alpha) \int_{\underline{p}}^{\bar{p}}\left(1-\chi f \bar{\mu}_{0}(p)-\lambda\right) n_{0}(p) f\left(p^{\prime} \mid p\right) d p \\
& \quad+(1-\alpha) f u \mu_{u}^{0}\left(p^{\prime}\right) g\left(p^{\prime}\right)+(1-\alpha) \chi f \int_{\underline{p}}^{\bar{p}}\left(n_{0}(p) \mu_{0}^{0}\left(p, p^{\prime}\right)+n_{1}(p) \mu_{1}^{0}\left(p, p^{\prime}\right)\right) g\left(p^{\prime}\right) d p
\end{aligned}
$$

and

$$
\begin{aligned}
n_{1}\left(p^{\prime}\right)=\left(1-\gamma_{1}\left(p^{\prime}\right)\right) \int_{\underline{p}}^{\bar{p}}\left(1-\chi f \bar{\mu}_{1}(p)-\lambda\right) n_{1}(p) f\left(p^{\prime} \mid p\right) d p \\
+\alpha f u \mu_{u}^{1}\left(p^{\prime}\right) g\left(p^{\prime}\right)+\alpha \chi f \int_{\underline{p}}^{\bar{p}}\left(n_{0}(p) \mu_{0}^{1}\left(p, p^{\prime}\right)+n_{1}(p) \mu_{1}^{1}\left(p, p^{\prime}\right)\right) g\left(p^{\prime}\right) d p \\
\quad+\left(1-\gamma_{1}\left(p^{\prime}\right)\right) \alpha \int_{\underline{p}}^{\bar{p}}\left(1-\chi f \bar{\mu}_{0}(p)-\lambda\right) n_{0}(p) f\left(p^{\prime} \mid p\right) d p
\end{aligned}
$$


where $g(p)$ is the p.d.f. of initial productivity draws. A non-eligible worker currently employed at a firm with productivity $p^{\prime}$ was either employed at the firm before and not laid off, or entered it from unemployment or a different job. An eligible worker was either employed before or promoted to be eligible.

Surplus functions in transition. To account for transition from the old to the new steady state, fix a value of $\theta$ and hence of $f$. The surplus function of the new-system workers is not affected and still satisfies equations (??) and (??) for a given $f$ (note that both equations coincide for $\psi=0$ ). Call it $\tilde{S}^{\text {new }}$, where tilde denotes values in transition in what follows. The old-system workers take into account that any new match will be subject to the new system. Hence, their surplus functions satisfy

$$
\begin{aligned}
\tilde{S}_{1}^{\text {old }}(p)=p-b+\delta f \int_{\underline{p}}^{\bar{p}}\left(\chi \tilde{\mu}_{1}^{\text {old }}\left(p, p^{o}\right)-\tilde{\mu}_{u}\left(p^{o}\right)\right) \beta \tilde{S}^{\text {new }}\left(p^{o}\right) d G\left(p^{o}\right) \\
\quad+\delta\left(1-\lambda-\chi f \overline{\tilde{\mu}}_{1}^{\text {old }}(p)\right) \int_{\underline{p}}^{\bar{p}}\left(1-\tilde{\gamma}_{1}^{\text {old }}\left(p^{\prime}\right)\right) \tilde{S}_{1}^{\text {old }}\left(p^{\prime}\right) d F\left(p^{\prime} \mid p\right)
\end{aligned}
$$

and

$$
\begin{aligned}
& \tilde{S}_{0}^{\text {old }}(p)=p-b+\delta f \int_{\underline{p}}^{\bar{p}}\left(\chi \tilde{\mu}_{0}^{\text {old }}\left(p, p^{o}\right)-\tilde{\mu}_{u}\left(p^{o}\right)\right) \beta \tilde{S}^{\text {new }}\left(p^{o}\right) d G\left(p^{o}\right) \\
+ & \delta\left(1-\lambda-\chi f \overline{\tilde{\mu}}_{0}^{\text {old }}(p)\right) \int_{\underline{p}}^{\bar{p}} \alpha\left(1-\tilde{\gamma}_{1}^{\text {old }}\left(p^{\prime}\right)\right) \tilde{S}_{1}^{\text {old }}\left(p^{\prime}\right)+(1-\alpha)\left(1-\tilde{\gamma}_{0}^{\text {old }}\left(p^{\prime}\right)\right) \tilde{S}_{0}^{\text {old }}\left(p^{\prime}\right) d F\left(p^{\prime} \mid p\right) .
\end{aligned}
$$

Optimal firm closures follow as

$$
\begin{aligned}
\tilde{\gamma}_{0}^{\text {old }}(p) & =\mathbb{1}\left\{\tilde{S}_{0}^{\text {old }}(p)<0\right\} \\
\tilde{\gamma}_{1}^{\text {old }}(p) & =\mathbb{1}\left\{\tilde{S}_{1}^{\text {old }}(p)<0\right\} \\
\tilde{\gamma}^{\text {new }}(p) & =\mathbb{1}\left\{\tilde{S}^{\text {new }}(p)<0\right\},
\end{aligned}
$$

while workers' acceptance rules are given by 


$$
\begin{aligned}
& \tilde{\mu}_{0}^{\text {old }}\left(p, p^{o}\right)=\mathbb{1}\left\{\beta \tilde{S}^{\text {new }}\left(p^{o}\right)>\alpha \psi+\int_{\underline{p}}^{\bar{p}} \alpha\left(1-\tilde{\gamma}_{1}^{\text {old }}\left(p^{\prime}\right)\right) \beta \tilde{S}_{1}^{\text {old }}\left(p^{\prime}\right)+(1-\alpha)\left(1-\tilde{\gamma}_{0}^{\text {old }}\left(p^{\prime}\right)\right) \beta \tilde{S}_{0}^{\text {old }}\left(p^{\prime}\right) d F\left(p^{\prime} \mid p\right)\right\} \\
& \tilde{\mu}_{1}^{\text {old }}\left(p, p^{o}\right)=\mathbb{1}\left\{\beta \tilde{S}^{\text {new }}\left(p^{o}\right)>\psi+\int_{\underline{p}}^{\bar{p}}\left(1-\tilde{\gamma}_{1}^{\text {old }}\left(p^{\prime}\right)\right) \beta \tilde{S}_{1}^{\text {old }}\left(p^{\prime}\right) d F\left(p^{\prime} \mid p\right)\right\} \\
& \tilde{\mu}^{\text {new }}\left(p, p^{o}\right)=\mathbb{1}\left\{\beta \tilde{S}^{\text {new }}\left(p^{o}\right)>\int_{\underline{p}}^{\bar{p}}\left(1-\tilde{\gamma}^{\text {new }}\left(p^{\prime}\right)\right) \beta \tilde{S}^{\text {new }}\left(p^{\prime}\right) d F\left(p^{\prime} \mid p\right)\right\} .
\end{aligned}
$$

\subsection{Model Extension: Temporary Jobs}

Environment. The environment in the baseline model is adapted by adding the possibility to create temporary jobs. We assume that temporary jobs are fixed-term. That is, with exogenous rate $\alpha_{t}$, temporary matches are dissolved at the beginning of the period.

Endogenous firm and worker decisions. We denote by $\gamma_{i}(p) \in\{0,1, t\}$ the endogenous firm closure decision given productivity $p$ and eligibity status $i$ of the worker, where $t$ now indicates a temporary job. Moreover, let $\mu_{i}^{j}\left(p, p^{o}\right)$ indicate the endogenous decision of a worker with current eligibility status $i \in\{0,1, t\}$ employed by a firm facing productivity $p$ to accept an outside offer by a firm facing productivity $p^{o}$ where she will have eligibility status $j \in\{0,1, t\}$. The overall probability that a worker accepts an outside offer for a regular job given productivity $p$ and eligibility status $i$ is given by

$$
\bar{\mu}_{i}(p)=\int_{\underline{p}}^{\bar{p}} \alpha \mu_{i}^{1}\left(p, p^{o}\right)+(1-\alpha) \mu_{i}^{0}\left(p, p^{o}\right) d G\left(p^{o}\right) .
$$

Similarly, denote by $\mu_{u}^{j}\left(p^{o}\right)$ the endogenous decision by an unemployed worker to accept an offer by a firm facing productivity $p^{o}$ where she will have eligibility status $j \in\{0,1, t\}$ and define the overall probability of accepting a regular job as

$$
\bar{\mu}_{u}(p)=\int_{\underline{p}}^{\bar{p}} \alpha \mu_{u}^{1}\left(p^{o}\right)+(1-\alpha) \mu_{u}^{0}\left(p^{o}\right) d G\left(p^{o}\right) .
$$

Bellman equations. The value of a firm with an eligible worker, $J_{1}(p)$, is given by

$$
\begin{aligned}
& J_{1}(p)=p-w_{1}(p)+\delta \lambda(-\psi)+ \\
& \quad \delta\left(1-\chi f_{r} \bar{\mu}_{1}(p)-\chi f_{t} \mu_{1}^{t}(p)-\lambda\right) \int_{\underline{p}}^{\bar{p}} \gamma_{1}\left(p^{\prime}\right)(-\psi)+\left(1-\gamma_{1}\left(p^{\prime}\right)\right) J_{1}\left(p^{\prime}\right) d F\left(p^{\prime} \mid p\right),
\end{aligned}
$$


where $f_{r}$ and $f_{t}$ denote the probability that a worker meets a firm offering a regular or temporary job, respectively.

The value of a firm with a non-eligible worker, $J_{0}(p)$, satisfies

$$
\begin{aligned}
& J_{0}(p)=p-w_{0}(p)+ \\
& \begin{aligned}
\delta\left(1-\chi f_{r} \bar{\mu}_{0}(p)-\chi f_{t} \mu_{0}^{t}(p)-\lambda\right) \int_{\underline{p}}^{\bar{p}} \alpha\left[\gamma_{1}\left(p^{\prime}\right)(-\psi)+\left(1-\gamma_{1}\left(p^{\prime}\right)\right) J_{1}\left(p^{\prime}\right)\right] \\
+(1-\alpha)\left(1-\gamma_{0}\left(p^{\prime}\right)\right) J_{0}\left(p^{\prime}\right) d F\left(p^{\prime} \mid p\right),
\end{aligned}
\end{aligned}
$$

while the value of a temporary job to a firm, $J_{t}(p)$, is given by

$$
J_{t}(p)=p-w_{t}(p)+\delta\left(1-\chi f_{r} \bar{\mu}_{t}(p)-\chi f_{t} \mu_{t}^{t}(p)-\lambda\right) \int_{\underline{p}}^{\bar{p}}\left(1-\alpha_{t}\right)\left(1-\gamma_{t}\left(p^{\prime}\right)\right) J_{t}\left(p^{\prime}\right) d F\left(p^{\prime} \mid p\right) .
$$

In addition to exogenous separations with rate $\lambda$ and job-to-job transitions, a temporary job is destroyed at the beginning of a period at rate $\alpha_{t}$.

The value of an eligible worker, $W_{1}(p)$, is given by

$$
\begin{aligned}
& W_{1}(p)=w_{1}(p)+\delta \lambda(U+\psi) \\
& +\delta \chi f_{r} \int_{\underline{p}}^{\bar{p}} \alpha \mu_{1}^{1}\left(p, p^{o}\right) W_{1}\left(p^{o}\right)+(1-\alpha) \mu_{1}^{0}\left(p, p^{o}\right) W_{0}\left(p^{o}\right) d G\left(p^{o}\right) \\
& \quad+\delta \chi f_{t} \int_{\underline{p}}^{\bar{p}} \mu_{1}^{t}\left(p, p^{o}\right) W_{t}\left(p^{o}\right) d G\left(p^{o}\right) \\
& +\delta\left(1-\chi f_{r} \bar{\mu}_{1}(p)-\chi f_{t} \mu_{t}^{1}(p)-\lambda\right) \int_{\underline{p}}^{\bar{p}} \gamma_{1}\left(p^{\prime}\right)(U+\psi)+\left(1-\gamma_{1}\left(p^{\prime}\right)\right) W_{1}\left(p^{\prime}\right) d F\left(p^{\prime} \mid p\right),
\end{aligned}
$$

where $U$ is the value when unemployed, $G\left(p^{o}\right)$ is the distribution of outside offers $p^{o}$ (i.e. the unconditional distribution of $p)$, and $\gamma_{1}(p)$ takes the value 1 if a firm with an eligible worker is shut down given $p$ and zero otherwise. A worker currently earns $w_{1}(p)$, with probability $\lambda$ an exogenous separation occurs, and with probability $\chi f$ an outside offer with productivity $p^{o}$ is obtained. If the workers does not receive an outside offer or turns it down, the worker becomes unemployed and receives $\psi$ if the firm is shut down, while receiving continuation value $W_{1}\left(p^{\prime}\right)$ otherwise. 
The value of a non-eligible worker, $W_{0}(p)$, is given by

$$
\begin{aligned}
& W_{0}(p)=w_{0}(p)+\delta \lambda U \\
& +\delta \chi f_{r} \int_{\underline{p}}^{\bar{p}} \alpha \mu_{0}^{1}\left(p, p^{o}\right) W_{1}\left(p^{o}\right)+(1-\alpha) \mu_{0}^{0}\left(p, p^{o}\right) W_{0}\left(p^{o}\right) d G\left(p^{o}\right) \\
& \quad+\delta \chi f_{t} \int_{\underline{p}}^{\bar{p}} \mu_{0}^{t}\left(p, p^{o}\right) W_{t}\left(p^{o}\right) d G\left(p^{o}\right) \\
& +\delta\left(1-\chi f_{r} \bar{\mu}_{0}(p)-\chi f_{t} \mu_{t}^{0}(p)-\lambda\right) \int_{\underline{p}}^{\bar{p}} \alpha\left[\gamma_{1}\left(p^{\prime}\right)(U+\psi)+\left(1-\gamma_{1}\left(p^{\prime}\right)\right) W_{1}\left(p^{\prime}\right)\right] \\
& +(1-\alpha)\left[\gamma_{0}\left(p^{\prime}\right) U+\left(1-\gamma_{0}\left(p^{\prime}\right)\right) W_{0}\left(p^{\prime}\right)\right] d F\left(p^{\prime} \mid p\right) .
\end{aligned}
$$

The value of a temporary worker, $W_{t}(p)$, is given by

$$
\begin{gathered}
\begin{array}{l}
W_{t}(p)=w_{t}(p)+\delta \lambda U \\
+\delta \chi f_{r} \int_{\underline{p}}^{\bar{p}} \alpha \mu_{t}^{1}\left(p, p^{o}\right) W_{1}\left(p^{o}\right)+(1-\alpha) \mu_{t}^{0}\left(p, p^{o}\right) W_{0}\left(p^{o}\right) d G\left(p^{o}\right) \\
\quad+\delta \chi f_{t} \int_{\underline{p}}^{\bar{p}} \mu_{t}^{t}\left(p, p^{o}\right) W_{t}\left(p^{o}\right) d G\left(p^{o}\right) \\
+\delta\left(1-\lambda-\chi f_{r} \bar{\mu}_{t}(p)-\chi f_{t} \mu_{t}^{t}(p)\right) \int_{\underline{p}}^{\bar{p}} \alpha_{t} U+\left(1-\alpha_{t}\right)\left[\gamma_{t}\left(p^{\prime}\right) U+\left(1-\gamma_{t}\left(p^{\prime}\right)\right) W_{t}\left(p^{\prime}\right)\right] d F\left(p^{\prime} \mid p\right) .
\end{array}
\end{gathered}
$$

The value when unemployed reads:

$$
\begin{aligned}
U=b+\delta f_{r} \int_{\underline{p}}^{\bar{p}} \alpha \mu_{u}^{1}\left(p, p^{o}\right) W_{1}\left(p^{o}\right) & +(1-\alpha) \mu_{u}^{0}\left(p, p^{o}\right) W_{0}\left(p^{o}\right) d G\left(p^{o}\right) \\
& +\delta f_{t} \int_{\underline{p}}^{\bar{p}} \mu_{u}^{t}\left(p^{o}\right) W_{t}\left(p^{o}\right) d G\left(p^{o}\right)+\delta\left(1-f_{r} \bar{\mu}_{u}-f_{t} \mu_{u}^{t}\right) U
\end{aligned}
$$

The surplus functions satisfy:

$$
\begin{gathered}
S_{1}(p)=\left(W_{1}(p)-(U+\psi)\right)+\left(J_{1}(p)-(-\psi)\right)=W_{1}(p)-U+J_{1}(p) . \\
W_{1}(p)-(U+\psi)=\beta S_{1}(p) \text { and } J_{1}(p)+\psi=(1-\beta) S_{1}(p), \\
S_{0}(p)=W_{0}(p)-U+J_{0}(p) \\
W_{0}(p)-U=\beta S_{0}(p) \text { and } J_{0}(p)=(1-\beta) S_{0}(p) . \\
S_{t}(p)=W_{t}(p)-U+J_{t}(p)
\end{gathered}
$$




$$
W_{t}(p)-U=\beta S_{t}(p) \text { and } J_{t}(p)=(1-\beta) S_{t}(p) .
$$

Combining the firm's and worker's value functions and using the bargaining assumption, we find

$$
\begin{aligned}
& S_{1}(p)=p-b+\delta f_{r} O_{1}(p)+\delta f_{t} O_{1}^{t}(p) \\
& +\delta\left(1-\chi f_{r} \bar{\mu}_{1}(p)-\chi f_{t} \mu_{t}^{1}(p)-\lambda\right) \int_{\underline{p}}^{\bar{p}}\left(1-\gamma_{1}\left(p^{\prime}\right)\right) S_{1}\left(p^{\prime}\right) d F\left(p^{\prime} \mid p\right), \\
& S_{0}(p)=p-b+\delta f_{r} O_{0}(p)+\delta f_{t} O_{0}^{t}(p) \\
& +\delta\left(1-\chi f_{r} \bar{\mu}_{0}(p)-\chi f_{t} \mu_{0}^{t}(p)-\lambda\right) \int_{\underline{p}}^{\bar{p}} \alpha\left(1-\gamma_{1}\left(p^{\prime}\right)\right) S_{1}\left(p^{\prime}\right) \\
& +(1-\alpha)\left(1-\gamma_{0}\left(p^{\prime}\right)\right) S_{0}\left(p^{\prime}\right) d F\left(p^{\prime} \mid p\right),
\end{aligned}
$$

and

$$
\begin{aligned}
S_{t}(p)=p- & b+\delta f_{r} O_{t}(p)+\delta f_{t} O_{t}^{t}(p) \\
+ & \delta\left(1-\chi f_{r} \bar{\mu}_{t}(p)-\chi f_{t} \mu_{t}^{t}(p)-\lambda\right) \int_{\underline{p}}^{\bar{p}}\left(1-\alpha_{t}\right)\left(1-\gamma_{t}\left(p^{\prime}\right)\right) S_{t}\left(p^{\prime}\right) d F\left(p^{\prime} \mid p\right) .
\end{aligned}
$$

where

$O_{i}(p)=\int_{\underline{p}}^{\bar{p}} \alpha\left(\chi \mu_{i}^{1}\left(p, p^{o}\right)-\mu_{u}^{1}\left(p^{o}\right)\right)\left(\beta S_{1}\left(p^{o}\right)+\psi\right)+(1-\alpha)\left(\chi \mu_{i}^{0}\left(p, p^{o}\right)-\mu_{u}^{0}\left(p^{o}\right)\right) \beta S_{0}\left(p^{o}\right) d G\left(p^{o}\right)$,

for $i \in\{0,1, t\}$, denotes the option value due to a potential transition to a regular job and

$$
O_{i}^{t}(p)=\int_{\underline{p}}^{\bar{p}}\left(\chi \mu_{i}^{t}\left(p, p^{o}\right)-\mu_{u}^{t}\left(p^{o}\right)\right) \beta S_{t}\left(p^{o}\right) d G\left(p^{o}\right)
$$

for $i \in\{0,1, t\}$, denotes the option value due to a potential transition to a temporary job.

$\mu_{u}\left(p^{o}\right)$ takes the value 1 if an unemployed accepts an offer with initial productivity $p^{o}$ and the decision rules to shut down the firm, $\gamma_{0}, \gamma_{1}$, and $\gamma_{t}$, are given by

$$
\gamma_{i}=\mathbb{1}\left\{S_{i}<0\right\} \text { for } i \in\{0,1, t\}
$$

That is, due to the bargaining assumption, it does not matter whether we think of a lay-off as firm- or worker-induced, since both parties choose to shut down the firm as soon as the joint surplus falls below zero. 
The decision rules of the workers are given by

$$
\mu_{i}^{j}\left(p, p^{o}\right)=\mathbb{1}\left[V_{j}^{o}\left(p^{o}\right)>V_{i}^{s}(p)\right] \text { for } i \in\{0,1, t, u\} \text { and } j \in\{0,1, t\},
$$

where $V_{i}^{o}$ and $V_{j}^{s}$ denote, respectively, the workers' value of staying with $i$ and the offer $j$. The value of the offer satisfies

$$
\begin{aligned}
V_{0}^{o}\left(p^{o}\right) & =\beta S_{0}\left(p^{o}\right) \\
V_{t}^{o}\left(p^{o}\right) & =\beta S_{t}\left(p^{o}\right) \\
V_{1}^{o}\left(p^{o}\right) & =\beta S_{1}\left(p^{o}\right)+\psi,
\end{aligned}
$$

while the value of staying can be written

$$
\begin{aligned}
& V_{0}^{s}(p)=\alpha \psi+\int_{\underline{p}}^{\bar{p}} \alpha\left[\left(1-\gamma_{1}\left(p^{\prime}\right)\right) \beta S_{1}\left(p^{\prime}\right)\right]+(1-\alpha)\left(1-\gamma_{0}\left(p^{\prime}\right)\right) \beta S_{0}\left(p^{\prime}\right) d F\left(p^{\prime} \mid p\right) \\
& V_{t}^{s}(p)=\int_{\underline{p}}^{\bar{p}}\left(1-\alpha_{t}\right)\left(1-\gamma_{t}\left(p^{\prime}\right)\right) \beta S_{t}\left(p^{\prime}\right) d F\left(p^{\prime} \mid p\right) \\
& V_{1}^{s}(p)=\psi+\int_{\underline{p}}^{\bar{p}}\left(1-\gamma_{1}\left(p^{\prime}\right)\right) \beta S_{1}\left(p^{\prime}\right) d F\left(p^{\prime} \mid p\right) \\
& V_{u}^{s}(p)=0 .
\end{aligned}
$$

Stationary productivity distribution. Since there is a unit measure of workers, the unemployment rate satisfies $u=\int_{\underline{p}}^{\bar{p}} n_{0}(p)+n_{1}(p)+n_{t}(p) d p$.

$n_{0}(p), n_{1}(p)$, and $n_{t}(p)$ satisfy the following properties: For all $p^{\prime} \in[\underline{p}, \bar{p}]$,

$$
\begin{aligned}
n_{0}\left(p^{\prime}\right)= & \left(1-\gamma_{0}\left(p^{\prime}\right)\right)(1-\alpha) \int_{\underline{p}}^{\bar{p}}\left(1-\chi f_{r} \bar{\mu}_{0}(p)-\chi f_{t} \mu_{0}^{t}(p)-\lambda\right) n_{0}(p) f\left(p^{\prime} \mid p\right) d p \\
& +(1-\alpha) f_{r} u \mu_{u}^{0}\left(p^{\prime}\right) g\left(p^{\prime}\right) \\
& +(1-\alpha) \chi f_{r} \int_{\underline{p}}^{\bar{p}}\left(n_{0}(p) \mu_{0}^{0}\left(p, p^{\prime}\right)+n_{1}(p) \mu_{1}^{0}\left(p, p^{\prime}\right)+n_{t}(p) \mu_{t}^{0}\left(p, p^{\prime}\right)\right) g\left(p^{\prime}\right) d p
\end{aligned}
$$




$$
\begin{aligned}
& n_{1}\left(p^{\prime}\right)=\left(1-\gamma_{1}\left(p^{\prime}\right)\right) \int_{\underline{p}}^{\bar{p}}\left(1-\chi f_{r} \bar{\mu}_{1}(p)-\chi f_{t} \mu_{t}^{1}(p)-\lambda\right) n_{1}(p) f\left(p^{\prime} \mid p\right) d p \\
& +\alpha f_{r} u \mu_{u}^{1}\left(p^{\prime}\right) g\left(p^{\prime}\right)+\alpha \chi f_{r} \int_{\underline{p}}^{\bar{p}}\left(n_{0}(p) \mu_{0}^{1}\left(p, p^{\prime}\right)+n_{1}(p) \mu_{1}^{1}\left(p, p^{\prime}\right)+n_{t}(p) \mu_{t}^{1}\left(p, p^{\prime}\right)\right) g\left(p^{\prime}\right) d p \\
& +\alpha\left(1-\gamma_{1}\left(p^{\prime}\right)\right) \int_{\underline{p}}^{\bar{p}}\left(1-\chi f_{r} \bar{\mu}_{0}(p)-\chi f_{t} \mu_{0}^{t}(p)-\lambda\right) n_{0}(p) f\left(p^{\prime} \mid p\right) d p, \quad
\end{aligned}
$$

and

$$
\begin{aligned}
& n_{t}\left(p^{\prime}\right)=\left(1-\alpha_{t}\right)\left(1-\gamma_{t}\left(p^{\prime}\right)\right) \int_{\underline{p}}^{\bar{p}}\left(1-\chi f_{r} \bar{\mu}_{t}(p)-\chi f_{t} \mu_{t}^{t}(p)-\lambda\right) n_{t}(p) f\left(p^{\prime} \mid p\right) d p \\
& +f_{t} u \mu_{u}^{t}\left(p^{\prime}\right) g\left(p^{\prime}\right)+\chi f_{t} \int_{\underline{p}}^{\bar{p}}\left(n_{0}(p) \mu_{u}^{t}\left(p, p^{\prime}\right)+n_{1}(p) \mu_{1}^{t}\left(p, p^{\prime}\right)+n_{t}(p) \mu_{t}^{t}\left(p, p^{\prime}\right)\right) g\left(p^{\prime}\right) d p
\end{aligned}
$$

Zero profit condition. We assume that there are two submarkets, one for permanent and one for temporary jobs. Denote by $v_{r}$ and $v_{t}$ the number of vacancies for permanent and temporary jobs, respectively. To keep things simple, we assume that the effective number of job seekers, $u+\chi(1-u)$, always searches in both markets.

The number of meetings between a vacant firm and a potential employee in submarket $i \in\{r, t\}$ is then given by the meeting function

$$
m_{i}=m\left(u+\chi(1-u), v_{i}\right) .
$$

Define labor market tightness $\theta_{i} \equiv \frac{v_{i}}{u+\chi(1-u)}$. Assuming that $m(u+\chi(1-u), v)$ satisfies constant returns to scale, we can write for the probability that a vacant firm meets a worker in submarket $i, q_{i}$,

$$
q_{i}=\frac{m_{i}}{v_{i}}=m\left(\theta_{i}^{-1}, 1\right) \equiv q\left(\theta_{i}\right) \text { with } q^{\prime}\left(\theta_{i}\right)<0
$$

The probability of meeting an unemployed person is given by $q_{i} u /(u+\chi(1-u))$, while the probability of meeting an employed person is given by $q_{i} \chi(1-u) /(u+\chi(1-u))$. The probability that an unemployed person meets a firm in submarket $i, f_{i}$, can be written

$$
f_{i}=\frac{m_{i}}{u+\chi(1-u)}=m\left(1, \theta_{i}\right) \equiv f\left(\theta_{i}\right) \text { with } f^{\prime}\left(\theta_{i}\right)>0
$$

while the probability that an employed person meets a firm is given by $\chi f_{i}$. 
Denote by $a_{i}\left(p^{o}\right)$ the probability that an offer by a firm with initial productivity $p^{o}$ and status $i \in\{0,1, t\}$ is accepted. It is given by

$a_{i}\left(p^{o}\right)=\frac{u}{u+\chi(1-u)} \cdot \mu_{u}^{i}\left(p^{o}\right)+\frac{\chi(1-u)}{u+\chi(1-u)} \cdot \frac{\int_{\underline{p}}^{\bar{p}} n_{0}(p) \mu_{0}^{i}\left(p, p^{o}\right)+n_{1}(p) \mu_{1}^{i}\left(p, p^{o}\right)+n_{t}(p) \mu_{t}^{i}\left(p, p^{o}\right) d p}{1-u}$.

The expected value of a vacancy in submarket $t, V_{t}$, then satisfies

$$
V_{t}=-c+\delta q\left(\theta_{t}\right) \int_{\underline{p}}^{\bar{p}} a_{t}\left(p^{o}\right)(1-\beta) S_{t}\left(p^{o}\right) d G\left(p^{o}\right),
$$

while the value of a vacancy in submarket $r, V_{r}$, satisfies

$$
V_{0}=-c+\delta q\left(\theta_{r}\right) \int_{\underline{p}}^{\bar{p}} \alpha a_{1}\left(p^{o}\right)\left((1-\beta) S_{1}\left(p^{o}\right)-\psi\right)+(1-\alpha) a_{0}\left(p^{o}\right)(1-\beta) S_{0}\left(p^{o}\right) d G\left(p^{o}\right) .
$$

A vacant firm pays hiring costs $c$ every period. With probability $q_{i}$ the firm meets a potential worker and draws initial productivity $p^{o}$ from the distribution $G\left(p^{o}\right)$. If the offer is accepted, the firm can start producing in the subsequent period, yielding value $J_{i}$.

Due to free entry, a vacancy has to yield zero expected profits, i.e.

$$
V_{i}=0 \text { for } i \in\{r, t\},
$$

also implying that firms are indifferent between creating temporary and permanent jobs in equilibrium.

\section{Equilibrium.}

Definition 2.1. An equilibrium is given by functions $\left\{n_{0}(p), n_{1}(p), n_{t}(p)\right\}$, values $\left\{S_{0}(p), S_{1}(p), S_{t}(p)\right\}$ and labor market tightness $\left\{\theta_{r}, \theta_{t}\right\}$ such that

1. $\left\{S_{0}(p), S_{1}(p), S_{t}(p)\right\}$ solve the recursive equations (7), (8), and (9);

2. $\left\{n_{0}(p), n_{1}(p), n_{t}(p)\right\}$ solve the recursive equations (10), (11), and (12);

3. $\left\{\theta_{r}, \theta_{t}\right\}$ solve the zero-profit condition (13). 


\section{Further Details on Structural Estimation}

For every given set of parameters, we solve for the equilibrium defined in Definition 5.1 of the main text by iterating on the equilibrium conditions pre- and post-reform. This allows us to simulate aggregate variables as well as policy functions contingent on being in a firm about to close down. Using these policy functions, we then simulate $H$ data sets of size $N_{0}$ and $N_{1}$ for the period before and after the reform, respectively, and estimate the RDD regressions and macro moments based on them.

Denote by $\boldsymbol{\beta} \equiv\left(\lambda, \sigma_{\varepsilon}, \xi, m_{0}, c\right)$ the parameters to be estimated and $\tilde{m}(\boldsymbol{\beta}, e)$ the simulated moments given parameters $\boldsymbol{\beta}$ and a set of shocks $e$. Call $m$ the corresponding vector of empirical moments. We choose $\boldsymbol{\beta}$ by solving

$$
\min _{\boldsymbol{\beta}}(\tilde{m}(\boldsymbol{\beta}, e)-m)^{\prime} W(\tilde{m}(\boldsymbol{\beta}, e)-m)
$$

where $W$ is a weighting matrix. Efficient GMM requires setting $W$ equal to the inverse of variance-covariance matrix of $m$. Instead, we choose $W$ equal to the identity matrix. ${ }^{1}$ The reason is that we view the model rather as a description of firms about to experience a mass layoff than as a representation of the entire economy. We include macro moments to ensure that the parameters are identified and not unrealistic but do not expect the model to reproduce macro moments and to be perfectly in line with aggregate data solely using data from firms experiencing negative shocks. In other words, we do not expect the parameters describing the behavior of these firms to be perfectly in line with the entire economy. Since the macro moments are measured with much less variance, efficient GMM will put much more weight on the macro moments, while our primary interest lies in explaining worker mobility in declining firms.

A well known problem with Method of Simulated Moments is that the simulated moments are a discontinuous function of the underlying parameters for a given set of random shocks, as we have a finite number of observations and discrete outcomes. This can pose problems to optimization algorithms, leading to non-convergence or convergence to local optima. Keane and Smith (2003) propose a remedy for this problem in the context of a random utility model: Suppose that a binary variable $y_{i}$ is 1 if a simulated latent utility given parameters $\beta, u_{i}(\beta)$, is positive and zero otherwise. Instead of using $y_{i}$ to calculate the simulated moments, they propose using a continuous function of the latent utility, $g\left(u_{i} ; \zeta\right)$, where $g\left(u_{i} ; \zeta\right) \rightarrow y_{i}$ as $\zeta \rightarrow 0$. Our choice for $g(u ; \zeta)$ is

$$
g(u ; \zeta)=\Phi(u / \zeta)
$$

where $\Phi(\cdot)$ denotes the c.d.f. of the standard normal distribution. Paralleling this strategy, we apply this smoothing procedure to all discrete outcomes of the model, i.e. to the policy

\footnotetext{
${ }^{1}$ We only give weight 0.1 to expected hiring costs, as this is the only moment not based on Austrian data.
} 
functions $\gamma_{0}(p), \gamma_{1}(p), \mu_{0}\left(p, p^{o}\right)$, and $\mu_{1}\left(p, p^{o}\right)$.

There is no clear rule as to which value should be chosen for the smoothing parameter $\zeta$ and the number of simulated data sets $H$. Larger values of $\zeta$ and $H$ lead to a smoother surface of the objective function, decreasing the risk of local optima where the optimization algorithm could get stuck. At the same time, increasing $\zeta$ increases the bias, while a higher $H$ is more computationally expensive. For the results reported here, we choose $H=5$, which still leads to manageable computation time. We then chose $\zeta$ so that the objective function is reasonably smooth. ${ }^{2}$

In Figure 10, we plot the stationary productivity distributions before and after the reform and the change in the number of matches in every productivity bin. Clearly, we observe a rightward shift as less productive firms exit the market more quickly, while more productive firms benefit from the higher arrival rate of workers. In reality, this effect might even be stronger as we have reason to believe that our model underestimates this effect. ${ }^{3}$

Figure 10: Stationary productivity distribution before and after the reform

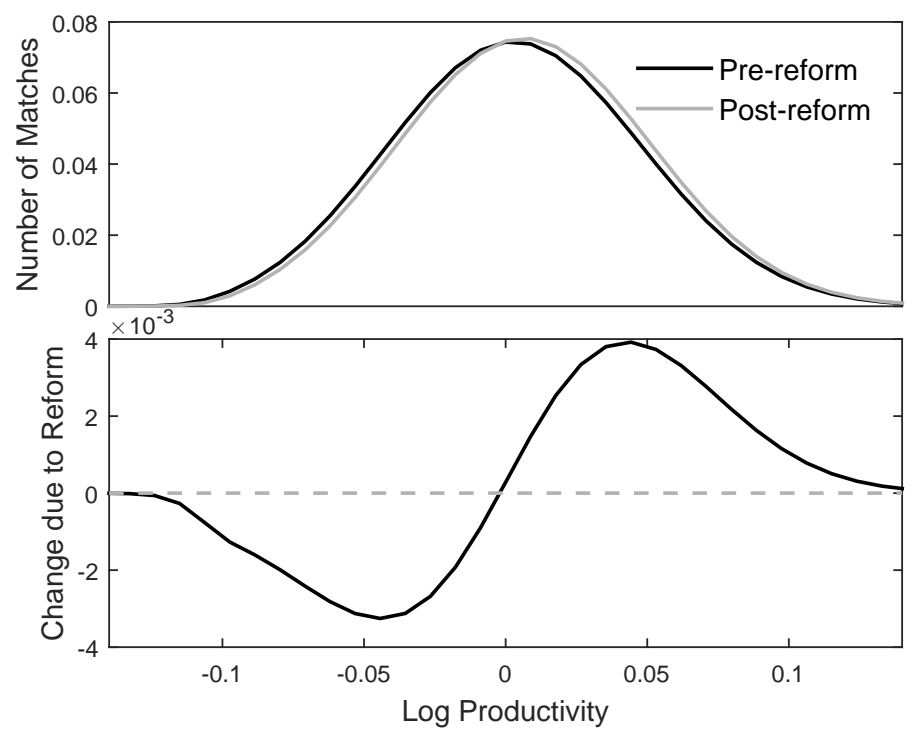

Note: The top plot shows the stationary number of workers of either eligibility status (i.e. $n_{0}(p)+n_{1}(p)$ ) per productivity state implied by the model using calibrated (Table 4 in the main text) and estimated (Table 5 in the main text) model parameters, distinguishing between the pre- and post-reform steady state. The bottom plot shows the difference in the number of workers per productivity state between the postand the pre-reform steady state.

\footnotetext{
${ }^{2}$ We choose $\zeta$ as low as possible. It turned out that $\zeta=0.2$ resulted in a reasonably smooth surface.

${ }^{3}$ To keep the model manageable for our structural estimation, we assume that entrepreneurs that exit the market get to draw from the stationary distribution again. Thus, a very bad entrepreneur might re-enter as a very good one.
} 
Figure 11: Cumulative share of workers leaving into unemployment and to another job, simulated values vs. data (allowing for temporary employment)

(a) Cumulative exit rates (all exits)

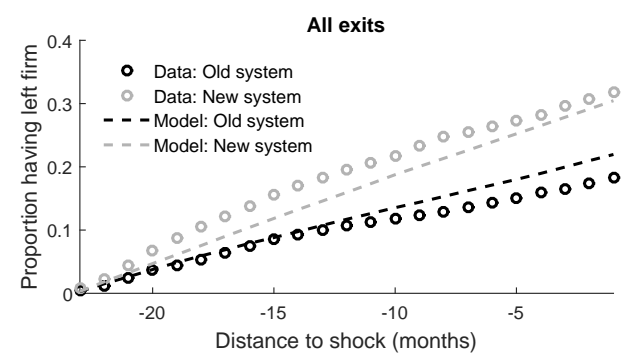

(b) Cumulative exit rates (JTJ)

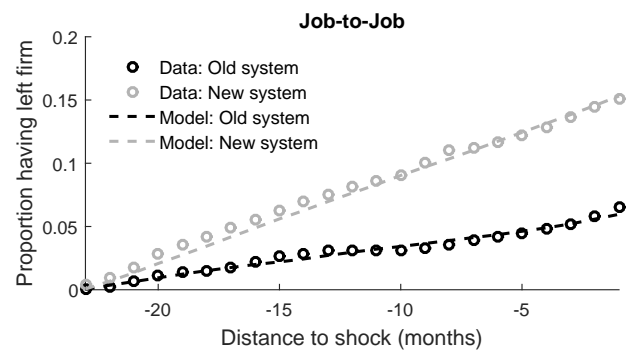

(c) Cumulative exit rates (JTU)

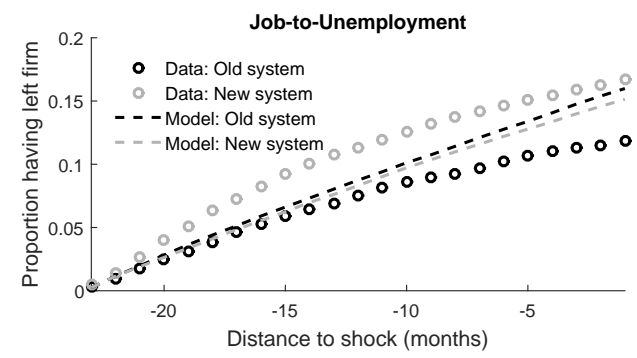

Note: The Figures compare cumulative exit rates implied by an RDD (see main text for details) on our baseline sample to an RDD based on artificial data generated by the model allowing for temporary jobs using calibrated (Table 4 in the main text) and estimated (Table 5 in the main text) model parameters. Figure (a) shows all exits, while figures (b) and (c) distinguish between JTJ and JTU transitions. Note that we only fit figures (b) and (c) as figure (a) corresponds to the sum of figures (b) and (c). 


\section{Further Details on the "Southern-European" Counterfac- tual}

In Figure 12, we plot the mandatory severance payment schemes for different Southern European countries versus the Austrian scheme. Whereas the level appears to be comparable, it is striking that the time to eligibility is generally lower than in Austria. Clearly, these numbers give an incomplete account of the actual dismissal costs for employers, as firing costs associated with litigation are not directly accounted for. In Portugal, for instance, the court sets an amount of indemnification between 15 and 45 days per year of tenure, never below three months of wages. Overall, the risk of litigation increases the expected size of the payment, but also entails considerable uncertainty.

Figure 12: Mandatory severance pay in selected countries

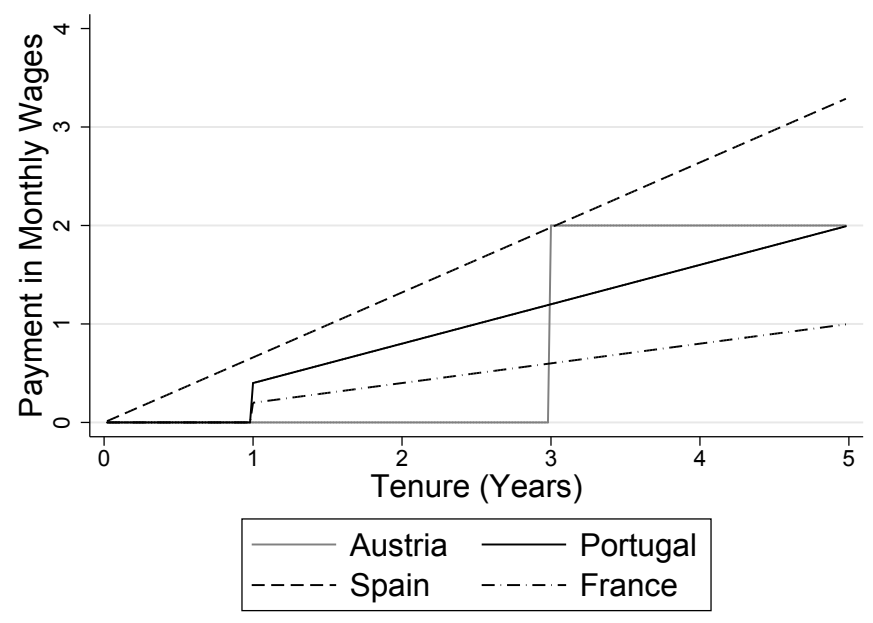

Note: The figure shows mandatory severance payment schemes in selected countries. The numbers are based on OECD Indicators of Employment Protection (http://www.oecd.org/employment/ emp/oecdindicatorsofemploymentprotection.htm, and ILO Employment Protection Legislation Database - EPLex, http://www.ilo.org/dyn/eplex/termmain.home, both accessed 12/21/2016).

These results suggest an important role for time to eligibility. In Figure 13 we look at the relationship between $\psi$ and $\alpha$ and the predicted reduction in equilibrium unemployment in more detail. Figure 13(a) demonstrates that, as long as $\alpha$ is fixed at $1 / 36$, the effect on unemployment never exceeds one percentage point even if severance pay is as high as four monthly wages. This changes markedly if we lower the time to eligibility to three months, where we predict drops in unemployment between 3 and 7 percentage points and an approximately linear relationship. The relationship to time to eligibility, by contrast, is 
highly nonlinear, as can be seen from Figure 13(b). ${ }^{4}$

Figure 13: The effect of varying severance pay or time to eligibility on unemployment

(a) Severance pay

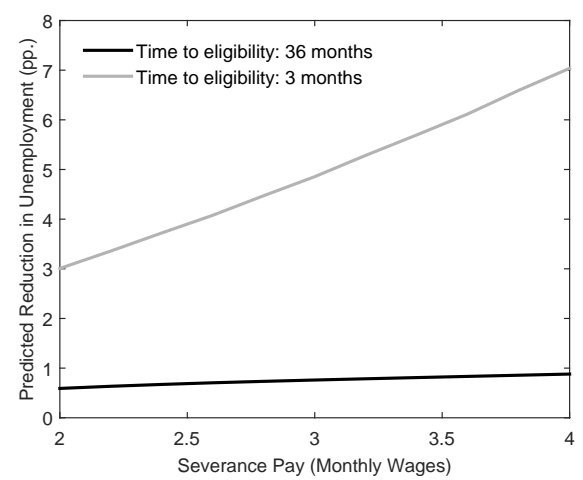

(b) Time to eligibility

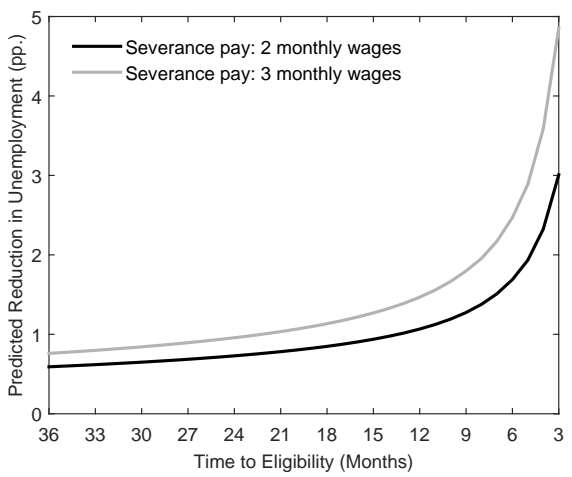

Note: Figure (a) shows the difference between post- and pre-reform equilibrium unemployment for different values of the mandatory severance payment amount, $\psi$, keeping expected time to eligibility, $1 / \alpha$, at 36 or 3. Figure (b) shows the same outcome for different values of expected time to eligibility, keeping the mandatory severance payment amount at 2 or 3 .

\footnotetext{
${ }^{4}$ As time to eligibility approaches zero, especially if combined with a high $\psi$, we also encounter the case where firms do not create any vacancies and an equilibrium is not defined.
} 


\section{References}

Imbens, G., \& Kalyanaraman, K. (2012). Optimal Bandwidth Choice for the Regression Discontinuity Estimator. Review of Economic Studies, 79(3), 933-959.

Keane, M., \& Smith, A. A. (2003). Generalized Indirect Inference for Discrete Choice Models. Mimeo. 